Roberto Ferraz de Campos Filho

\title{
Abordagem estocástica com fusão sensorial para mapeamento geográfico utilizando VANTs
}

Dissertação apresentada à Escola Politécnica da Universidade de São Paulo para obtenção do Título de Mestre em Engenharia Mecânica. 
Roberto Ferraz de Campos Filho

\section{Abordagem estocástica com fusão sensorial para mapeamento geográfico utilizando VANTs}

Dissertação apresentada à Escola Politécnica da Universidade de São Paulo para obtenção do Título de Mestre em Engenharia Mecânica.

Área de concentração:

Engenharia de Controle e Automação Mecânica

Orientador:

Prof. Dr. Newton Maruyama 
à minha família. 


\section{Agradecimentos}

Aos meus pais e minha irmã, que sempre me apoiaram nas decisões tomadas durante minha vida pessoal e profissional.

Ao meu orientador Prof. Dr. Newton Maruyama, que me orientou desde a iniciação científica feita durante o período de graduação.

À equipe da XMobots e colegas do Laboratório de Sistemas Embarcados, que ajudaram e motivaram o desenvolvimento deste trabalho.

À Coordenação de Aperfeiçoamento de Pessoal de Nível Superior (CAPES), pela bolsa de mestrado. 


\section{Resumo}

Mapas fotogramétricos são de extrema importância para monitorar grandes áreas periodicamente. Alguns exemplos são: monitoramento de florestas, plantas invasivas, crescimento urbano, etc. Estes mapas são comumente construídos utilizando imagens de satélites ou aviões. Para se obter um mapa com proporções reais, uma operação de distorção destas imagens é realizada utilizando informações fornecidas por Pontos de Controle em Solo e triangulando features naturais das imagens ou utilizando um outro mapa conhecido a priori. A utilização de VANTs (Veículos Aéreos Não Tripulados) mostra-se uma solução mais segura quando comparada a um avião devido a não existência de tripulação. É uma solução mais flexível quando comparada a satélites, pois um VANT pode voar algumas horas ou mesmo minutos após um vôo anterior, enquanto um satélite estará disponível novamente após alguns dias na mesma área. Algumas partes do mapa podem não ser visíveis devido a nuvens e o VANT pode sobrevoar a área novamente para recuperar estas partes (sobrevoaria abaixo das nuvens caso necessário). Um método de fusão sensorial estocástico é proposto e combina técnicas de Visão Computacional, sensores inerciais e GPS a fim de estimar um mapa esparso tridimensional e a posição do VANT simultaneamente utilizando a técnica conhecida como SLAM (Simultaneous Localization and Mapping). O mapa completo é gerado projetando as imagens no mapa esparso. A principal vantagem deste método é que o mapa é construído sem conhecimento a priori do terreno. As principais contribuições deste trabalho são: a integração de técnicas de SLAM na área de Aerofotogrametria e o desenvolvimento de um método que realiza o mapeamento 3D sem o uso de conhecimento a priori do terreno.

Palavras-chave: Robótica. Filtros de Kalman. Visão Computacional. Aerofotogrametria. 


\section{Abstract}

Photogrammetric maps are of extreme importance in order to monitor large areas periodically. Some examples are: monitoring of forests, invasive plants, urban growth, etc. These maps are commonly built using images from satellites or planes. In order to obtain a map with real proportions, an operation of distortion of these images is realized using information provided by Ground Control Points and triangulating natural features in the scene or using another a priori known map. The utilization of an Unmanned Aerial Vehicle (UAV) provides a safer solution when compared to a plane mainly due to the non existence of a crew. It is also a more flexible solution when compared to satellites because an UAV can fly again some hours or even minutes after a previous flight, while a satellite will be available in some days for the same area. Some parts of the map might not be visible because of clouds and the UAV needs to fly again to recover these parts (flying below the clouds if necessary). A stochastic sensor fusion method is proposed that combines computational vision techniques, inertial sensors and GPS in order to estimate both the three dimensional sparse map and the UAV position using the technique known as SLAM (Simultaneous Localization and Mapping). The complete map is generated projecting the images into the sparse map. The main advantage of this method is that the map is constructed without the use of a priori knowledge of the terrain. The main contributions of this work are: the integration of SLAM techniques into the Aerophotogrammetry field and the development of a method that can realize a 3D mapping without the use of a priori knowledge of the terrain.

Keywords: Robotics. Kalman Filter. Computer Vision. Aerophotogrammetry. 


\title{
Sumário
}

\section{Lista de Figuras}

\author{
Lista de Tabelas
}

Lista de Símbolos

1 Introdução 1

1.1 Motivação . . . . . . . . . . . . . . . . . . . . . . 1

1.2 Objetivos e Contribuições . . . . . . . . . . . . . . . . . 4

1.3 Organização do Texto . . . . . . . . . . . . . . . . 5

$\begin{array}{lll}\text { I Fundamentação Teórica } & 7\end{array}$

2 Aerofotogrametria Convencional $\quad 8$

3 Formulação do Problema 11

3.1 Navegação Inercial . . . . . . . . . . . . . . . . . . . . . . . . 11

3.2 Simultaneous Localization And Mapping (SLAM) . . . . . . . . . 12

3.3 Levantamento Bibliográfico . . . . . . . . . . . . . . . 15

4 Modelo de Predição de Estado $\quad 17$

5 Modelo de Sensores $\quad 20$

5.1 Unidade de Medição Inercial . . . . . . . . . . . . . . . . . . 21

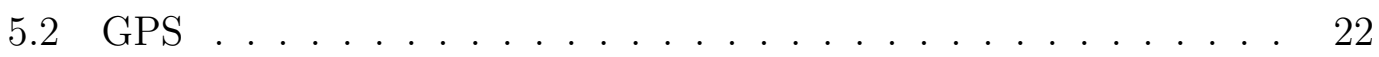

5.3 Visão . . . . . . . . . . . . . . . . . . . . . . . . 22

5.3.1 Modelo de Câmera de Orifício Normalizada . . . . . . . . 23 
5.3.2 Correção de Distorção de Lentes . . . . . . . . . . . . . . . 24

5.3 .3 Digitalização . . . . . . . . . . . . . . . . 24

5.3.4 Calibração de Câmera . . . . . . . . . . . . . 25

5.3.5 Identificação de Features . . . . . . . . . . . . . . . . 26

5.3.6 Modelo de Sensor de Visão . . . . . . . . . . . . . . . . . 27

6 Aumento de Estado $\quad 29$

$\begin{array}{ll}\text { II Resultados } & 32\end{array}$

$\begin{array}{lll}7 & \text { Simulações } & 33\end{array}$

7.1 Simulação 1: Avaliação de diferentes combinações de sensores . 33

7.2 Simulação 2: Análise quantitativa de resultados . . . . . . . . . . 37

$\begin{array}{ll}\text { IIIConclusões } & 65\end{array}$

8 Conclusões e Trabalhos Futuros $\quad 66$

$\begin{array}{ll}\text { Referências } & 68\end{array}$

$\begin{array}{ll}\text { Apêndice A - Quaternions } & 72\end{array}$

A.1 Operações e propriedades . . . . . . . . . . . . . . 72

A.2 Exponencial . . . . . . . . . . . . . . . . 73

A.3 Notação matricial e vetorial . . . . . . . . . . . . . . 74

A.4 Matriz de rotação . . . . . . . . . . . . . . . . . 74

A.5 Vetor rotação . . . . . . . . . . . . . . . . . . 75 


\section{Lista de Figuras}

1.1 Exemplos de Veículo Aéreo Não Tripulado (VANT)s comerciais nacionais e importados. (a) X100 da Gatewing (Bélgica), (b) Tiriba da $A G X$ (Brasil), (c) Nauru e (d) Apoena da XMobots (Brasil). . 3

2.1 Geração de mapa a partir de fotos aéreas. . . . . . . . . . . . . . 9

2.2 Sistemas de aquisição de imagens de grande formato para aerofotogrametria. (a) ADS80 da Leica Geosystems, (b) POS AV da Trimble e (c) SAAPI da Engemap. . . . . . . . . . . . . . . 10

3.1 Algoritmo de Navegação Inercial. . . . . . . . . . . . . . . . . . . 12

3.2 SLAM. . . . . . . . . . . . . . . . . . . 13

5.1 Modelo de Câmera de Orifício. . . . . . . . . . . . . . . . . . 23

5.2 Correção de distorção radial gerada pelo efeito da lente. . . . . . . 24

5.3 Exemplo de imagens utilizadas na calibração de câmera. . . . . . 25

5.4 Exemplo de identificação de features. . . . . . . . . . . . . . 26

6.1 Incerteza na inicialização de uma feature utilizando modelo de câmera de orifício.

7.1 Estimação de terreno e trajetória onde pontos e linhas vermelhas são as features e trajetórias reais e pontos e linhas azuis são as estimadas. A Figura (a) mostra o caso de fusão entre Global Positioning System (GPS) e Inertial Measurement Unit (IMU) sem estimação de terreno, na Figura (b) a fusão entre IMU e Câmera e na Figura (c) a fusão entre GPS, IMU e Câmera. . . . . . . . . . 35

7.2 Erro de trajetória do VANT. . . . . . . . . . . . . . 36

7.3 Erro na estimação de posição de cada feature. A Figura (a) mostra o histograma de erros para a configuração GPS, IMU e Câmera e a Figura (b) para a configuração IMU e Câmera. . . . . . . . . . . 36

7.4 Vista superior do algoritmo de SLAM em operação com o VANT estável. . . . . . . . . . . . . . . . . . . . . . 40 
7.5 Vista lateral do algoritmo de SLAM em operação com o VANT estável. . . . . . . . . . . . . . . . . . . . . . . 44 41

7.6 Vista superior do algoritmo de SLAM em operação com o VANT oscilando. . . . . . . . . . . . . . . . . . . . . 42

7.7 Vista lateral do algoritmo de SLAM em operação com o VANT oscilando. . . . . . . . . . . . . . . . . . . . . 43

7.8 Região utilizada para análise de erro delimitada pelo retângulo preto. 44

7.9 Variação da aceleração e velocidade angular no sistema de coorde-

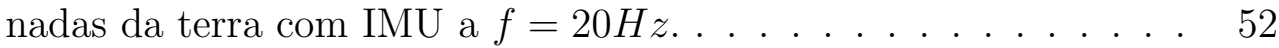

7.10 Variação da aceleração e velocidade angular no sistema de coordenadas da terra com IMU a $f=50 H z \ldots . . . . . . . . .53$

7.11 Variação da aceleração e velocidade angular no sistema de coordenadas da terra com IMU a $f=100 H z \ldots . . . . . . . . .554$ 


\section{Lista de Tabelas}

7.1 Características dos sensores. . . . . . . . . . . . . . . 34

7.2 Características do filtro. . . . . . . . . . . . . . . . . 34

7.3 Características do filtro. . . . . . . . . . . . . . . . 37

7.4 Características da câmera. . . . . . . . . . . . . . . . . 38

7.5 Resultados de simulações para avaliação de erro de posicionamento de features. Voo a 600m de altitude, 2 faixas, sem oscilação e 400 features distribuídas no solo. Comparação feita entre features reais e estimadas pelo filtro. . . . . . . . . . . . . .

7.6 Resultados de simulações para avaliação de erro de posicionamento de features. Voo a $600 \mathrm{~m}$ de altitude, 2 faixas, sem oscilação e 400 features distribuídas no solo. Dados calculados a partir da matriz

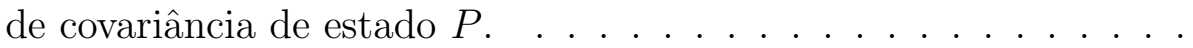

7.7 Resultados de simulações para avaliação de erro de posicionamento de features. Voo a $600 \mathrm{~m}$ de altitude, 2 faixas, com oscilação e 400 features distribuídas no solo. Comparação feita entre features reais e estimadas pelo filtro. . . . . . . . . . . . . . .

7.8 Resultados de simulações para avaliação de erro de posicionamento de features. Voo a 600m de altitude, 2 faixas, com oscilação e 400 features distribuídas no solo. Dados calculados a partir da matriz de covariância de estado $P$.

7.9 Resultados de simulações para avaliação de erro de posicionamento de features. Voo a $600 \mathrm{~m}$ de altitude, 6 faixas, sem oscilação e 400 features distribuídas no solo. Comparação feita entre features reais e estimadas pelo filtro.

7.10 Resultados de simulações para avaliação de erro de posicionamento de features. Voo a $600 \mathrm{~m}$ de altitude, 6 faixas, sem oscilação e 400 features distribuídas no solo. Dados calculados a partir da matriz de covariância de estado $P$ 
7.11 Resultados de simulações para avaliação de erro de posicionamento de features. Voo a $600 \mathrm{~m}$ de altitude, 6 faixas, com oscilação e 400 features distribuídas no solo. Comparação feita entre features reais e estimadas pelo filtro. . . . . . . . . . . . . . . . . . 50

7.12 Resultados de simulações para avaliação de erro de posicionamento de features. Voo a 600m de altitude, 6 faixas, com oscilação e 400 features distribuídas no solo. Dados calculados a partir da matriz

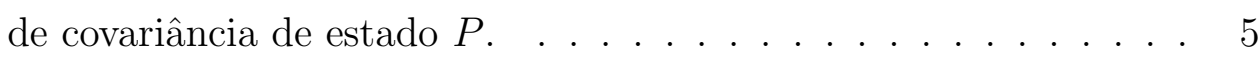

7.13 Resultados de simulações para avaliação de erro de posicionamento de features. Voo a 600m de altitude, 6 faixas, com oscilação e 1200 features distribuídas no solo. Comparação feita entre features reais e estimadas pelo filtro.

7.14 Resultados de simulações para avaliação de erro de posicionamento de features. Voo a 600m de altitude, 6 faixas, com oscilação e 1200 features distribuídas no solo. Dados calculados a partir da matriz de covariância de estado $P$

7.15 Resultados de simulações para avaliação de erro de posicionamento do VANT. Voo a 600m de altitude, 2 faixas, sem oscilação e 400 features distribuídas no solo. Comparação feita entre posicionamento real e estimado pelo filtro.

7.16 Resultados de simulações para avaliação de erro de posicionamento do VANT. Voo a 600m de altitude, 2 faixas, sem oscilação e 400 features distribuídas no solo. Dados calculados a partir da matriz de covariância de estado $P$.

7.17 Resultados de simulações para avaliação de erro de posicionamento do VANT. Voo a 600m de altitude, 2 faixas, com oscilação e 400 features distribuídas no solo. Comparação feita entre posicionamento real e estimado pelo filtro.

7.18 Resultados de simulações para avaliação de erro de posicionamento do VANT. Voo a 600m de altitude, 2 faixas, com oscilação e 400 features distribuídas no solo. Dados calculados a partir da matriz de covariância de estado $P$. 
7.19 Resultados de simulações para avaliação de erro de posicionamento do VANT. Voo a $600 \mathrm{~m}$ de altitude, 6 faixas, sem oscilação e 400 features distribuídas no solo. Comparação feita entre posicionamento real e estimado pelo filtro. . . . . . . . . . . . . . . .

7.20 Resultados de simulações para avaliação de erro de posicionamento do VANT. Voo a 600m de altitude, 6 faixas, sem oscilação e 400 features distribuídas no solo. Dados calculados a partir da matriz de covariância de estado $P$.

7.21 Resultados de simulações para avaliação de erro de posicionamento do VANT. Voo a 600m de altitude, 6 faixas, com oscilação e 400 features distribuídas no solo. Comparação feita entre posicionamento real e estimado pelo filtro. . . . . . . . . . . . . 58

7.22 Resultados de simulações para avaliação de erro de posicionamento do VANT. Voo a 600m de altitude, 6 faixas, com oscilação e 400 features distribuídas no solo. Dados calculados a partir da matriz de covariância de estado $P$.

7.23 Resultados de simulações para avaliação de erro de posicionamento do VANT. Voo a 600m de altitude, 6 faixas, com oscilação e 1200 features distribuídas no solo. Comparação feita entre posicionamento real e estimado pelo filtro. . ......

7.24 Resultados de simulações para avaliação de erro de posicionamento do VANT. Voo a 600m de altitude, 6 faixas, com oscilação e 1200 features distribuídas no solo. Dados calculados a partir da matriz de covariância de estado $P$.

7.25 Resultados de simulações para avaliação de erro angular do VANT. Voo a 600m de altitude, 2 faixas, sem oscilação e 400 features distribuídas no solo. Comparação feita entre posicionamento real e estimado pelo filtro.

7.26 Resultados de simulações para avaliação de erro angular do VANT. Voo a 600m de altitude, 2 faixas, sem oscilação e 400 features distribuídas no solo. Dados calculados a partir da matriz de covariância de estado $P$ 
7.27 Resultados de simulações para avaliação de erro angular do VANT. Voo a 600m de altitude, 2 faixas, com oscilação e 400 features distribuídas no solo. Comparação feita entre posicionamento real e estimado pelo filtro. . . . . . . . . . . . . . . . . .

7.28 Resultados de simulações para avaliação de erro angular do VANT. Voo a 600m de altitude, 2 faixas, com oscilação e 400 features distribuídas no solo. Dados calculados a partir da matriz de co-

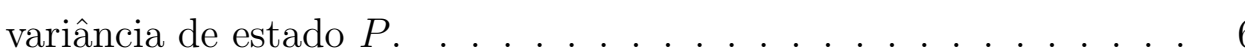

7.29 Resultados de simulações para avaliação de erro angular do VANT. Voo a $600 \mathrm{~m}$ de altitude, 6 faixas, sem oscilação e 400 features distribuídas no solo. Comparação feita entre posicionamento real e estimado pelo filtro. . . . . . . . . . . . . . . . . . . . .

7.30 Resultados de simulações para avaliação de erro angular do VANT. Voo a 600m de altitude, 6 faixas, sem oscilação e 400 features distribuídas no solo. Dados calculados a partir da matriz de co-

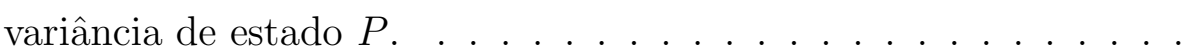

7.31 Resultados de simulações para avaliação de erro angular do VANT. Voo a 600m de altitude, 6 faixas, com oscilação e 400 features distribuídas no solo. Comparação feita entre posicionamento real e estimado pelo filtro. . . . . . . . . . . . . . . . . .

7.32 Resultados de simulações para avaliação de erro angular do VANT. Voo a 600m de altitude, 6 faixas, com oscilação e 400 features distribuídas no solo. Dados calculados a partir da matriz de covariância de estado $P$

7.33 Resultados de simulações para avaliação de erro angular do VANT. Voo a 600m de altitude, 6 faixas, com oscilação e 1200 features distribuídas no solo. Comparação feita entre posicionamento real e estimado pelo filtro.

7.34 Resultados de simulações para avaliação de erro angular do VANT. Voo a 600m de altitude, 6 faixas, com oscilação e 1200 features distribuídas no solo. Dados calculados a partir da matriz de covariância de estado $P$. 


\section{LISTA DE ABREVIATURAS}

ANAC Agência Nacional de Aviação Civil

AUV Autonomous Underwater Vehicle

CCD Charge-Coupled Device

DECEA Departamento de Controle do Espaço Aéreo

EKF Extended Kalman Filter

FOG Fibre optic gyroscope

GPS Global Positioning System

IMU Inertial Measurement Unit

KF Kalman Filter

MDE Modelo Digital de Elevação

MEMS Micro-Electro-Mechanical Systems

MPF Marginalized Particle Filter

NOTAM Notice To Airmen

PF Particle Filter

RBPF Rao-Blackwellized Particle Filter

SAD Sum of Absolute Differences

SLAM Simultaneous Localization And Mapping

UAV Unmanned Aerial Vehicle

UKF Unscented Kalman Filter

VANT Veículo Aéreo Não Tripulado 


\section{Lista de Símbolos}

$b_{t}^{e} \quad$ Posição da IMU em relação ao sistema de coordenadas da Terra

$\dot{b}_{t}^{e} \quad$ Velocidade da IMU em relação ao sistema de coordenadas da Terra

$\ddot{b}_{t}^{e} \quad$ Aceleração da IMU em relação ao sistema de coordenadas da Terra

$q_{t}^{b e} \quad$ Orientação da IMU em relação ao sistema de coordenadas da Terra

$\omega_{e b, t}^{b} \quad$ Velocidade angular da IMU em relação ao sistema de coordenadas da Terra

$\delta_{\omega, t}^{b} \quad$ Bias de giroscópio em relação ao sistema de coordenadas da IMU

$\delta_{a, t}^{b} \quad$ Bias de acelerômetro em relação ao sistema de coordenadas da IMU

$m_{i, t} \quad$ Posição de cada feature em relação ao sistema de coordenadas da Terra

$y_{G P S, t}$ Vetor de medidas do GPS

$y_{I M U, t}$ Vetor de medidas da IMU

$y_{V I S I O N, t}$ Vetor de medidas da Câmera

$y_{a, t} \quad$ Aceleração medida pelos acelerômetros da IMU

$y_{\omega, t} \quad$ Velocidade angular medida pelos giroscópios da IMU

$r^{G P S}$ Distância entre a antena de GPS e a IMU em relação ao sistema de coordenadas da IMU

$r^{c}$ Distância entre o Centro de Câmera e IMU em relação ao sistema de coordenadas da Câmera

$x_{t}^{c} \quad$ Coordenada $x$ de feature em relação ao sistema de coordenada da Câmera

$y_{t}^{c} \quad$ Coordenada $y$ de feature em relação ao sistema de coordenada da Câmera

$z_{t}^{c} \quad$ Coordenada $z$ de feature em relação ao sistema de coordenada da Câmera 


\section{Introdução}

Este capítulo apresenta a motivação, os objetivos e as principais contribuições deste trabalho.

\subsection{Motivação}

A geração de mapas por imagens aéreas é uma ferramenta muito utilizada no monitoramento periódico de grandes áreas como florestas e plantações (MEDLIN et al., 2000; KLINKEN et al., 2007), por exemplo. O objetivo nestas situações podem ser a identificação de desmatamento não autorizado, acompanhamento de supressão, verificação de encostas, etc no caso de florestas e identificação de plantas invasivas, estimação de produtividade, falhas no plantio, etc no caso de plantações. Medições de distâncias e áreas são as principais informações extraídas destes mapas, portanto há a necessidade destes mapas apresentarem uma relação de proporção com as dimensões reais e uma avaliação de acurácia do mesmo é de extrema importância para se quantificar o erro destas medições.

Estes mapas são comumente construídos a partir de fotos de satélites ou fotos tiradas utilizando aeronaves tripuladas convencionais. A utilização de um VANT para este propósito possibilita a geração de um mapa de maior resolução do que os gerados por satélites. A resolução obtida por um satélite gira em torno de 15 m/pixel (LANDSAT-7, por exemplo, que orbita a Terra a $705 \mathrm{~km}$ de altitude) e pode chegar até a $50 \mathrm{~cm} /$ pixel (como o satélite WorldView-2, por exemplo, orbitando a Terra a $770 \mathrm{~km}$ de altitude). Um VANT pode obter imagens com uma resolução variando de $50 \mathrm{~cm} /$ pixel até $3 \mathrm{~cm} /$ pixel com uma altitude de voo de 500 m a 2000 m. A alteração de resolução de câmera e distância focal de lente podem variar ainda mais estes valores de resolução e altitude. Também há a possibilidade de cobrir áreas maiores devido ao fato de um VANT autônomo não possuir um piloto e, por conseqüência, o tempo de vôo não está limitado ao tempo que o mesmo suportaria controlar a aeronave com segurança, mas estaria limitado ao alcance de comunicação e a autonomia de voo do VANT. 
A Figura 1.1 mostra alguns exemplos de VANTs comerciais de tamanhos variados utilizados para monitoramento aéreo. Todos eles executam voos de maneira autônoma, ou seja, define-se previamente as coordenadas, ou waypoints, (latitude, longitude e altitude) aonde a aeronave deve passar e o voo é somente observado em solo por um computador que recebe dados de telemetria dos sensores embarcados. Atualmente, a Agência Nacional de Aviação Civil (ANAC) vem trabalhado para o processo de certificação de VANTs, mas estes ainda não podem sobrevoar em espaço aéreo compartilhado e somente em áreas com baixa densidade populacional. Para um VANT realizar voos de maneira segura e não apresentar perigo a outras aeronaves, é necessário a emissão de uma notificação dos dias, horários e a área que estes voos estarão sendo realizados. Esta notificação é chamada de Notice To Airmen (NOTAM) e é emitida no Brasil pelo Departamento de Controle do Espaço Aéreo (DECEA), que é uma organização governamental subordinada ao Ministério da Defesa e ao Comando da Aeronáutica. Estes NOTAMs são pedidos com base na Circular de Informações Aeronáuticas AIC N 21/10 (DECEA, 2010), onde apresenta as informações necessárias para o uso de VANTs no espaço aéreo brasileiro. Outro fator limitante para a operação destes é a obrigatoriedade de manter a comunicação a todo instante com a aeronave. Isto pode diminuir significativamente o alcance dependendo da altitude de voo, do relevo e de condições climáticas. Um exemplo de alcance, com tecnologia nacional, seria o VANT Nauru (Figuras 1.1(c)) que alcançou $65 \mathrm{~km}$ a $1400 \mathrm{~m}$ de altitude em relação ao solo em região de floresta amazônica. Com este exemplo, conclui-se que um VANT pode substituir uma aeronave convencional em operações grandes de aerofotogrametria.

O X100 (Figura 1.1(a)) é uma aeronave elétricas de 2kg e envergadura de 1m. É utilizada para monitoramento de regiões pequenas devido a sua autonomia de 45min, possibilita a aquisição de imagens em alta resolução da ordem de $5 \mathrm{~cm} /$ pixel realizando voos a uma altitude de até $750 \mathrm{~m}$ em relação ao solo. O Tiriba (Figura 1.1(b)) também é uma aeronave elétrica que pesa $4 \mathrm{~kg}$ com uma evergadura de $3 \mathrm{~m}$. É utilizada para monitoramento de regiões pequenas possuindo autonomia de $35 \mathrm{~min}$ a $60 \mathrm{~min}$ e aquisição de imagens em alta resolução da ordem de $5 \mathrm{~cm} /$ pixel realizando voos a uma altitude de até $600 \mathrm{~m}$ em relação ao solo. O VANT Nauru (Figura 1.1(c)) é uma aeronave a gasolina pesando 15kg com envergadura de 2,3m. É utilizada para monitoramento de regiões de maior extensão possuindo autonomia de 5 h e aquisição de imagens com resolução de $5 \mathrm{~cm} /$ pixel a $45 \mathrm{~cm} /$ pixel realizando voos a uma altitude de até $2000 \mathrm{~m}$. O VANT Apoena (Figura 1.1(d)) é uma aeronave a gasolina pesando $32 \mathrm{~kg}$ com envergadura 
de 2,5m. É utilizada para monitoramento de regiões de maior extensão possuindo autonomia de $8 \mathrm{~h}$ e aquisição de imagens com resolução de $5 \mathrm{~cm} /$ pixel a $50 \mathrm{~cm} /$ pixel realizando voos a uma altitude de até $3000 \mathrm{~m}$. Estes exemplos de VANTs mostram que já existem aeronaves capazes de realizar voos com duração e altitude igual ou superior a uma aeronave convencional e outras possuindo características que se enquadram muito bem para monitoramento de regiões pequenas, onde o custo de um avião seria muito alto.

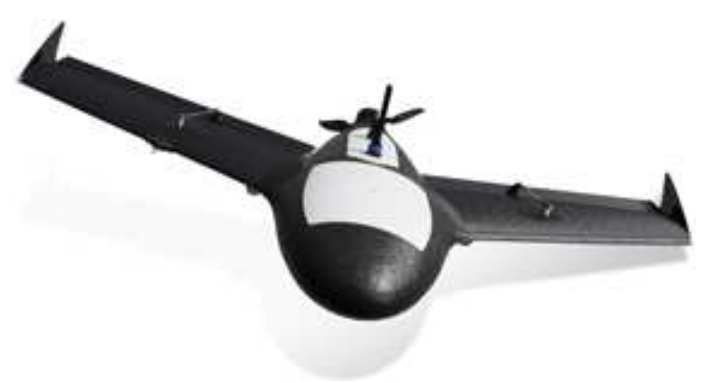

(a)

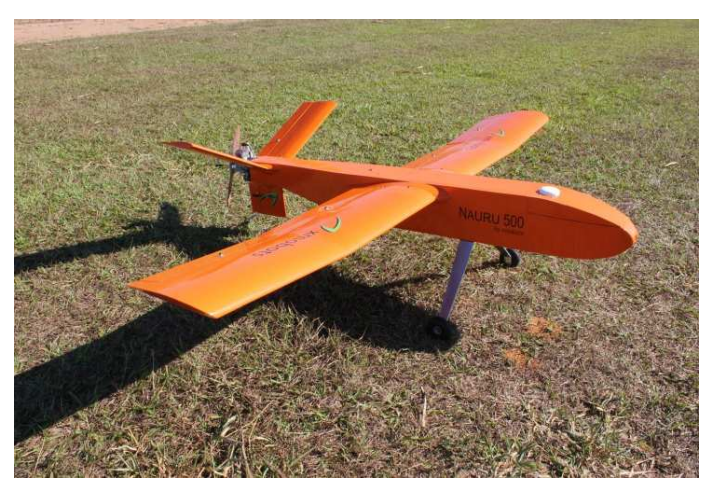

(c)

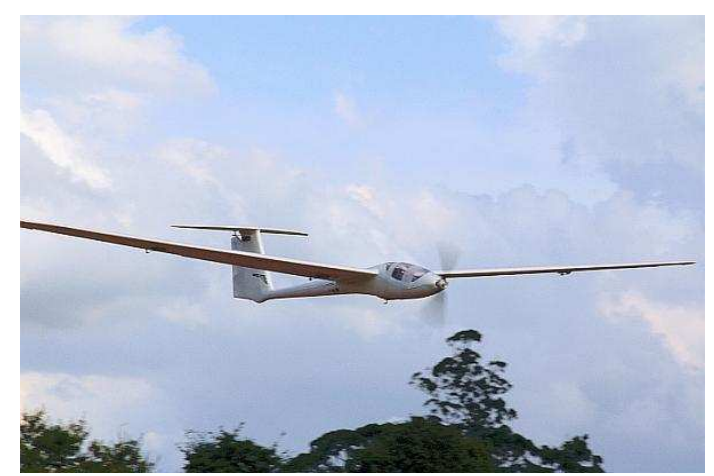

(b)

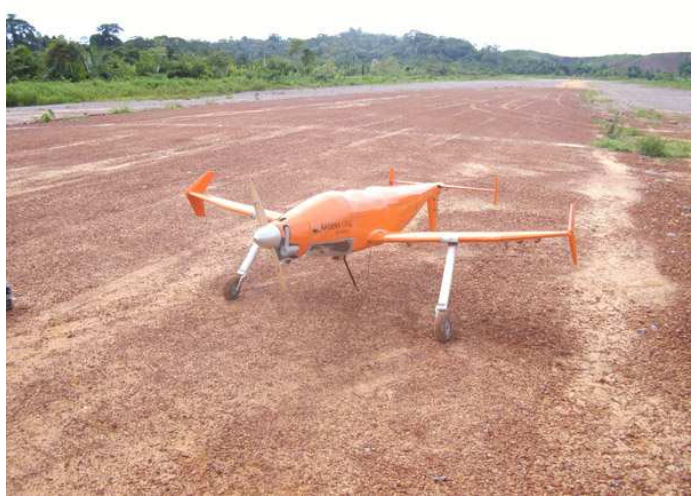

(d)

Figura 1.1: Exemplos de VANTs comerciais nacionais e importados. (a) X100 da Gatewing (Bélgica), (b) Tiriba da AGX (Brasil), (c) Nauru e (d) Apoena da XMobots (Brasil).

Na aerofotogrametria, o problema de geração de mapas é comumente abordado separando-se a parte de estimação de posição e atitude da aeronave da parte de imagens (SANTOS, 2004; IDOETA, 2007; RUY, 2008), ou seja, existe um filtro para estimação de posicionamento da aeronave que não leva em conta as imagens e um outro passo de filtragem que utiliza as imagens e os dados anteriores já filtrados excluindo-se os dados onde não houve captura de imagem. Isto significa que os dados de sensores e das imagens são interpretados como não correlacionados, o que não é verdade. A técnica SLAM (DURRANT-WHYTE; BAILEY, 2006a; DURRANT-WHYTE; BAILEY, 2006b), largamente utilizado no campo da robótica, unifica estes dois pontos fazendo a estimação de posição simultaneamente com 
o mapeamento. Desta forma, as imagens são vistas como um sensor e modelos deste são integrados com modelos dos outros sensores da aeronave, definindo o problema como um problema único de estimação de posição que inclui a geração de mapas.

A localização espacial ou estimação de posição é um problema comumente encontrado desde pessoas andando em uma cidade, até viagens espaciais e também no campo da robótica. Para que seja possível explorar um ambiente ou mesmo percorrer uma trajetória para atingir um objetivo é necessário saber a própria localização neste ambiente.

Uma pessoa andando em uma cidade localiza-se utilizando nomes de ruas e um mapa, ou observando o próprio ambiente (casas, prédios, praças, etc); uma aeronave utiliza diversos sensores, por exemplo GPS (Global Positioning System ou do português Sistema de Posicionamento Global) para obter um posicionamento absoluto, IMU (Inertial Measurement Unit ou Unidade de Medição Inercial) para obter a atitude da aeronave, Tubo de Pitot para obter a velocidade da aeronave em relação ao ar, etc. Todos estes sensores e outros mais são utilizados para encontrar a posição da aeronave e também outras informações importantes para a navegação em um ambiente qualquer.

A abordagem utilizada para a estimação de posição depende muito do ambiente que será utilizado. Um robô terreste utilizado em ambientes fechados como casas, utilizaria odômetros, lasers e uma IMU, por exemplo, e ainda o equacionamento do problema pode ser simplificado bastante se este se movimenta em um plano. Se este robô fosse utilizado em ambientes externos já seria possível utilizar um GPS e provavelmente o equacionamento do problema consideraria movimentos no espaço 3D.

\subsection{Objetivos e Contribuições}

O objetivo deste trabalho é propor a técnica conhecida como SLAM para a geração de mapas baseado em imagens e dados de sensores aquisitados por uma aeronave. Esta técnica realiza o mapeamento e localização da aeronave de forma simultânea, sendo que o mapa é representado na forma esparsa, ou seja, por pontos espalhados na região visualizada. Como o foco deste trabalho é a análise da viabilidade do uso de SLAM utilizando a configuração de sensores de aerofotogrametria, foram feitas diversas simulações estudando diferentes valores de frequência de amostragem de sensores e padrões de voos com o objetivo de quantificar os 
erros na geração do mapa esparso.

Uma vez obtido o mapa esparso, o mapa completo é obtido projetando as imagens nestes pontos utilizando distorções Perspectiva, Polinomial, Piecewise Linear (GOSHTASBY, 1986) ou Local Weighted Mean (GOSHTASBY, 1988), por exemplo. A escolha do tipo de distorção utilizada depende da variação de altitude do terreno mapeado. No caso de uma região plana, a distorção perspectiva é suficiente para a representação. Este trabalho não aborda a parte final da geração do mapa completo, uma vez que o intuito das simulações é avaliar a precisão obtida nos pontos em solo, que servem como base para estas projeções de imagens obtidas em voos reais.

Além disto, defende-se o uso de VANTs para estas operações visto que apresentam inúmeras vantagens com relação a imagens de satélite e imagens aquisitadas por aeronaves tripuladas.

Este trabalho apresenta como principais contribuições:

- Aplicação de SLAM para geração de mapas aéreos;

- Possibilita um aumento de precisão nos mapas resultantes ou a diminuição da qualidade dos sensores embarcados para obter os resultados com mesmo padrão de precisão;

- Geração de mapas 3D com imagens aéreas sem conhecimento a priori do relevo. É comum a projeção de fotos aéreas utilizando Pontos de Controle em Solo ou em superfícies 3D que representam o relevo para obter este tipo de mapa;

- Propõe a utilização de VANTs para aerofotogrametria. Uma característica observada é que, para regiões longas e estreitas como rios, por exemplo, a precisão e acurácia dos mapas gerados podem ser aumentadas efetuandose manobras durante a captura de imagens, algo cansativo, difícil e até perigoso de se realizar com aeronaves tripuladas convencionais.

\subsection{Organização do Texto}

O trabalho está dividido basicamente em duas partes. A Parte I mostra os principais pontos do problema de estimação de posição e desenvolve os modelos implementados. A Parte II mostra resultados obtidos por simulação e avalia os resultados. 
O Capítulo 2 mostra como é o processo de geração de mapas atualmente na área de Aerofotogrametria. O Capítulo 3 explica as principais características dos sensores utilizados e a abordagem escolhida para implementação. Os Capítulos 4 e 5 desenvolvem os modelos de predição de estado e de sensores, respectivamente, utilizados na implementação do estimador estocástico escolhido. O Capítulo 6 mostra como é feita a inserção de novas features de forma controlada no vetor de estados. Simulações são feitas no Capítulo 7 onde é mostrada uma simulação utilizando características de sensores comumente utilizados em SLAM e também são comparadas diversas combinações de frequências de sensores em áreas de tamanhos diferentes, executando manobras e com voos estáveis e aumentando a quantidade de pontos em solo. O Capítulo 8 conclui o trabalho e levanta idéias para futuros trabalhos baseados neste. 
Parte I

Fundamentação Teórica 


\section{Aerofotogrametria Convencional}

Existem basicamente dois métodos utilizados na área de aerofotogrametria para a geração de mapas georreferenciados com fotos aéreas: orientação indireta e orientação direta. Vários softwares comerciais implementam estes métodos, por exemplo: INPHO da Trimble, TNT Mips da MicroImages, LPS (Leica Photogrammetry Suite) da Leica Geosystems, etc.

A abordagem utilizando orientação indireta pressupõe que são conhecidos somente os parâmetros de orientação interior da câmera, ou seja, parâmetros intrínsecos da câmera como distância focal, parâmetros de distorção de lente, tamanho do CCD, etc. Além disso, cada foto deve possuir alguns pontos que podem ser distinguidos visualmente e com coordenadas geográficas conhecidas (Pontos de Controle). Através destes pontos e utilizando modelos matemáticos, a posição da câmera no instante de cada captura é calculada. A partir daí comparase cada pixel que possui sobreposição com outra imagem e gera-se um Modelo Digital de Elevação (MDE) que é uma representação do relevo do ambiente em 3D. O mapa é finalmente construido reprojetando perspectivamente a imagem no MDE e depois projetando ortogonalmente em um plano, conforme ilustrado na Figura 2.1.

A abordagem utilizando orientação direta utiliza sensores embarcados na aeronave que possibilita a obtenção precisa da posição da mesma no ambiente necessitando de poucos Pontos de Controle em Solo ou até mesmo descartá-los, dependendo da precisão obtida por estes sensores. Utiliza-se geralmente um GPS e uma IMU embarcados na aeronave para realizar o cálculo da posição da câmera. Para obtenção de resultados de maior precisão do que é fornecido pelos dados dos equipamentos, é feita a fusão sensorial entre estes dois sensores utilizando um Filtro de Kalman. Os dados resultantes do filtro utilizados são a posição e atitude da câmera no instante da captura da imagem, ou seja, é feita uma sincronização com as fotos e os outros dados em instantes em que não é feita nenhuma captura são descartados. Estes são utilizados como posicionamento inicial 
da imagem e um método conhecido como Bundle Block Adjustment ou Ajustamento em Bloco (TRIGGS et al., 2000) é utilizado para diminuir o erro de posição e atitude da câmera analisando e comparando as imagens. Este método encontra pontos homólogos (tie points) na imagem, que são pontos que aparecem na região de sobreposição das duas imagens, e, conhecido os parâmetros intrínsecos, tenta diminuir o erro de posicionamento da câmera. Obtida a correção de posição através do Bundle Block Adjustment, o processo segue com a geração do MDE, projeção perspectiva da imagem neste modelo e projeção ortogonal, da mesma maneira que é feita na parte final da orientação indireta. Este passo de correção com o Bundle Block Adjustment também pode ser aplicado ao outro método para melhorias nos resultados.

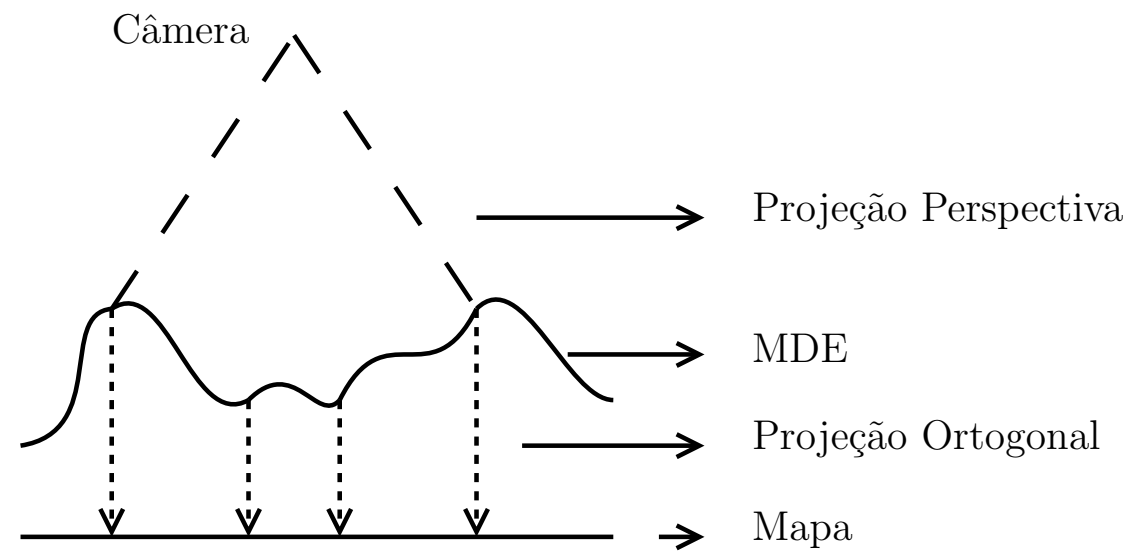

Figura 2.1: Geração de mapa a partir de fotos aéreas.

Esta separação entre a fusão sensorial no Filtro de Kalman e a etapa de Bundle Block Adjustment é o ponto onde ocorre a separação entre navegação e estimação de terreno. Apesar do Bundle Block Adjustment utilizar a coordenada e orientação da câmera no momento da captura, este processo não leva em conta a trajetória entre uma captura e outra e nem as leituras originais dos sensores (como aceleração e velocidade angular da IMU). A vantagem do uso de SLAM é exatamente neste ponto, pois todos os sensores, inclusive a câmera, estão fundidos em um mesmo nível e a propagação da trajetória no filtro ocorre simultaneamente com a geração do terreno, aproveitando-se da correlação existente nestas duas informações para minimizar os erros.

A Figura 2.2 mostra alguns exemplos de sistemas de aquisição de imagens de grande formato. Ao comparar com peso típico de VANTs, estes sistemas são relativamente pesados variando de 45kg, SAAPI da Engemap (Figura 2.2(c)), até $150 \mathrm{~kg}$, ADS80 da Leica Geosystems (Figura 2.2(a)). Estes sistemas possibilitam a geração de mapas através do método de orientação direta. 


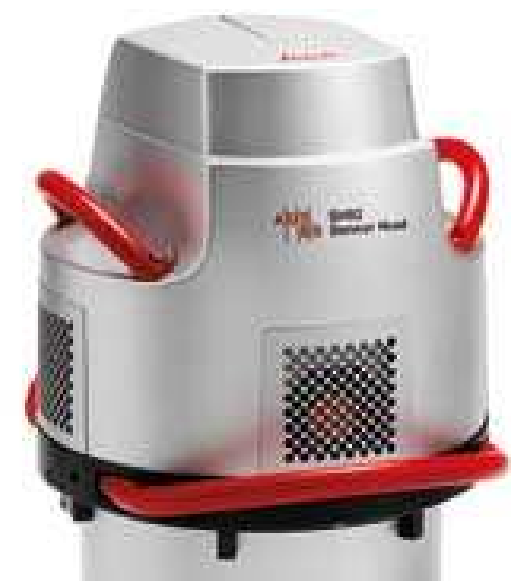

(a)

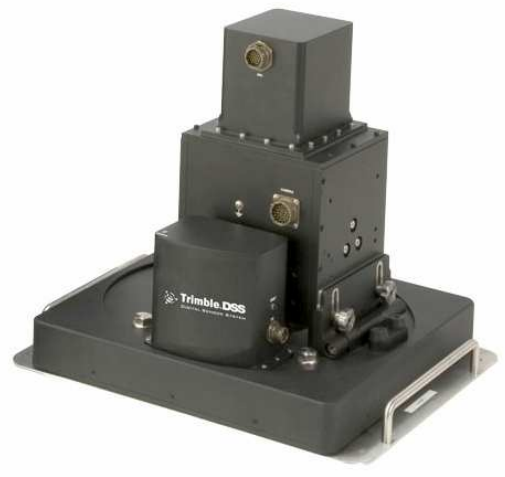

(b)

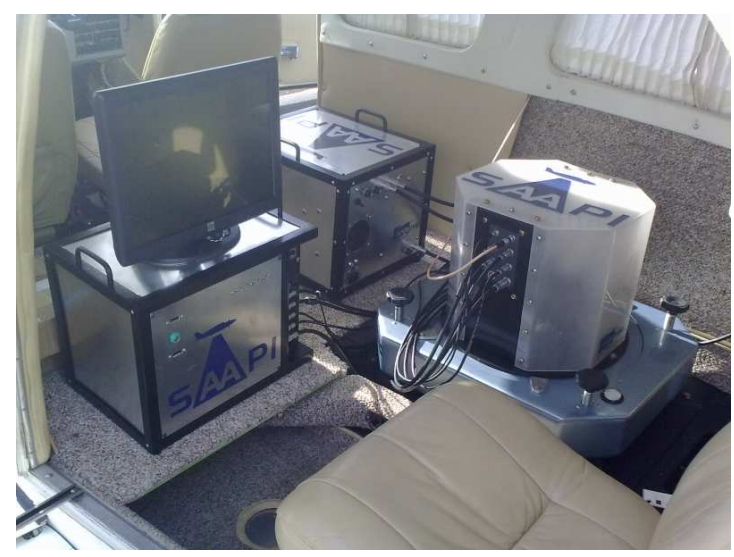

(c)

Figura 2.2: Sistemas de aquisição de imagens de grande formato para aerofotogrametria. (a) ADS80 da Leica Geosystems, (b) POS AV da Trimble e (c) SAAPI da Engemap. 


\section{Formulação do Problema}

Um ponto importante para se gerar um mapa a partir de fotos aéreas é estimar a posição espacial na qual a aeronave se encontra no momento em que as imagens são capturadas. Com a utilização de técnicas de visão computacional ou navegação inercial, de forma isolada, é possível resolver este problema, mas a fusão sensorial dos dois tipos de informação resulta em estimativas de maior acurácia, uma vez que os sensores possuem características complementares. Um sistema de navegação inercial possui respostas melhores com acelerações e rotações altas, situação em que um sistema de visão computacional apresenta maiores falhas. Um sistema de visão computacional apresenta resultados melhores com movimentos lentos, já, nesta situação, um sistema de navegação inercial começaria a apresentar grandes erros com o tempo. Porém, a combinação dos dois sensores ainda não possibilita a geração de mapas com grande acurácia, pois, como não existem dados com referências absolutas, o sistema sempre apresentará um drift à medida que distâncias mais longas são percorridas. Para eliminar este problema, é feita a fusão sensorial com um GPS. Nesta situação, a IMU também atua na diminuição da influência do ruído que o GPS insere no sistema.

\subsection{Navegação Inercial}

A navegação inercial é uma técnica usada para calcular posição e orientação a partir de acelerômetros e giroscópios, ou seja, medidas de aceleração e velocidade angular, respectivamente. Estas medidas são aquisitadas em relação a um referencial fixo na IMU, ao invés de um referencial inercial.

Quando um acelerômetro encontra-se parado, ou seja, em uma situação onde esperar-se-ia obter medidas nulas, a medida obtida é o valor da gravidade local. Isto ocorre porque o acelerômetro é um dispositivo que realiza medições de forças e a partir destes, calculam-se as acelerações. Por este motivo, as medidas de acelerações devem ser rotacionadas para um referencial fixo na Terra para que o efeito da gravidade local seja removido, como ilustra a Figura 3.1. Para calcular 
esta rotação é necessário conhecer a orientação $q^{e b}$ que é calculada pela integração da velocidade angular $\omega_{e b}^{b}$ (medidas obtidas a partir dos giroscópios). A partir da aceleração $\ddot{b}^{e}$, integra-se para se obter a velocidade $\dot{b}^{e}$ e integra-se novamente encontrando a posição $b^{e}$.

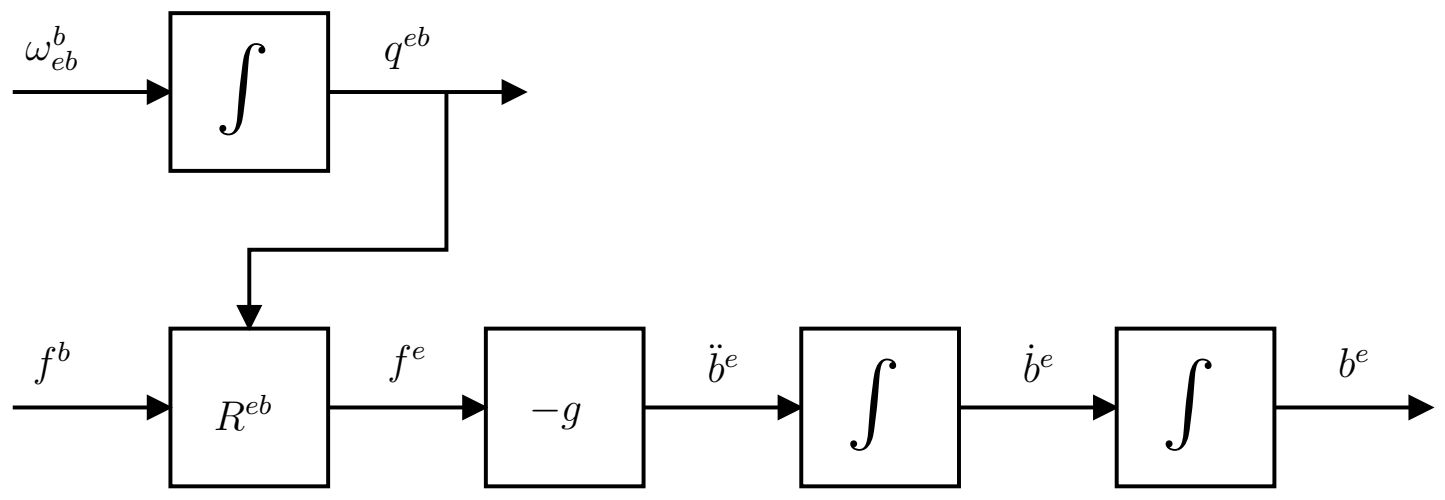

Figura 3.1: Algoritmo de Navegação Inercial.

As medidas de acelerômetros $f^{b}$ e giroscópios $\omega_{e b}^{b}$ apresentam ruídos e bias, como qualquer medida de outro tipo de sensor. A integração desses erros gera um erro acumulativo, conhecido como drift, na posição e orientação. Por este motivo, a navegação puramente inercial pode ser utilizada até um determinado instante de tempo. A partir deste instante, os resultados de posição e orientação já não são válidos por apresentarem um erro muito grande.

Devido ao drift da navegação puramente inercial, é comum a fusão da IMU com outros sensores para diminuir ou até mesmo eliminar este tipo de erro. Um odômetro, que fornece medidas de velocidade, é um tipo de sensor utilizado para diminuir o drift e o GPS para eliminar. Estes sensores atuam em pontos diferentes do processo de integração diminuindo a propagação do erro até o calculo da posição.

\section{$3.2 \quad$ SLAM}

Neste trabalho, utilizam-se técnicas Visão Computacional para visualizar e estimar o ambiente e diminuir o drift (o GPS é outro sensor responsável dela eliminação do drift). Uma câmera é fixada rigidamente em relação à IMU e ao GPS e utiliza-se uma técnica de localização e mapeamento simultâneos, conhecida como SLAM (Simultaneous Localization And Mapping), para fazer a fusão de todos os sensores. Esta técnica consiste em mapear um ambiente em relação a um referencial fixo e localizar a plataforma a partir de medidas obtidas em um local do ambiente já mapeado ou em processo de mapeamento. Alguns sensores utilizados em SLAM são: câmeras, lasers, sonares, radar, etc. 
A Figura 3.2 ilustra um robô se movendo em um ambiente e o funcionamento básico do SLAM. Nesta situação, ocorre um drift na trajetória porque o robô passou somente uma vez nesta região, mas quando esta é visualizada diversas vezes, o drift tende a sumir ou estabilizar, ao contrário da navegação inercial.

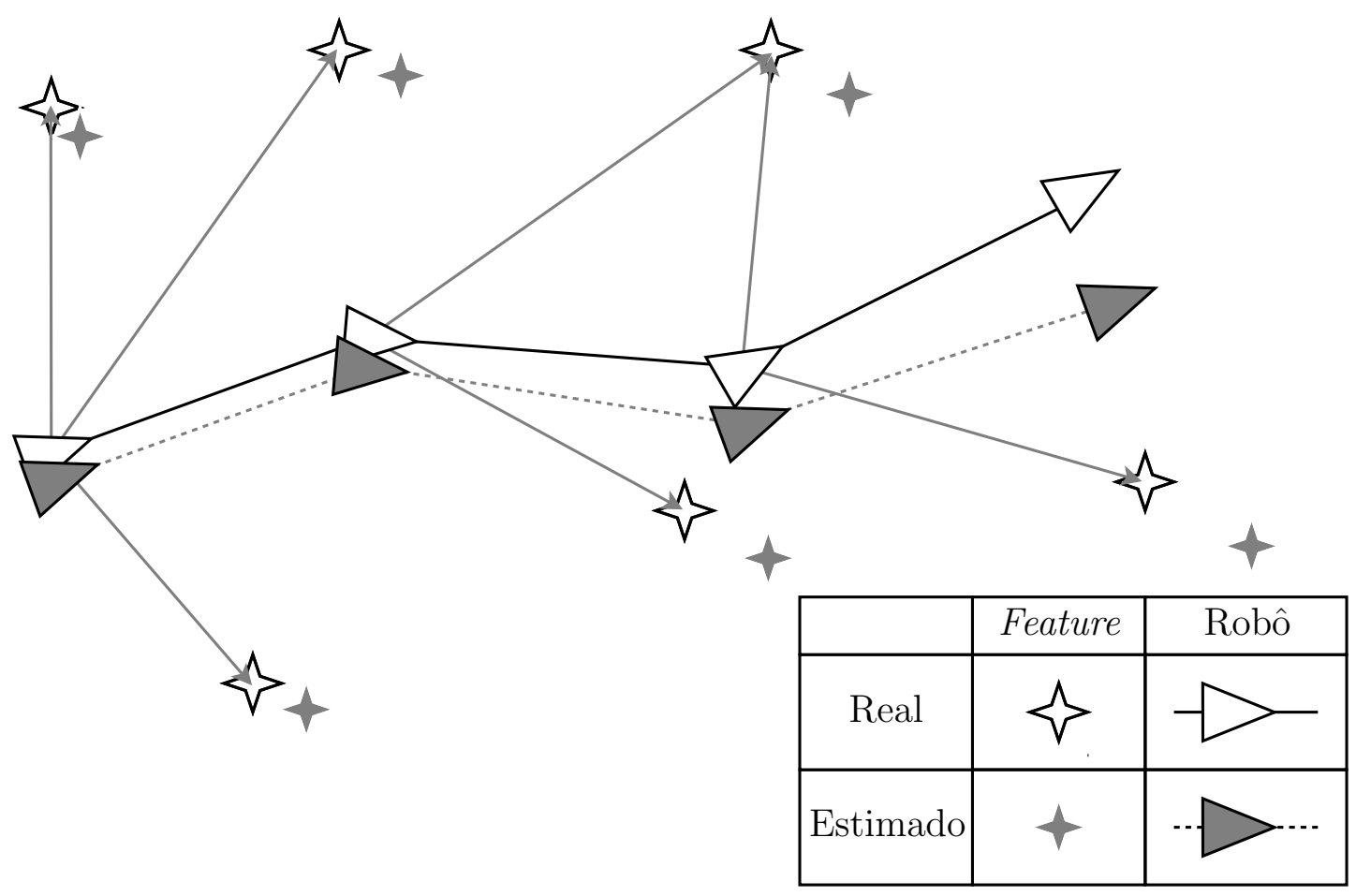

Figura 3.2: SLAM.

Utilizando imagens de uma câmera, o SLAM consiste em encontrar pontos nas imagens, rastreá-los, montar um mapa do ambiente e estimar a posição do conjunto câmera/IMU. Estes pontos, comumente denominados de features, são regiões de grande contraste nas imagens (cantos e curvas acentuadas) que podem ser rastreados.

Tanto o problema de navegação inercial como o de SLAM podem ser vistos como um problema de estimação bayesiana e existem diversos métodos amplamente conhecidos e difundidos como: Filtro de Kalman (Kalman Filter - KF), Filtro de Kalman Estendido (Extended Kalman Filter - EKF), Unscented Kalman Filter (UKF), Filtro de Partículas (Particle Filter - PF), Filtro de Partículas Marginalizado (Marginalized Particle Filter - MPF) ou Rao-Blackwellized Particle Filter (RBPF), etc.

Neste trabalho optou-se pelo EKF, pois o sistema desenvolvido é não linear (descartando-se o KF) e também por ser um filtro de compreensão mais simples do que os demais citados anteriormente. A implementação com PF ou MPF é vantajosa quando a quantidade de variáveis de estado começa a crescer muito (a região explorada pelo robô aumenta com o tempo), pois o processamento começa 
a ser menor do que na implementação com o EKF.

Os filtros ou estimadores citados lidam com o problema da estimação recursiva da função densidade de probabilidade $p\left(x_{t} \mid y_{t}\right)$, onde $x_{t}$ e $y_{t}$ são o estado e as medidas no instante $t$, respectivamente. Para isto, $x$ e $y$ são descritos da seguinte forma:

$$
\begin{aligned}
x_{t+1} & =f\left(x_{t}, u_{t}, v_{t}\right) \\
y_{t} & =h\left(x_{t}, e_{t}\right),
\end{aligned}
$$

, onde $v_{t}$ e $e_{t}$ são ruídos de processo e de medida, respectivamente, $f$ é denominado como modelo de predição de estado e $h$ como modelo de sensores.

O EKF é dividido em um passo de Predição e outro de Atualização (KALMAN, 1960; WELCH; BISHOP, 2001), descritos abaixos.

Predição:

$$
\begin{aligned}
& x_{t+1}^{-}=f\left(x_{t}, u_{t}, 0\right) \\
& P_{t+1}^{-}=F_{t+1} P_{t} F_{t+1}^{T}+Q_{t} .
\end{aligned}
$$

Atualização:

$$
\begin{aligned}
K_{t} & =P_{t}^{-} H_{t}^{T}\left(H_{t} P_{t}^{-} H_{t}^{T}+R_{t}\right)^{-1} \\
x_{t} & =x_{t}^{-}+K_{t}\left(y_{t}-h\left(x_{t}^{-}, 0\right)\right) \\
P_{t} & =\left(I-K_{t} H_{t}\right) P_{t}^{-}
\end{aligned}
$$

onde $x^{-}$é a predição de estado a priori, $P^{-}$é a predição da matriz de covariância de estado a priori, $x$ é a atualização de estado a posteriori, $P$ é a atualização da matriz de covariância de estado a posteriori, $F$ é o Jacobiano do modelo de predição de estado, $H$ é o Jacobiano do modelo de sensores, $Q$ é a matriz de covariância de ruído de processo, $R$ é a matriz de covariância de ruído de medidas e $K$ é o ganho de Kalman,

O passo de predição realiza uma estimativa do próximo estado e sua covariância dado o estado e a covariância anteriores. Obtendo-se um conjunto de medidas, o passo de atualização corrige o estado e sua covariância estimados no passo de predição. A fusão sensorial, foco deste trabalho, ocorre no passo de atualização. Maiores detalhes do equacionamento podem ser encontrados em Kalman (1960) e Welch e Bishop (2001). 


\subsection{Levantamento Bibliográfico}

Existem alguns trabalhos na literatura que fazem uma introdução à área de estimação de posição. Uma introdução à percepção inercial e visual é feita em Corke, Lobo e Dias (2007), onde comparam-se perspectivas biológica e robótica. Os trabalhos Durrant-Whyte e Bailey (2006a), Durrant-Whyte e Bailey (2006b) mostram os conceitos básicos de funcionamento do SLAM utilizando EKF e RBPF, também conhecido como FastSLAM. Duas formulações são abordadas: uma estima o mapa com o estado do veículo (posição, atitude, velocidade, etc) e outra estima a trajetória completa como estado e acumula todas as leituras dos sensores no vetor de medidas $y_{t}$.

Davison (2003), Davison et al. (2007) realiza um SLAM com uma câmera e monta online um mapa esparso de features utilizando EKF. Este trabalho foi desenvolvido para localização em ambientes internos e movimentação da câmera na mão de uma pessoa. Hol et al. (2007), Hol (2008) fazem fusão sensorial de uma IMU com Visão para localização em ambientes internos com mapa esparso do ambiente conhecido a priori. A comparação de imagens com mapa é feito utilizando o algoritmo SAD (Sum of Absolute Differences). Ambos trabalhos utilizam a estimação de posição para inserir objetos virtuais nas imagens (técnica conhecida como Realidade Aumentada) de forma que o vídeo gera a sensação de que os objetos estão realmente na cena.

A fusão de sensores embarcados e Visão Computacional é um tema em desenvolvimento também usado para aplicações com VANTs. Lindsten et al. (2010) faz a fusão de IMU com Visão para navegação de um VANT, sendo que a visão é baseada em mapas georeferenciados conhecidos a priori e possibilita a navegação em grandes distâncias sem o uso do GPS. Estes mapas são classificados previamente em regiões com casas, asfalto ou grama e a localização no mapa é feito comparando imagens da câmera (que passam pelo mesmo processo de classificação) com o mapa classificado. Este trabalho utiliza o Filtro de Partículas Marginalizado ou MPF. Törnqvist et al. (2009) realiza a fusão de IMU, Visão e sensor de pressão de ar utilizando o algoritmo FastSLAM para navegação de um VANT. É gerado um mapa tridimensional esparso onde as features encontradas são armazenadas como pontos no vetor de estado $x_{t}$. Uma aplicação com um microVANT helicóptero em ambiente interno é desenvolvido por Çelik et al. (2009), onde utiliza-se FastSLAM somente com uma câmera. Assume-se que a navegação é feita em local onde não há sinal de GPS e o ambiente é representado por linhas aplicando-se a Transformada de Hough nas imagens (HOUGH, 1962; DUDA; HART, 1972) para 
identificação de arestas.

Alguns trabalhos recentes já utilizam VANTs para gerar mapas densos e também através de SLAM cooperativo. Bryson, Johnson-Roberson e Sukkarieh (2009) faz a fusão de IMU, GPS e Visão em um VANT realizando a reconstrução de um mapa denso da região sobrevoada. Neste trabalho o estado aumenta a cada instante de tempo armazenando a trajetória completa percorrida pela aeronave e a cada nova feature encontrada na região. Bryson e Sukkarieh (2009) propõe duas arquiteturas para realizar um SLAM cooperativo, ou seja, vários VANTs para o mapeamento de um ambiente. Nas duas arquiteturas, cada VANT realiza um SLAM de acordo com seus sensores, porém na primeira abordagem cada veículo comunica a sua estimativa de mapa para um filtro de dados central que retorna a informação para cada veículo utilizar como atualização de seus mapas locais. $\mathrm{Na}$ segunda abordagem, os VANTs comunicam-se entre si utilizando os mapas das outras aeronaves para atualização de seu mapa local.

Ribas et al. (2006), Ribas, Ridao e Neira (2010) utilizam SLAM para navegar um veículo submarino (Autonomous Underwater Vehicle (AUV)) em ambientes parcialmente estruturados, ou seja, barragens, portos e plataformas marinhas. O ambiente é segmentado e somente estruturas planas são utilizadas no filtro. Sáez et al. (2006) faz a reconstrução de mapas 3D densos de ambientes aquáticos utilizando visão estéreo. Estes mapas são refinados utilizando conceitos de minimização de entropia.

Em Campos Filho e Maruyama (2011) foi publicado parte desse trabalho, onde é feita a análise de influência de cada sensor em três combinações de fusão sensorial, sendo GPS e IMU a primeira, IMU e Câmera a segunda e GPS, IMU e Câmera a terceira. Já em Campos Filho et al. (2009) foi publicado um trabalho de rastreamento de objetos utilizando PF. 


\section{Modelo de Predição de Estado}

Como o sistema é formado basicamente por dois sensores (câmera e IMU), é necessário fixar os sistemas de coordenadas de cada um e, além disso, um sistema de coordenadas global onde ocorre a localização propriamente dita e geração do mapa. Os sistemas de coordenadas são definidos como:

- Earth $(e)$ : Sistema de coordenadas onde é descrito o movimento do conjunto IMU/câmera e a posição das features.

- Camera $(c)$ : Sistema de coordenadas fixo na câmera.

- Body (b): Sistema de coodenadas fixo na IMU.

O modelo de predição de estado é baseado no desenvolvido por Hol (2008), porém aqui adiciona-se as coordenadas das features $m_{t}$ ao vetor de estado:

$$
x_{t}=\left(\begin{array}{llllllllll}
b_{t}^{e} & \dot{b}_{t}^{e} & \ddot{b}_{t}^{e} & q_{t}^{b e} & \omega_{e b, t}^{b} & \delta_{\omega, t}^{b} & \delta_{a, t}^{b} & m_{1, t} & \ldots & \left.m_{M, t}\right)^{T}
\end{array}\right.
$$

O vetor de estado consiste na posição da IMU $b_{t}^{e}$ em relação ao sistema de coordenadas da Terra, sua velocidade $\dot{b}_{t}^{e}$, aceleração $\ddot{b}_{t}^{e}$, orientação da IMU $q_{t}^{b e} \mathrm{em}$ relação ao sistema de coordenadas da Terra, sua velocidade angular $\omega_{e b, t}^{b}$, bias dos giroscópios $\delta_{\omega, t}^{b}$, bias dos acelerômetros $\delta_{a, t}^{b}$ em relação ao sistema de coordenadas da IMU e posição de cada feature em relação ao sistema de coordenadas da Terra $m_{i, t}$, sendo $i=1 \ldots M$. Todos os elementos do vetor de estado possuem três dimensões, exceto a orientação que é descrita como um quaternion possuindo quatro dimensões, resultando em um total de 22 estados mais as coordenadas de cada feature, que aumenta a cada nova feature encontrada. Utiliza-se quaternions pelo fato destes não apresentarem singularidades, como apresentado pelos ângulos de Euler.

Definido o vetor de estado e os sistemas de coordenadas, o modelo de predição de estado é dado por: 


$$
\begin{aligned}
b_{t+1}^{e} & =b_{t}^{e}+T \dot{b}_{t}^{e}+\frac{T^{2}}{2} \ddot{b}_{t}^{e} \\
\dot{b}_{t+1}^{e} & =\dot{b}_{t}^{e}+T \ddot{b}_{t}^{e} \\
\ddot{b}_{t+1}^{e} & =\ddot{b}_{t}^{e}+v_{\ddot{b}, t}^{e} \\
q_{t+1}^{b e} & =\exp \left(-\frac{T}{2} \omega_{e b, t}^{b}\right) \odot q_{t}^{b e} \\
\omega_{e b, t+1}^{b} & =\omega_{e b, t}^{b}+v_{\omega, t}^{b} \\
\delta_{\omega, t+1}^{b} & =\delta_{\omega, t}^{b}+v_{\delta_{\omega}, t}^{b} \\
\delta_{a, t+1}^{b} & =\delta_{a, t}^{b}+v_{\delta_{a}, t}^{b} \\
m_{j, t+1} & =m_{j, t},
\end{aligned}
$$

onde a multiplicação de quaternions e a exponencial (veja Hamilton (1844), Kuipers (1999) ou Hol (2008)) são definidos por:

$$
\begin{aligned}
\left(\begin{array}{c}
p_{0} \\
\mathbf{p}
\end{array}\right) \odot\left(\begin{array}{c}
q_{0} \\
\mathbf{q}
\end{array}\right) & =\left(\begin{array}{c}
p_{0} q_{0}-\mathbf{p} \cdot \mathbf{q} \\
p_{0} \mathbf{q}+q_{0} \mathbf{p}+\mathbf{p} \times \mathbf{q}
\end{array}\right) \\
\exp (v) & =\left(\begin{array}{c}
\cos \|v\| \\
\frac{v}{\|v\|} \sin \|v\|
\end{array}\right) .
\end{aligned}
$$

Utiliza-se um modelo de aceleração constante (Equações 4.2a à 4.2c) para modelagem de posição, velocidade e aceleração. Adiciona-se ruído $\left(v_{\ddot{b}, t}^{e}\right)$ no termo de aceleração (Equação 4.2c) para aproximação com o movimento real, pois este não é sempre uniformemente acelerado. Este ruído é propagado para os termos de velocidade e posição a cada passo de predição. A dinâmica do quaternion (Equações $4.2 \mathrm{~d}$ e $4.2 \mathrm{e}$ ) é descrita com um modelo de velocidade angular constante. Os termos de bias são modelados como um random walk. Por fim, as features são modeladas como estacionárias.

Uma rotação em torno de um eixo $n$ por um ângulo $\alpha$ é definido pelo vetor $e \triangleq$ $\alpha n$ e a sua conversão para quaternion é $q^{a b}=\exp \left(\frac{1}{2} e^{a b}\right)$. Desta forma, o termo $-T \omega_{e b, t}^{b}$ da Equação $4.2 \mathrm{~d}$ representa o vetor $e$ e a multiplicação de quaternion aplica esta rotação no termo $q_{t}^{b e}$. Detalhes sobre quaternions e suas propriedades podem ser encontradas no Apêndice A. 
Para implementação deste modelo utilizando Filtro de Kalman Estendido, é descrito abaixo o jacobiano deste modelo de predição de estado:

$$
\mathbf{F}=\left[\begin{array}{cccccccc}
I_{3} & T I_{3} & \frac{T^{2}}{2} I_{3} & 0_{3 \times 4} & 0_{3} & 0_{3} & 0_{3} & 0_{3 \times 3 M} \\
0_{3} & I_{3} & T I_{3} & 0_{3 \times 4} & 0_{3} & 0_{3} & 0_{3} & 0_{3 \times 3 M} \\
0_{3} & 0_{3} & I_{3} & 0_{3 \times 4} & 0_{3} & 0_{3} & 0_{3} & 0_{3 \times 3 M} \\
0_{4 \times 3} & 0_{4 \times 3} & 0_{4 \times 3} & \exp \left(-\frac{T}{2} \omega_{e b}^{b}\right)_{L} & F_{1} & 0_{4 \times 3} & 0_{4 \times 3} & 0_{4 \times 3 M} \\
0_{3} & 0_{3} & 0_{3} & 0_{3} & I_{3} & 0_{3} & 0_{3} & 0_{3 \times 3 M} \\
0_{3} & 0_{3} & 0_{3} & 0_{3} & 0_{3} & I_{3} & 0_{3} & 0_{3 \times 3 M} \\
0_{3} & 0_{3} & 0_{3} & 0_{3} & 0_{3} & 0_{3} & I_{3} & 0_{3 \times 3 M} \\
0_{3 M \times 3} & 0_{3 M \times 3} & 0_{3 M \times 3} & 0_{3 M \times 3} & 0_{3 M \times 3} & 0_{3 M \times 3} & 0_{3 M \times 3} & I_{3 M \times 3 M}
\end{array}\right],
$$

onde:

$$
\begin{aligned}
F_{1} & \triangleq \frac{\partial}{\partial \omega_{e b}^{b}}\left(\exp \left(-\frac{T}{2} \omega_{e b}^{b}\right) \odot q^{b e}\right) \\
& =-\frac{T}{2}\left(q^{b e}\right)_{R}\left[\begin{array}{c}
-\frac{v^{T}}{\|v\|} \sin \|v\| \\
\left.\frac{1}{\|v\|}\left[I-\frac{v v^{T}}{\|v\|^{2}}\right] \sin \|v\|+\frac{v v^{T}}{\|v\|^{2}} \cos \|v\|\right]_{v=-\frac{T}{2} \omega_{e b}^{b}}
\end{array}\right.
\end{aligned}
$$

Para pequenos ângulos, $\cos x=1$ e $\sin x=x$, esta expressão é simplificada para:

$$
F_{1} \approx-\frac{T}{2}\left(q^{b e}\right)_{R}\left[\begin{array}{c}
\frac{T}{2} \omega_{e b}^{b, T} \\
I_{3}
\end{array}\right]
$$




\section{$5 \quad$ Modelo de Sensores}

Em instantes onde as medidas de todos os sensores estão disponíveis, o vetor de medidas e o jacobiano do modelo de sensor são:

$$
\begin{aligned}
y & =\left(\begin{array}{lll}
y_{I M U, t}^{T} & y_{G P S, t}^{T} & y_{V I S I O N, t}^{T}
\end{array}\right)^{T} \\
\mathbf{H} & =\left[\begin{array}{lll}
\mathbf{H}_{\mathbf{I M U}}{ }^{T} & \mathbf{H}_{\mathbf{G P S}}{ }^{T} & \mathbf{H}_{\text {VISION }}
\end{array}\right]^{T} .
\end{aligned}
$$

Como a aquisição de leituras dos sensores ocorrem em taxas de amostragens diferentes, o vetor de medidas varia de acordo com a medida de sensor disponível em cada instante. Geralmente as medidas da IMU estão sempre presentes no vetor de medidas, pois é o sensor mais rápido entre os três. Outras variações de vetor de medidas ficariam da seguinte forma:

$$
\begin{aligned}
y & =y_{I M U, t} \\
\mathbf{H} & =\mathbf{H}_{\mathrm{IMU}} .
\end{aligned}
$$

$$
\begin{aligned}
y & =\left(\begin{array}{ll}
y_{I M U, t}^{T} & y_{G P S, t}^{T}
\end{array}\right)^{T} \\
\mathbf{H} & =\left[\begin{array}{ll}
\mathbf{H}_{\mathbf{I M U}}^{T} & \mathbf{H}_{\mathbf{G P S}}
\end{array}\right]^{T} . \\
y & =\left(\begin{array}{ll}
y_{I M U, t}^{T} & y_{\text {VISION,t }}^{T}
\end{array}\right)^{T} \\
\mathbf{H} & =\left[\begin{array}{ll}
\mathbf{H}_{\mathbf{I M U}} & \mathbf{H}_{\mathrm{VISION}}
\end{array}\right]^{T} .
\end{aligned}
$$




\subsection{Unidade de Medição Inercial}

Neste trabalho utiliza-se uma IMU de baixo custo que possui acelerômetros e giroscópios MEMS (Micro-Electro-Mechanical Systems) de três eixos. Existem outros tipos de maior custo, como as que utilizam giroscópios com tecnologia FOG (Fibre optic gyroscope), que utiliza interferência da luz para detectar rotação mecânica, por exemplo.

O vetor de medidas da IMU é:

$$
y_{I M U, t}=\left(\begin{array}{ll}
y_{a, t}^{T} & y_{\omega, t}^{T}
\end{array}\right)^{T},
$$

onde $y_{a, t}$ é aceleração medida pelos acelerômetros e $y_{\omega, t}$ é a velocidade angular medida pelos giroscópios. As duas medidas são feitas em relação ao sistema de coordenadas da IMU.

O modelo de sensor da IMU é definido como:

$$
\begin{aligned}
& y_{a, t}=R_{t}^{b e}\left(\ddot{b}_{t}^{e}-g^{e}\right)+\delta_{a, t}^{b}+e_{a, t}^{b} \\
& y_{\omega, t}=\omega_{e b, t}^{b}+\delta_{\omega, t}^{b}+e_{\omega, t}^{b}
\end{aligned}
$$

onde $R_{t}^{b e}$ é a forma matricial da rotação do sistema de coordenadas da Terra para o corpo da IMU calculado a partir do quaternion $q_{t}^{b e}, g^{e}$ é a aceleração da gravidade no sistema de coordenadas da Terra e $e_{a, t}^{b}$ e $e_{\omega, t}^{b}$ são os ruídos de medidas dos acelerômetros e dos giroscópios, respectivamente.

A Equação 5.6 é o ponto do equacionamento em que observa-se claramente a remoção da aceleração da gravidade lida pelos acelerômetros , conforme ilustrado no esquemático da Figura 3.1, porém a sequência do algoritmo não é exatamente a da ilustração. Como o estado estimado é "convertido"para as grandezas medidas, o que se observa é a adição da gravidade nas variáveis de estado de aceleração seguida pela rotação dos mesmos para o sistema de coordenadas da IMU, adição de termos de bias e ruído e por fim é feita a comparação com a medição.

Segue abaixo o jacobiano do modelo de sensor da IMU para implementação no Filtro de Kalman Estendido:

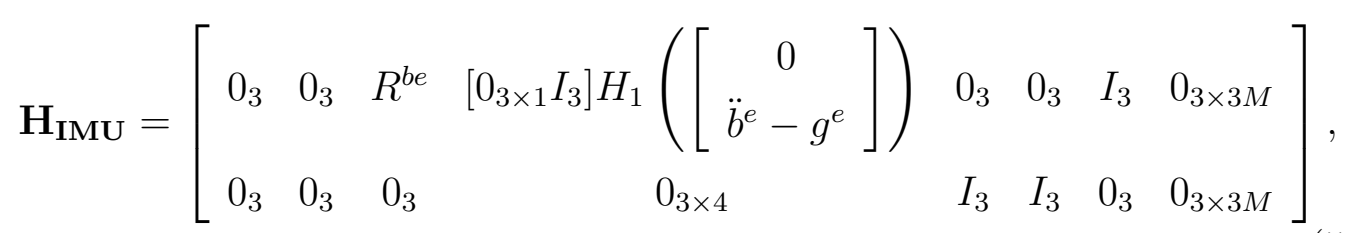


onde:

$$
H_{1}\left(v^{e}\right) \triangleq \frac{\partial}{\partial q^{b e}}\left(q^{b e} \odot v^{e} \odot q^{e b}\right)=\left(q^{b e}\right)_{R}^{T}\left(v^{e}\right)_{R}+\left(q^{b e}\right)_{L}\left(v^{e}\right)_{L}\left[\begin{array}{cc}
1 & 0 \\
0 & -I_{3}
\end{array}\right] .
$$

\subsection{GPS}

Os dados fornecidos por um GPS são comumente fornecidos em latitude e longitude em graus e altitude em metros em relação ao nível do mar. Como todo o modelo é baseado em distâncias métricas, estes valores de latitude e longitude devem ser convertidos para metros. Define-se uma coordenada qualquer como a origem do sistema de coordenadas da Terra e as coordenadas obtidas pelo GPS devem ser pré-processadas calculando-se a posição em relação a este sistema de coordenadas. Desta forma, o modelo de sensor do GPS fica:

$$
y_{G P S, t}=b_{t}^{e}+r^{G P S},
$$

onde $r^{G P S}$ é a distância entre a antena de GPS e a IMU em relação ao sistema de coordenadas da IMU.

A partir desta equação, desenvolve-se o Jacobiano do mesmo e obtém-se:

$$
\mathbf{H}_{\mathrm{GPS}}=\left[\begin{array}{lll}
I_{3} & 0_{3 \times 19} & 0_{3 \times 3 M}
\end{array}\right]
$$

\subsection{Visão}

O processo de formação de imagem consiste basicamente em três etapas. A primeira é a incidência dos raios de luz no sensor CCD (Charge-Coupled Device), descrito como uma projeção perspectiva e discutida na Seção 5.3.1. A segunda etapa é a remoção da distorção causada pela lente, descrita na Seção 5.3.2. A terceira consiste na digitalização da imagem feita pelo sensor CCD, Seção 5.3.3. A Seção 5.3.4 descreve o processo de calibração de câmera, onde é obtido os parâmetros utilizados nas três etapas descritas acima. A Seção 5.3.5 explica como é feita a identificação de features. Por fim, o modelo do sensor de visão é descrito na Seção 5.3.6. 


\subsubsection{Modelo de Câmera de Orifício Normalizada}

O modelo de câmera de orifício (HARTLEY; ZISSERMAN, 2000; KARLSTROEM, 2007; HOL, 2008; CRIMINISI; REID; ZISSERMAN, 1997) é o modelo mais simples e comumente utilizado para representar o comportamento de câmeras de sensor CCD (Charge-Coupled Device). Este modelo representa a projeção de um ponto no espaço 3D para o plano de imagem. De acordo com Karlstroem (2007), um ponto 3D com coordenadas $\mathbf{X}=\left(\begin{array}{lll}X & Y & Z\end{array}\right)^{T}$ é mapeado para o ponto onde a reta que passa por $\mathbf{X}$ e pelo centro de câmera encontra o plano de imagem, conforme mostrado na figura 5.1.
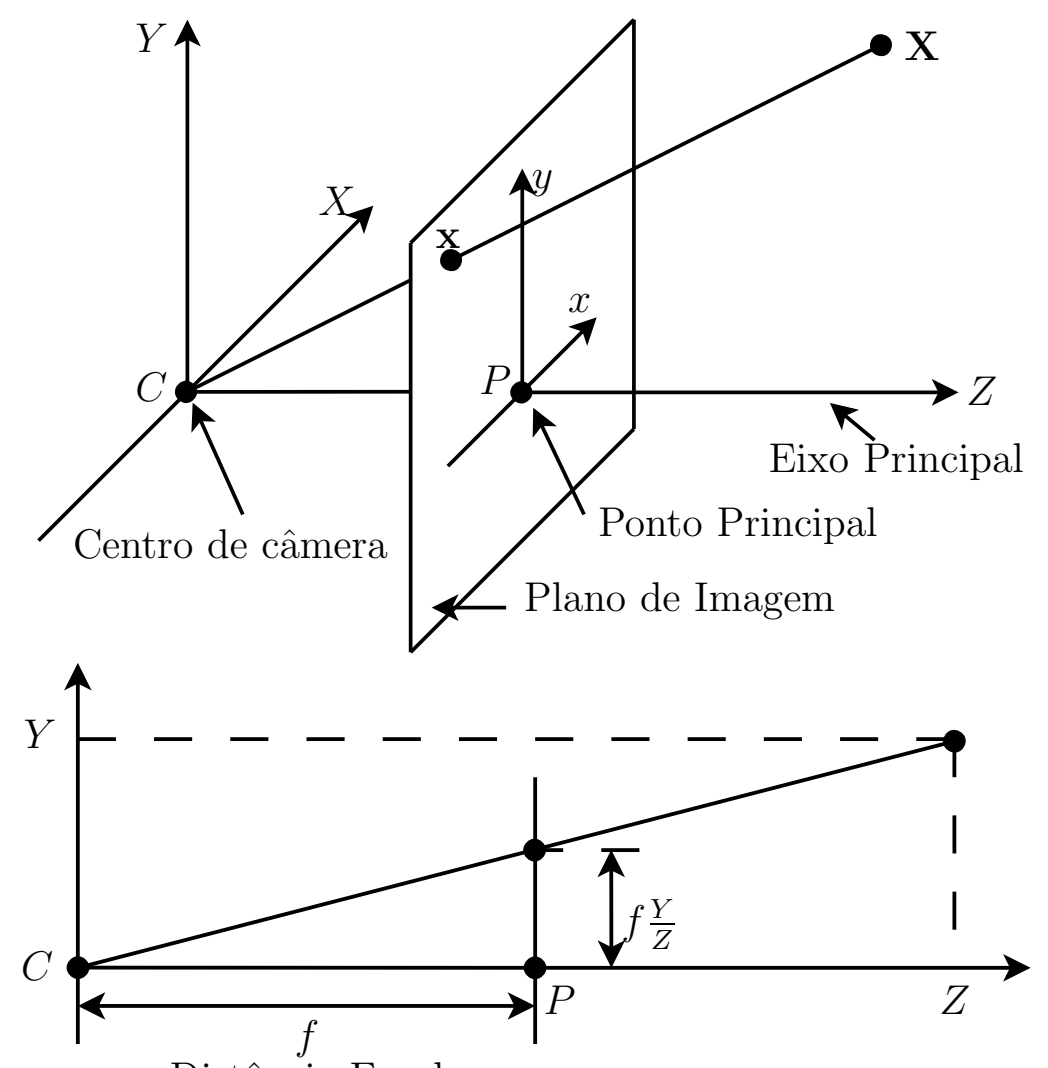

Distância Focal

Figura 5.1: Modelo de Câmera de Orifício.

Desta forma o ponto $\left(\begin{array}{llll}X & Y & Z\end{array}\right)^{T}$ é mapeado para o ponto $\left(\begin{array}{lll}f X / Z & f Y / Z\end{array}\right)^{T}$ sobre o plano de imagem. Assumindo que a distância focal do modelo é $f=1$, a projeção na forma homogênea fica:

$$
Z\left(\begin{array}{c}
x_{n} \\
y_{n} \\
1
\end{array}\right)=\left[\begin{array}{llll}
1 & 0 & 0 & 0 \\
0 & 1 & 0 & 0 \\
0 & 0 & 1 & 0
\end{array}\right]\left(\begin{array}{c}
X \\
Y \\
Z \\
1
\end{array}\right)
$$

A representação de um ponto na forma homogênea permite que $\left(\begin{array}{lll}k_{1} x & k_{1} y & k_{1}\end{array}\right)^{T}$ 
e $\left(\begin{array}{lll}k_{2} x & k_{2} y & k_{2}\end{array}\right)^{T}$, sendo $k_{1} \neq k_{2}$ e ambos não nulos, representem o mesmo ponto $\left(\begin{array}{lll}x & y & 1\end{array}\right)^{T}$.

\subsubsection{Correção de Distorção de Lentes}

O modelo de câmera de orifício é um modelo de projeção perspectiva ideal e o processo de formação de imagens reais difere deste por causa do efeito das lentes sobre a projeção. Um exemplo desta distorção e sua correção é mostrado na Figura 5.2. Um modelo de distorção simples que considera a distorção radial expressa as coordenadas da imagem distorcida $p_{d}^{i}=\left(\begin{array}{ll}x_{d} & y_{d}\end{array}\right)^{T}$ como função das coordenadas da imagem normalizada $p_{n}^{i}=\left(\begin{array}{ll}x_{n} & y_{n}\end{array}\right)^{T}$ (HOL, 2008):

$$
p_{d}^{i}=\left(1+k_{1}\left\|p_{n}^{i}\right\|^{2}+k_{2}\left\|p_{n}^{i}\right\|^{4}\right) p_{n}^{i}
$$

onde $k_{i}$ são coeficientes de distorção.
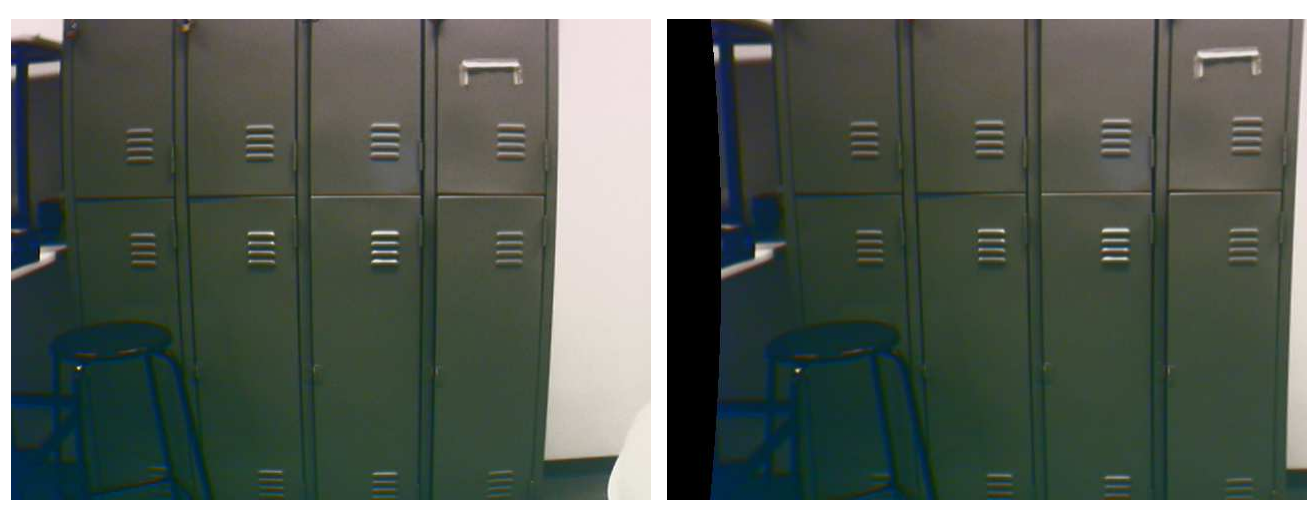

Figura 5.2: Correção de distorção radial gerada pelo efeito da lente.

\subsubsection{Digitalização}

O modelo de digitalização é uma transformação linear que representa a digitalização da imagem pelo sensor CCD, ou seja, uma transformação para coordenadas em pixel. Pode-se modelar pixels não quadradros e não ortogonais. A transformação converte coordenadas da imagem distorcida $p_{d}^{i}=\left(\begin{array}{ll}x_{d} & y_{d}\end{array}\right)^{T}$ para coordenadas em pixel $p^{i}=\left(\begin{array}{ll}x & y\end{array}\right)^{T}$ :

$$
\left(\begin{array}{l}
x \\
y \\
1
\end{array}\right)=\left[\begin{array}{ccc}
f s_{x} & f s_{\theta} & x_{0} \\
0 & f s_{y} & y_{0} \\
0 & 0 & 1
\end{array}\right]\left(\begin{array}{c}
x_{d} \\
y_{d} \\
1
\end{array}\right)
$$

onde $f$ é a distância focal, $s_{x}$ e $s_{y}$ são os tamanhos dos pixels, $x_{0}$ e $y_{0}$ é a coordenada do ponto principal e $s_{\theta}$ é o parâmetro de inclinação. A matriz da Equação 
(5.13) é definida como matriz de calibração de câmera $K$ e seus parâmetros são denominados parâmetros intrínsecos.

\subsubsection{Calibração de Câmera}

O procedimento de calibração de câmera tem como objetivo encontrar todos os parâmetros intrínsecos da câmera. Estes parâmetros são a matriz de calibração de câmera e os parâmetros de distorção de lente. Este procedimento de calibração é um problema bem conhecido em visão computacional e existem diversas ferramentas disponíveis para este fim, por exemplo Bouguet (2003), Zhang (1998) e Kannala e Brandt (2006).

Estas ferramentas utilizam um objeto com pontos de referência em coordenadas conhecidas e a partir destes pontos nas imagens (ou seja, coordenadas em pixel) calculam-se os parâmetros intrínsecos da câmera. Geralmente este objeto é um tabuleiro de xadrez e as ferramentas possuem algoritmos que encontram os quadrados do tabuleiro. A Figura 5.3 mostra imagens do tabuleiro utilizado no procedimento de calibração de câmera.
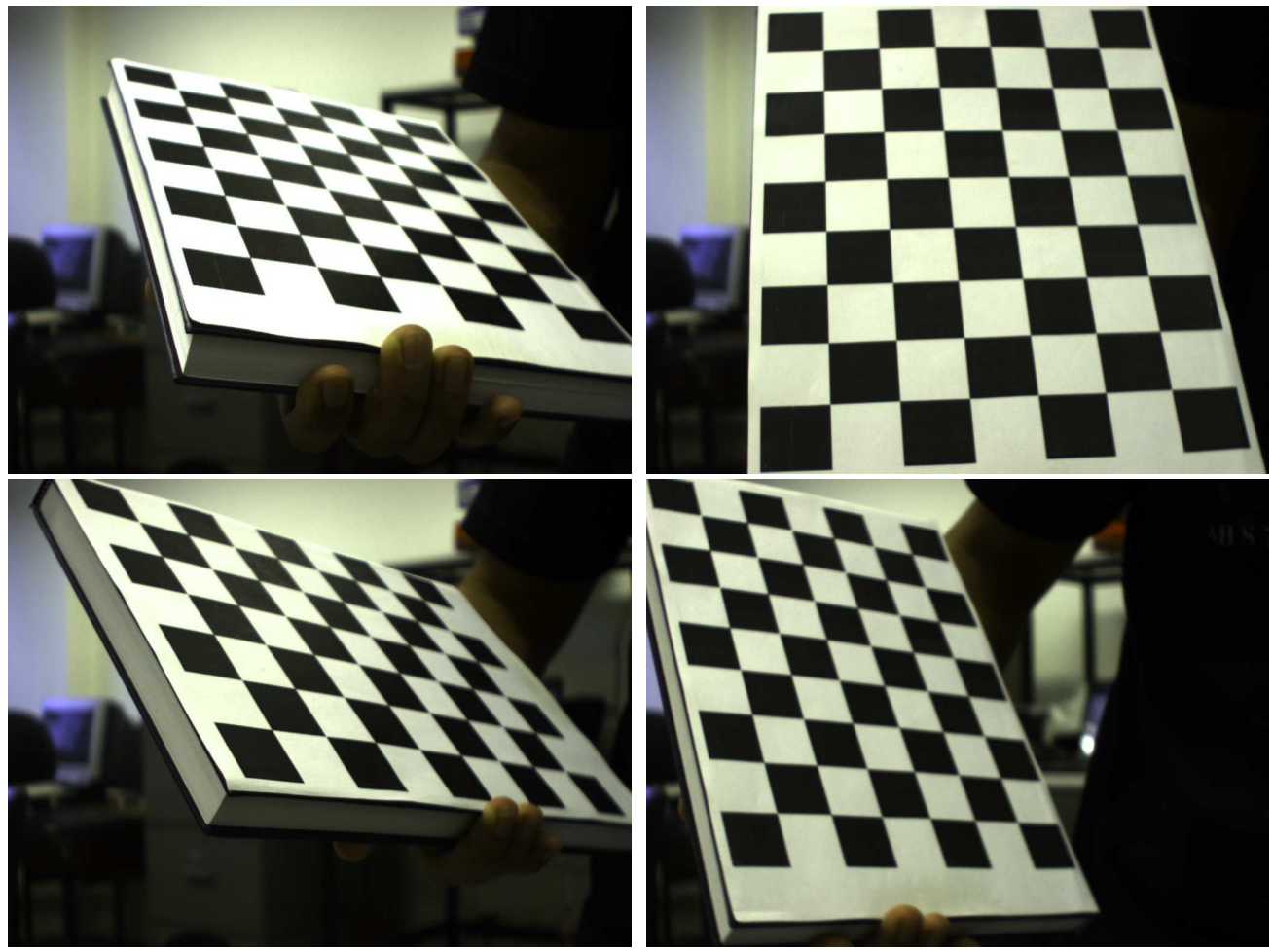

Figura 5.3: Exemplo de imagens utilizadas na calibração de câmera. 


\subsubsection{Identificação de Features}

O mapa gerado a partir do SLAM é formado por features detectadas e rastreadas automaticamente em cada imagem. A detecção destas é um problema bem conhecido possuindo diversas implementações com grandes variações na qualidade das features encontradas e no tempo de resposta. Algumas das implementações mais conhecidas e utilizadas são Harris Corner Detection (HARRIS; STEPHENS, 1988), Minimum Eigenvalue (SHI; TOMASI, 1994), Local Intensity Comparison (ROSTEN; DRUMMOND, 2005), SURF (BAY; TUYTELAARS; GOOL, 2006) e SIFT (LOWE, 1999).

Estes algoritmos basicamente identificam regiões na imagem com boas características para serem rastreadas, ou seja, curvas acentuadas e grandes variações de cores. Um trecho de uma reta não pode ser rastreado sem apresentar falhas porque não é possível distinguir o trecho do restante da reta. A região próxima ao vértice de um quadrado já é algo que apresenta menos falhas, pois é possível distingui-lo dos lados do quadrado. Ao utilizar estes algoritmos em uma imagem com uma figura quadrada, por exemplo, as features detectadas seriam basicamente os vértices da figura. A Figura 5.4 mostra um exemplo de identificação de features. Observa-se que os pontos encontrados são basicamente os cantos dos objetos e regiões com gradientes altos, incluindo regiões com árvores.
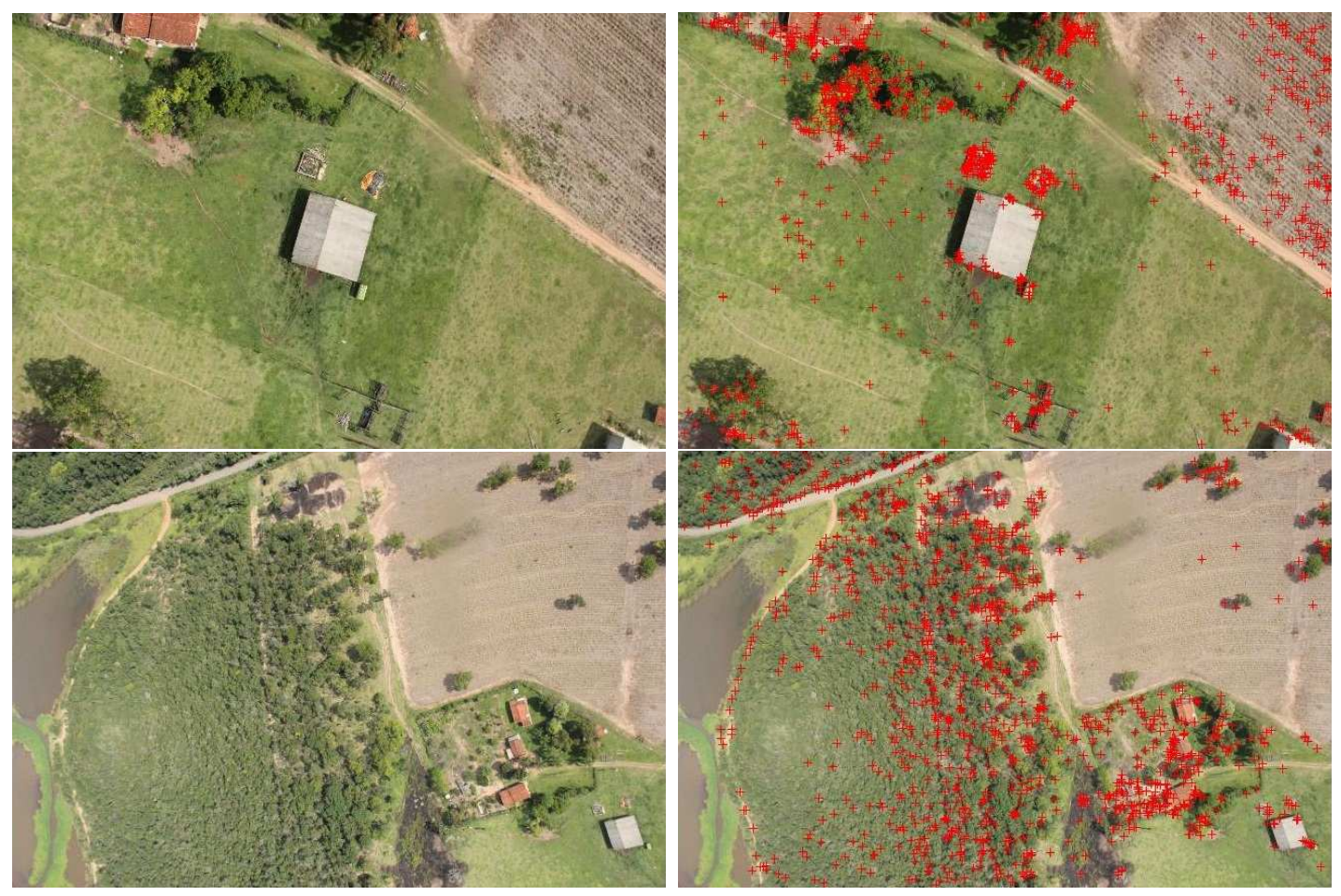

Figura 5.4: Exemplo de identificação de features.

Os algoritmos mais rápidos e robustos citados acima são SURF e SIFT. Além 
de identificarem as features, estes algoritmos geram descritores para cada uma. O descritor é representado por um vetor possuindo características dos pixels ao redor da feature e são usados para distingui-las e correlacioná-las entre uma imagem e outra. A principal características destes algoritmos é que são invariantes a escala e rotação.

\subsubsection{Modelo de Sensor de Visão}

Combinando as Equações (5.11), (5.12) e (5.13) em um modelo de câmera único, a projeção no plano de imagem $p^{i}=\left(\begin{array}{ll}x & y\end{array}\right)^{T}$ do ponto 3D $p^{c}=\left(\begin{array}{lll}X & Y & Z\end{array}\right)^{T}$ é dado por:

$$
p^{i}=\left(A \circ D \circ P_{n}\right)\left(p^{c}\right)
$$

onde $P_{n}$ é a função de câmera de orifício normalizada (Equação (5.11)), D é a função de distorção de lente (Equação (5.12)) e $A$ é a função de digitalização (Equação (5.13).

O desenvolvimento do modelo de sensor de visão a partir da Equação (5.14) gera uma complexidade de equacionamento desnecessária, pois a imagem ou cada feature podem ter suas coordenadas pré-processadas e as coordenadas de imagem normalizadas utilizadas no modelo de medida. O pré-processamento é dado por:

$$
p_{n}^{i}=\left(D^{-1} \circ A^{-1}\right)\left(p^{i}\right)
$$

O modelo de sensor de câmera para cada feature encontrada na imagem é baseado no desenvolvido em Törnqvist et al. (2009):

$$
y_{v, t}=y_{m_{j}, t}=\frac{1}{z_{t}^{c}}\left(\begin{array}{c}
x_{t}^{c} \\
y_{t}^{c}
\end{array}\right)+e_{v, t}^{c},
$$

onde

$$
m_{j, t}^{c}=\left(\begin{array}{c}
x_{t}^{c} \\
y_{t}^{c} \\
z_{t}^{c}
\end{array}\right)=R\left(q^{c b}\right) R\left(q_{t}^{b e}\right)\left(m_{j, t}-b_{t}^{e}\right)+r^{c}
$$


A partir deste modelo obtém-se o Jacobiano:

$$
\mathbf{H}_{\text {VISION }}=\left[\begin{array}{cccccccccccc}
H_{m_{1}, 1} & 0 & 0 & H_{m_{1}, 2} & 0 & 0 & 0 & H_{m_{1}, 3} & \cdots & 0 & \cdots & 0 \\
\vdots & \vdots & \vdots & \vdots & \vdots & \vdots & \vdots & \vdots & \ddots & \vdots & \vdots & \vdots \\
H_{m_{j}, 1} & 0 & 0 & H_{m_{j}, 2} & 0 & 0 & 0 & 0 & \cdots & H_{m_{j}, 3} & \cdots & 0 \\
\vdots & \vdots & \vdots & \vdots & \vdots & \vdots & \vdots & \vdots & \vdots & \vdots & \ddots & \vdots \\
H_{m_{M}, 1} & 0 & 0 & H_{m_{M}, 2} & 0 & 0 & 0 & 0 & \cdots & 0 & \cdots & H_{m_{M}, 3}
\end{array}\right],
$$

sendo as submatrizes $0=0_{2 \times 3}$,

$$
\begin{gathered}
H_{m_{j}, 1}=\frac{\partial h_{j}^{c}}{\partial b_{t}^{e}}=\frac{\partial h_{j}^{c}}{\partial m_{j}^{c}} \frac{\partial m_{j}^{c}}{\partial b_{t}^{e}}=\frac{\partial h_{j}^{c}}{\partial m_{j}^{c}}\left(-R\left(q^{c b}\right) R\left(q_{t}^{b e}\right)\right) \\
H_{m_{j}, 2}=\frac{\partial h_{j}^{c}}{\partial q_{t}^{b e}}=\frac{\partial h_{j}^{c}}{\partial m_{j}^{c}} \frac{\partial m_{j}^{c}}{\partial q_{t}^{b e}}=\frac{\partial h_{j}^{c}}{\partial m_{j}^{c}} R\left(q^{c b}\right)\left[0_{3 \times 1} I_{3}\right] H_{1}\left(\left[\begin{array}{c}
0 \\
m_{j, t}-b_{t}^{e}
\end{array}\right]\right) \\
H_{m_{j}, 3}=\frac{\partial h_{j}^{c}}{\partial m_{j}}=\frac{\partial h_{j}^{c}}{\partial m_{j}^{c}} \frac{\partial m_{j}^{c}}{\partial m_{j}}=\frac{\partial h_{j}^{c}}{\partial m_{j}^{c}} R\left(q^{c b}\right) R\left(q_{t}^{b e}\right) \\
\frac{\partial h_{j}^{c}}{\partial m_{j}^{c}}=\left[\begin{array}{ccc}
\frac{1}{z_{j}^{c}} & 0 & -\frac{x_{j}^{c}}{\left(z_{j}^{c}\right)^{2}} \\
0 & \frac{1}{z_{j}^{c}} & -\frac{y_{j}^{c}}{\left(z_{j}^{c}\right)^{2}}
\end{array}\right] .
\end{gathered}
$$




\section{Aumento de Estado}

Quando uma nova feature é encontrada em uma imagem, é necessário aumentar o vetor de estados para inseri-la no mapa e também aumentar a matriz de covariância de estado nos termos correlacionados ao mesmo. Segundo (DURRANTWHYTE; BAILEY, 2006b), a idéia geral do aumento de estado pode ser aplicada sempre que novos estados são função de uma parte dos estados existentes:

$$
\begin{gathered}
x=\left[\begin{array}{c}
x_{1} \\
x_{2} \\
f\left(x_{2}, q\right)
\end{array}\right] \\
P=\left[\begin{array}{ccc}
P_{11} & P_{12} & P_{12} \nabla f_{x_{2}}^{T} \\
P_{12}^{T} & P_{22} & P_{22} \nabla f_{x_{2}}^{T} \\
\nabla f_{x_{2}} P_{12}^{T} & \nabla f_{x_{2}} P_{22}^{T} & \nabla f_{x_{2}} P_{22} \nabla f_{x_{2}}^{T}+\nabla f_{q} Q \nabla f_{q}^{T}
\end{array}\right]
\end{gathered}
$$

Sendo $Z$ uma estimativa inicial da distância da feature em relação a câmera e $\left(\begin{array}{lll}y_{x} & y_{y} & 1\end{array}\right)^{T}$ a sua coordenada na forma homogênea na imagem, de acordo com as Equações 5.16 e 5.17, este ponto estará em relação ao referencial na Terra na posição:

$$
\begin{aligned}
\left(\begin{array}{c}
y_{x} \\
y_{y} \\
1
\end{array}\right) Z & =R\left(q_{t}^{c b}\right) R\left(q_{t}^{b e}\right)\left(m_{j, t}-b_{t}^{e}\right)+r^{c} \Rightarrow \\
m_{j, t} & =R\left(q_{t}^{b e}\right)^{T} R\left(q_{t}^{c b}\right)^{T}\left(\left(\begin{array}{c}
y_{x} \\
y_{y} \\
1
\end{array}\right) Z-r^{c}\right)+b_{t}^{e}
\end{aligned}
$$


Aplicando a Equação 6.2 em 6.1, tem-se:

$$
\begin{aligned}
x_{2} & =\left\{\begin{array}{ll}
b_{t}^{e} & q_{t}^{b e}
\end{array}\right\} \\
\nabla f_{x_{2}} & =\left[\begin{array}{ll}
I_{3} & H
\end{array}\right] \\
q & =\left\{\begin{array}{lll}
y_{x} & y_{y} & Z
\end{array}\right\} \\
Q & =\left[\begin{array}{ccc}
\sigma_{y_{x}} & 0 & 0 \\
0 & \sigma_{y_{y}} & 0 \\
0 & 0 & \sigma_{Z}
\end{array}\right] \\
\nabla f_{q} & =R\left(q_{t}^{b e}\right)^{T} R\left(q_{t}^{c b}\right)^{T}\left[\begin{array}{ccc}
Z & 0 & y_{x} \\
0 & Z & y_{y} \\
0 & 0 & 1
\end{array}\right],
\end{aligned}
$$

onde:

$$
\begin{gathered}
H=\frac{\partial}{\partial q^{b e}}\left(q^{e b} \odot v^{e} \odot q^{b e}\right)=\left(q^{b e}\right)_{L}^{T}\left(v^{e}\right)_{L}+\left(q^{b e}\right)_{R}\left(v^{e}\right)_{R}\left[\begin{array}{cc}
1 & 0 \\
0 & -I_{3}
\end{array}\right] \\
\left.v^{e}=\left[\begin{array}{c}
0 \\
R\left(q_{t}^{c b}\right)^{T}\left(\left(\begin{array}{c}
y_{x} \\
y_{y} \\
1
\end{array}\right) Z-r^{c}\right)
\end{array}\right)\right]
\end{gathered}
$$

De acordo com a Figura 6.1, a estimativa de posicionamento da feature tem uma incerteza maior na direção radial em relação ao centro de câmera, ou seja, $\sigma_{Z}>\sigma_{y_{x}}$ e $\sigma_{Z}>\sigma_{y_{y}}$. Esta incerteza é reduzida de acordo com a movimentação da câmera, pois a triangulação é feita de maneira implícita pelo filtro. A distância $Z$ e a matriz de covariância $Q$ podem ser consideradas fixas, pois $Q$ é escrita em função do sistema de coordenadas da câmera e $\sigma_{Z}$ deve ser suficientemente grande para garantir a convergência da posição da feature. Estas hipóteses podem ser assumidas porque o modelo é utilizado em imagens aéreas capturadas próximas ao plano horizontal (situação normal de vôo), onde a distância média das features em relação ao avião não apresenta grandes variações. 


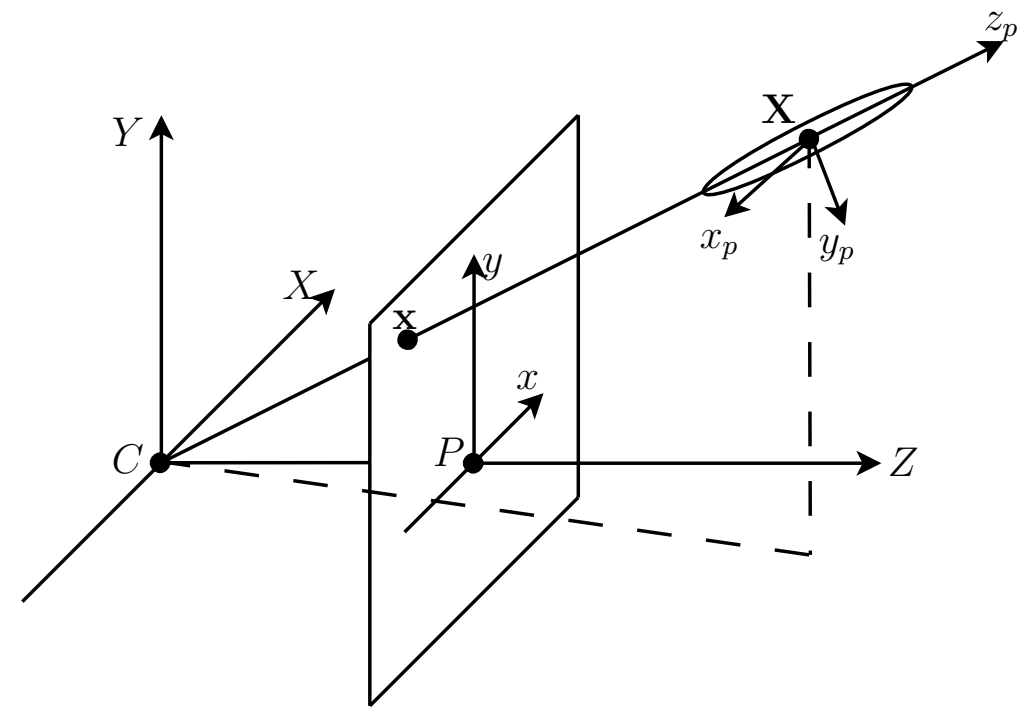

Figura 6.1: Incerteza na inicialização de uma feature utilizando modelo de câmera de orifício. 
Parte II

Resultados 


\section{Simulações}

Este capítulo realiza duas avaliações utilizando-se de simulações do sistema implementado. A Seção 7.1 faz a avaliação de diversas combinações de sensores para observar a influência de cada um nos resultados, ou seja, remove-se alguns sensores para observar drift e aumento de precisão. A Seção 7.2 foca na análise quantitativa dos resultados obtidos utilizando todos os sensores variando-se frequência de amostragem, tamanho de área sobrevoada e execução de manobras.

\subsection{Simulação 1: Avaliação de diferentes com- binações de sensores}

Foram comparadas três combinações de sensores para avaliar a influência de cada um no filtro. O primeiro é a fusão entre GPS e IMU sem a utilização do SLAM, pois não há sensor que captura informações do ambiente. Esta configuração é usada como referência para avaliar o impacto gerado pela adição da Câmera. $\mathrm{Na}$ segunda é analisada a fusão entre IMU e Câmera. Esta é uma abordagem normalmente estudada em cenários de guerra onde o sinal de satélites para uso em GPS pode não estar disponível ou mesmo suscetível a falhas (BRYSON; SUKKARIEH, 2008; TÖRNQVIST et al., 2009). O último é a fusão entre GPS, IMU e Câmera, proposta deste trabalho.

Os dados são gerados com o VANT realizando uma manobra em oito a 800 metros de altitude a uma velocidade de $32 \mathrm{~m} / \mathrm{s}$. Features são aleatoriamente distribuídas sobre uma superfície qualquer que descreve o terreno e cada uma possui um descritor associado. Os descritores simulam os que seriam obtidos com imagens reais utilizando algoritmos como o SIFT (Scale-invariant feature transform) ou SURF (Speeded Up Robust Features), por exemplo. Eles são utilizados para correlacionar as features identificadas em uma imagem com as presentes no vetor de estado. A Tabela 7.1 mostra as caracteristicas de cada sensor e a Tabela 7.2 os valores de ruído utilizados no filtro. Os valores de ruído de sensores utilizados nesta simulação são típicos dos sensores mais baratos disponíveis no mercado 
atualmente e também possuem ruídos elevados. Esta condição de sensores ruins foi imposta nessa simulação para que fique evidente a influência de cada sensor ao comparar as diferentes combinações de fusão sensorial no filtro.

\begin{tabular}{|ll|}
\hline $\begin{array}{l}\text { IMU } \\
\text { Taxa de amostragem }\end{array}$ & $100 \mathrm{~Hz}$ \\
\hline GPS & \\
Taxa de amostragem & $12.5 \mathrm{~Hz}$ \\
\hline Câmera & \\
Taxa de amostragem & $12.5 \mathrm{~Hz}$ \\
Resolução & $640 \times 480$ pixel \\
Campo de Visão & 60 graus \\
\hline
\end{tabular}

Tabela 7.1: Características dos sensores.

\begin{tabular}{|c|c|}
\hline Ruído de medida de acelerômetros & $3.9 \mathrm{~m} / \mathrm{s}^{2}$ \\
\hline Ruído de medida de giroscópios & $0.38 \mathrm{rad} / \mathrm{s}$ \\
\hline Ruído de medida de GPS & $10 \mathrm{~m}$ \\
\hline Ruído de medida de Câmera & 0.035 \\
\hline Ruído de processo de aceleração & $0.1 \mathrm{~m} / \mathrm{s}^{2}$ \\
\hline Ruído de processo de velocidade angular & $0.03 \mathrm{rad} / \mathrm{s}$ \\
\hline Ruído de processo de bias de giroscópios & $0.5 \mathrm{mrad} / \mathrm{s}$ \\
\hline Ruído de processo de bias de acelerômetros & $0.5 \mathrm{~mm} / \mathrm{s}^{2}$ \\
\hline
\end{tabular}

Tabela 7.2: Características do filtro.

A Figura 7.1 mostra as três simulações. A fusão entre IMU e Câmera não é suficiente para estimar o terreno com grande acurácia, pois não há uma referencia absoluta real. Apesar da posição das features serem estáticas, não é uma referencia absoluta porque são estimadas baseadas nas outras ao redor dela, ocorrendo desta forma um drift. Este drift ocorre quando novas features são adicionadas no filtro, gerando um deslocamento no terreno e na trajetória praticamente constantes. As Figuras 7.1(b) e 7.2 mostram este drift no terreno e trajetória.

Quando um GPS é adicionado ao filtro, este drift não ocorre, pois este sensor atua como uma referência absoluta de posição. A trajetória estimada pela configuração GPS e IMU apresenta um erro de $\sigma_{G P S, I M U}=6.9 \mathrm{~m}$ e a estimada pela configuração GPS, IMU e Câmera apresenta um erro de of $\sigma_{G P S, I M U, C a m}=2.2 \mathrm{~m}$. Isto pode ser visto na Figura 7.2. 

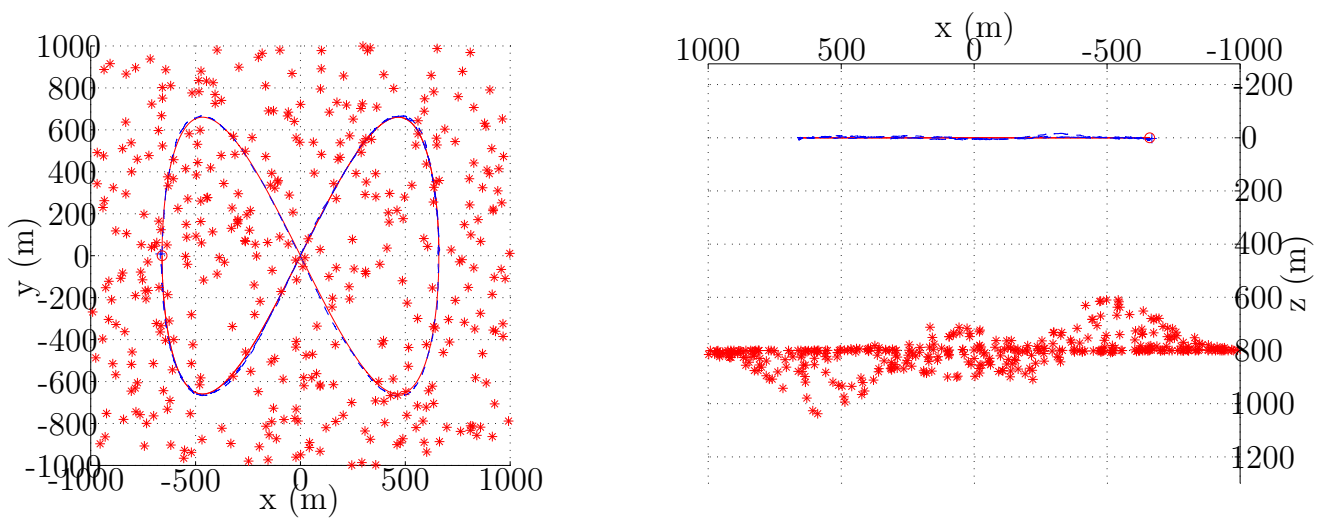

(a)
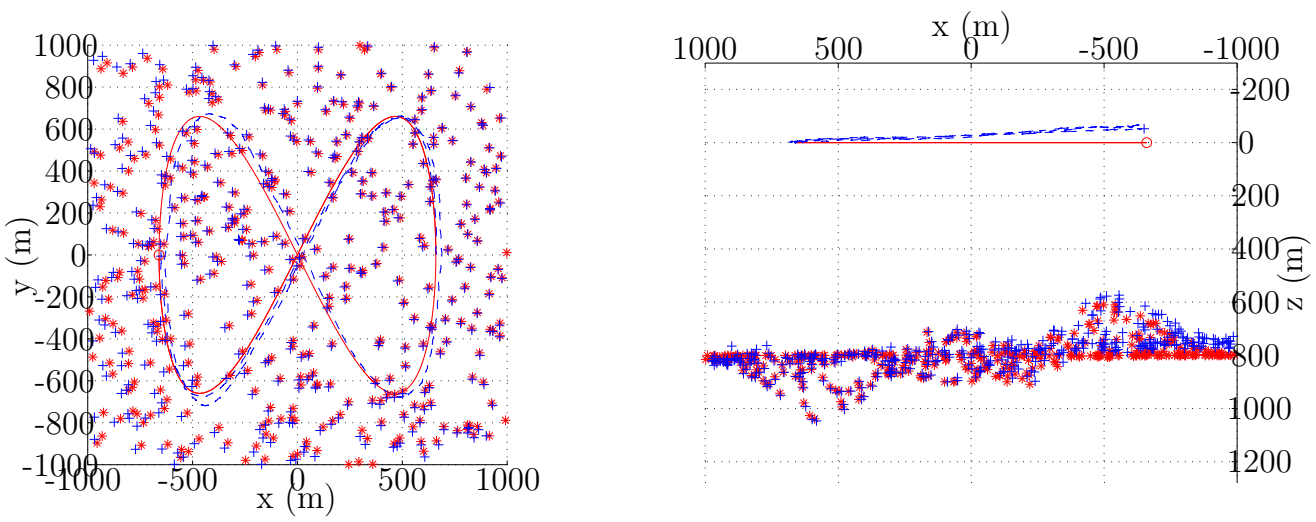

(b)
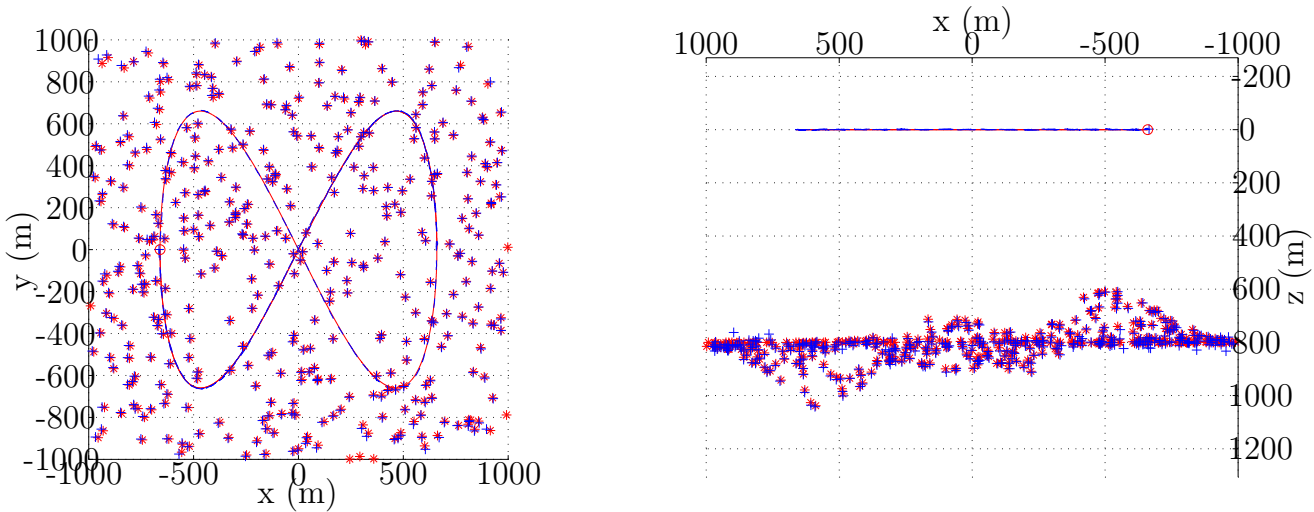

(c)

Figura 7.1: Estimação de terreno e trajetória onde pontos e linhas vermelhas são as features e trajetórias reais e pontos e linhas azuis são as estimadas. A Figura (a) mostra o caso de fusão entre GPS e IMU sem estimação de terreno, na Figura (b) a fusão entre IMU e Câmera e na Figura (c) a fusão entre GPS, IMU e Câmera. 

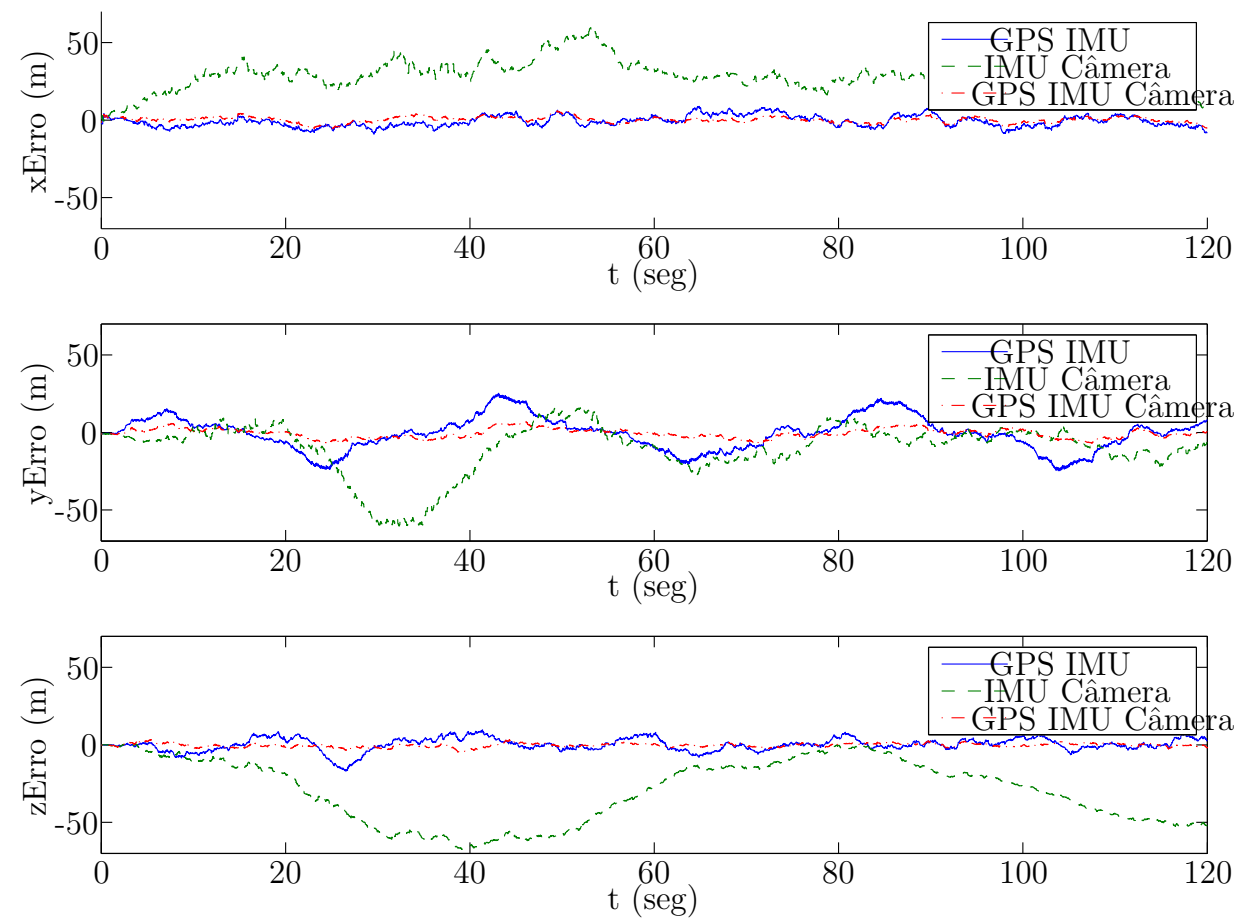

Figura 7.2: Erro de trajetória do VANT.

A análise de erro de posição das features é feito na Figura 7.3. O histograma da Figura 7.3(b) mostra o erro causado pelo drift na configuração IMU e Câmera. A configuração GPS, IMU e Câmera apresenta uma resultado de maior precisão e acurácia com um erro de $\sigma_{\text {feature }}=6.6 \mathrm{~m}$, que é uma precisão típica de GPS.

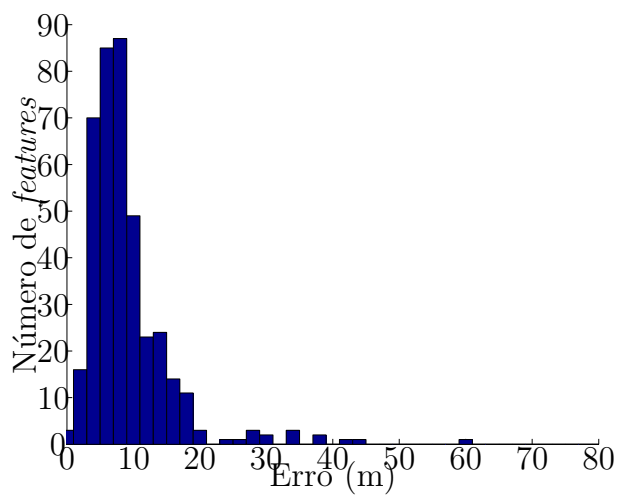

(a)

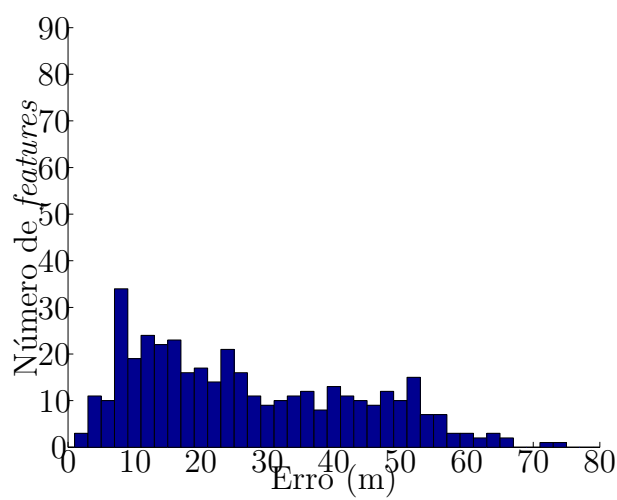

(b)

Figura 7.3: Erro na estimação de posição de cada feature. A Figura (a) mostra o histograma de erros para a configuração GPS, IMU e Câmera e a Figura (b) para a configuração IMU e Câmera. 


\subsection{Simulação 2: Análise quantitativa de resul- tados}

O objetivo destas simulações é avaliar o impacto na estimação de posição das features, posição e atitude do VANT em um voo padrão de aerofotogrametria utilizando sensores de melhor qualidade do que os utilizados na simulação anterior em diversas frequências e também em dois padrões de voo, um estável e outro com oscilação em roll. Foram utilizados os ruídos dos sensores presentes no VANT Nauru, da empresa XMobots, e também parâmetros do mesmo tipo de câmera que este usa (Fabricante CANON, modelo EOS Rebel T2i com uma lente de distância focal de $18 \mathrm{~mm})$. Para as primeiras simulações foram gerados 400 pontos em solo em uma área de $3400 m$ X $3400 m$ e na outra simulação aumentou-se a quantidade de features em solo para 1200. O VANT sobrevoa esta área fazendo faixas paralelas e mantendo uma sobreposição lateral nas imagens de $30 \%$ e sobreposição frontal de $60 \%$, que são os valores comumente utilizados na aerofotogrametria. A Tabela 7.3 mostra a configuração utilizada no filtro e a Tabela 7.4 mostra a configuração da câmera. Como pode ser observado nesta tabela, a frequência de amostragem da câmera em um voo padrão de aerofotogrametria é muito mais baixa do que a utilizada normalmente em aplicações de SLAM, onde utilizam-se vídeos a uma frequência de $5 \mathrm{~Hz}$ à $30 \mathrm{~Hz}$. Isto ocorre por causa da resolução das câmeras utilizadas neste tipo de aplicação, que atingem até 60 Megapixel. Esta resolução alta é utilizada por causa da necessidade de observar detalhes nas imagens e a aquisição ser feita a grandes distâncias.

\begin{tabular}{|c|c|}
\hline Ruído de medida de acelerômetros & $0,09 \mathrm{~m} / \mathrm{s}^{2}$ \\
\hline Ruído de medida de giroscópios & $0,015 \mathrm{rad} / \mathrm{s}$ \\
\hline Ruído de medida de GPS & $4 \mathrm{~m}$ \\
\hline Ruído de medida de Câmera & 0,0068 \\
\hline Ruído de processo de aceleração & $4 \mathrm{~m} / \mathrm{s}^{2}$ \\
\hline Ruído de processo de velocidade angular & $0,2 \mathrm{rad} / \mathrm{s}$ \\
\hline Ruído de processo de bias de giroscópios & $0,5 * 10^{-3} \mathrm{rad} / \mathrm{s}$ \\
\hline Ruído de processo de bias de acelerômetros & $0,5 * 10^{-3} \mathrm{~m} / \mathrm{s}^{2}$ \\
\hline
\end{tabular}

Tabela 7.3: Características do filtro. 


\begin{tabular}{|c|c|}
\hline Câmera & EOS Rebel T2 $i$ \\
\hline Distância focal & $18 \mathrm{~mm}$ \\
\hline Resolução & 5184 X 3456 (18 Megapixel) \\
\hline HFOV & $65^{\circ}$ \\
\hline VFOV & $45^{\circ}$ \\
\hline Período de amostragem & $6,62 \mathrm{seg}(\mathrm{f}=0,15 \mathrm{~Hz})$ \\
\hline
\end{tabular}

Tabela 7.4: Características da câmera.

As Figuras 7.4 e 7.6 mostram uma vista superior dos instantes de captura de imagem em duas simulações (voo estável e oscilatório, respectivamente) e as Figuras 7.5 e 7.7 mostram uma vista lateral da altitude do VANT e do relevo. Os pontos em vermelho indicam a posição real das features e os pontos e elipses em azul são as coordenadas e o erro, respectivamente, estimados pelo filtro. As etapas de aumento de estado são executadas a cada nova foto e as features adicionadas no estado são as que aparecem pela primeira vez com um erro maior do que as identificadas anteriormente. Isto ocorre porque não é conhecida a altitude deste novo ponto e um erro grande de posição para estas novas features deve ser adicionado no filtro para que ocorra a triangulação nas próximas aquisições de imagem. Este erro diminui à medida que estas features são visualizadas novamente.

O mesmo padrão de voo foi simulado para diversas configurações de frequência de sensores. Basicamente, foram escolhidas três frequências para a leitura da IMU $(100 \mathrm{~Hz}, 50 \mathrm{~Hz}$ e $20 \mathrm{~Hz})$ e, para cada uma destas, variou-se a de leitura do GPS de $50 \mathrm{~Hz}$ até $1 \mathrm{~Hz}$ de forma que a frequência da IMU seja múltipla da frequência do GPS. Além destas combinações, dois padrões de voo foram simulados. No primeiro, o VANT sobrevoa as retas de maneira estável, ou seja, sem nenhuma oscilação. No segundo, é inserido oscilações perpendiculares ao sentido de voo e um movimento oscilatório em roll (com amplitude de $10^{\circ}$ e distância máxima da reta central de voo de $5 \mathrm{~m}$ ) como se o VANT estivesse sobrevoando estas retas de maneira instável. As Figuras 7.4 e 7.5 mostram uma simulação sem oscilação e as Figuras 7.6 e 7.7 com oscilação. Na última, observa-se que à medida que o VANT avança nas retas, algumas features não são visualizadas na imagem consecutiva por causa da oscilação imposta na trajetória, por isso a sua covariância não diminui, acontecendo isto somente na próxima reta paralela. Outra região em que não ocorre a diminuição da covariância são as curvas, pois além da frequência de aquisição de imagens ser baixa, é onde ocorre a maior variação de atitude da aeronave diminuindo ainda mais a região de sobreposição das imagens. Em um voo real de monitoramento, as curvas devem ser feitas 
fora da área de interesse, portanto esta região é excluída da análise de erro. O retângulo tracejado na Figura 7.8 indica a região utilizada para avaliação de erro em uma das simulações. 

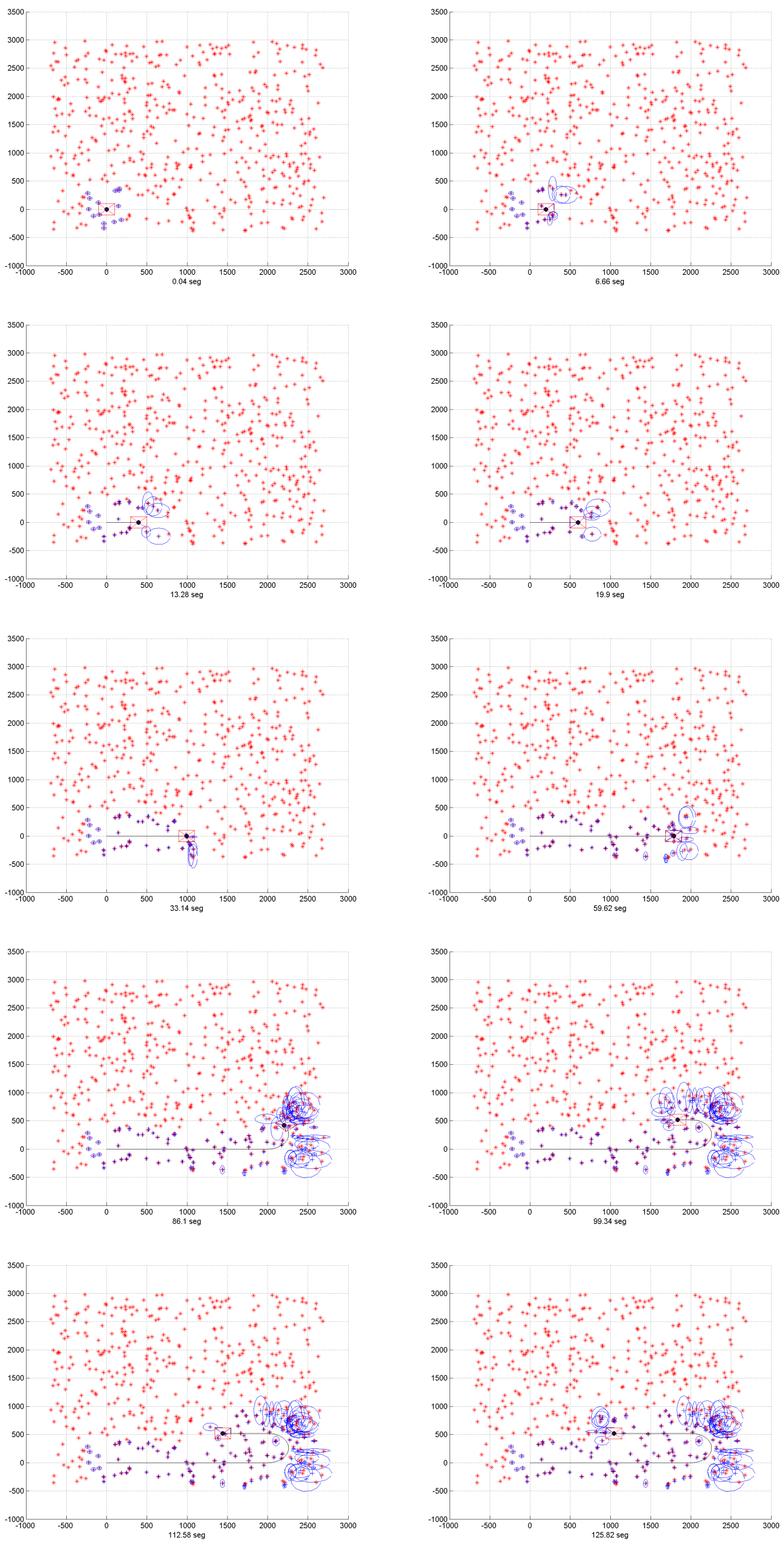

Figura 7.4: Vista superior do algoritmo de SLAM em operação com o VANT estável. 


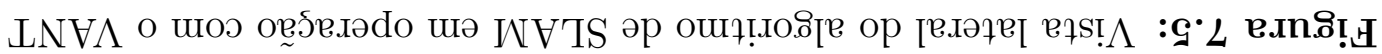
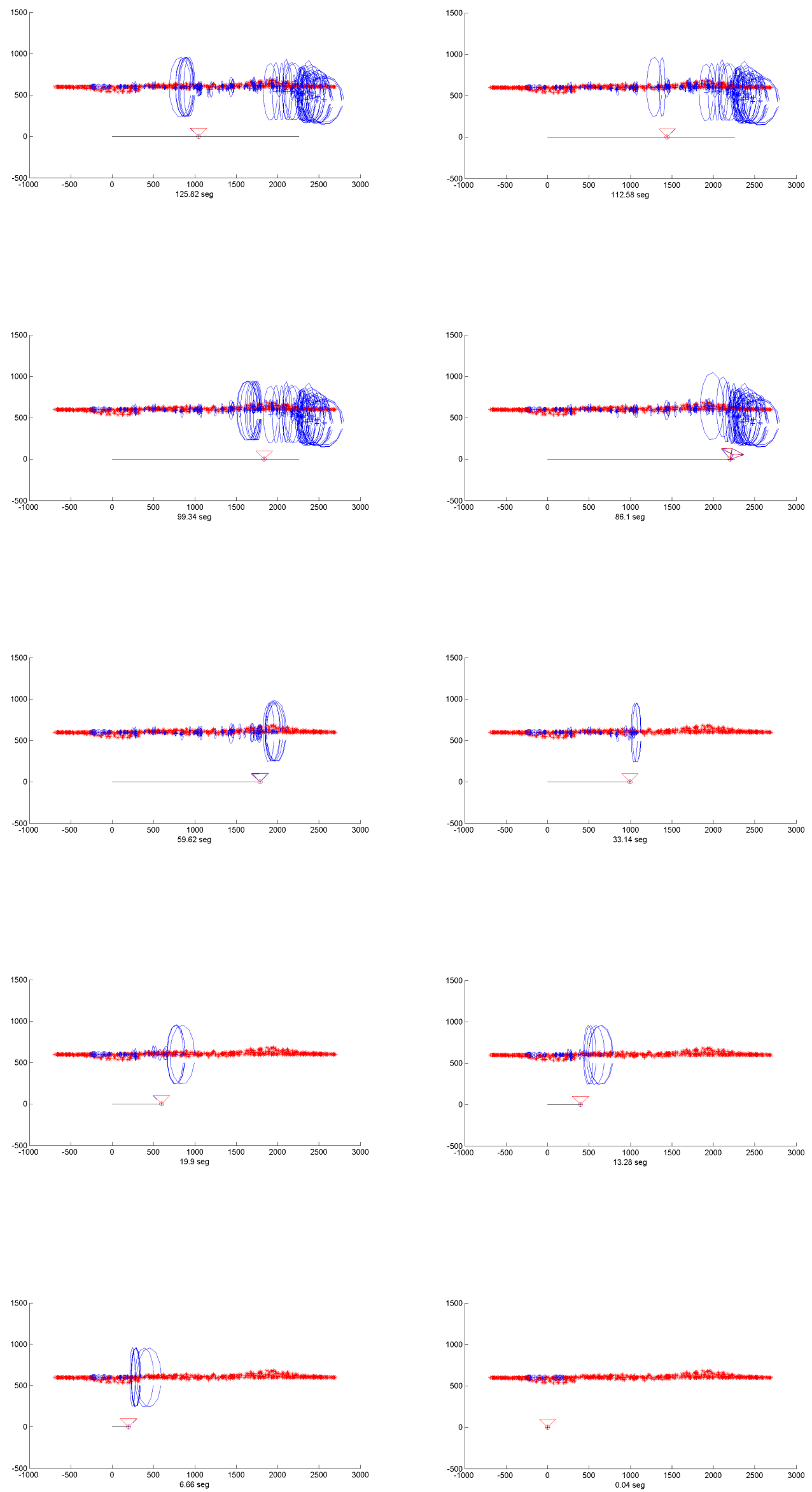

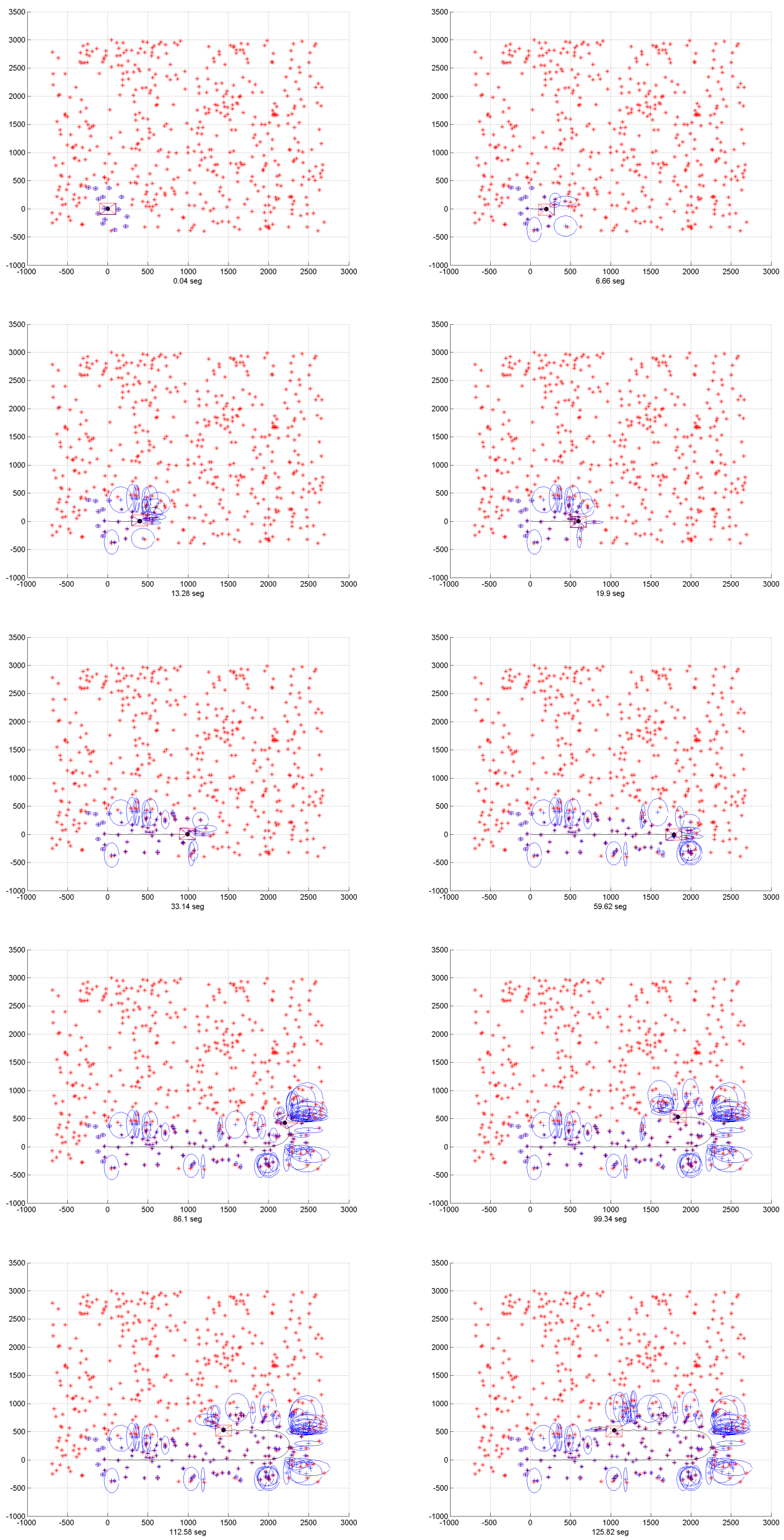

Figura 7.6: Vista superior do algoritmo de SLAM em operação com o VANT oscilando. 

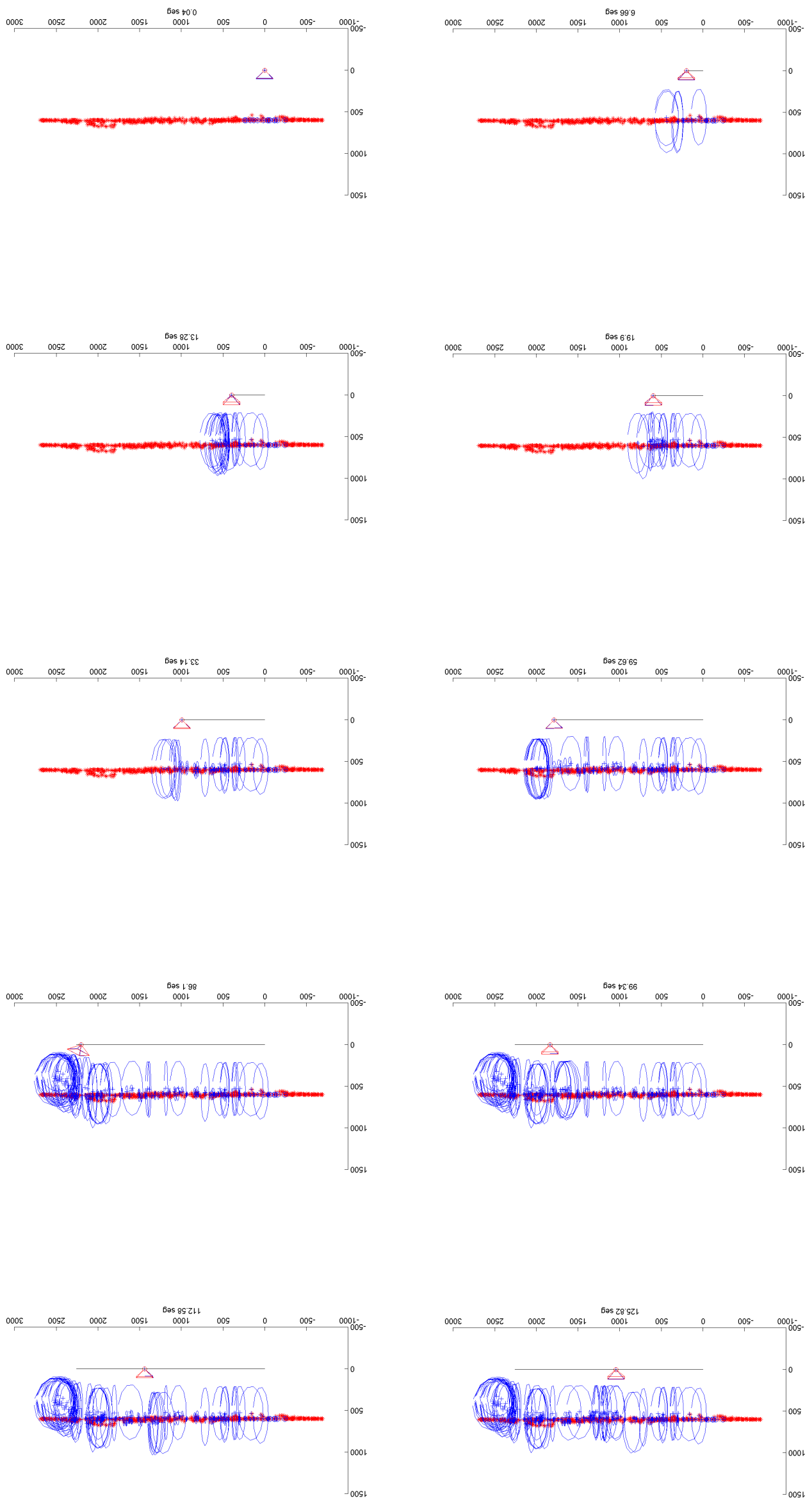

Figura 7.7: Vista lateral do algoritmo de SLAM em operação com o VANT oscilando. 


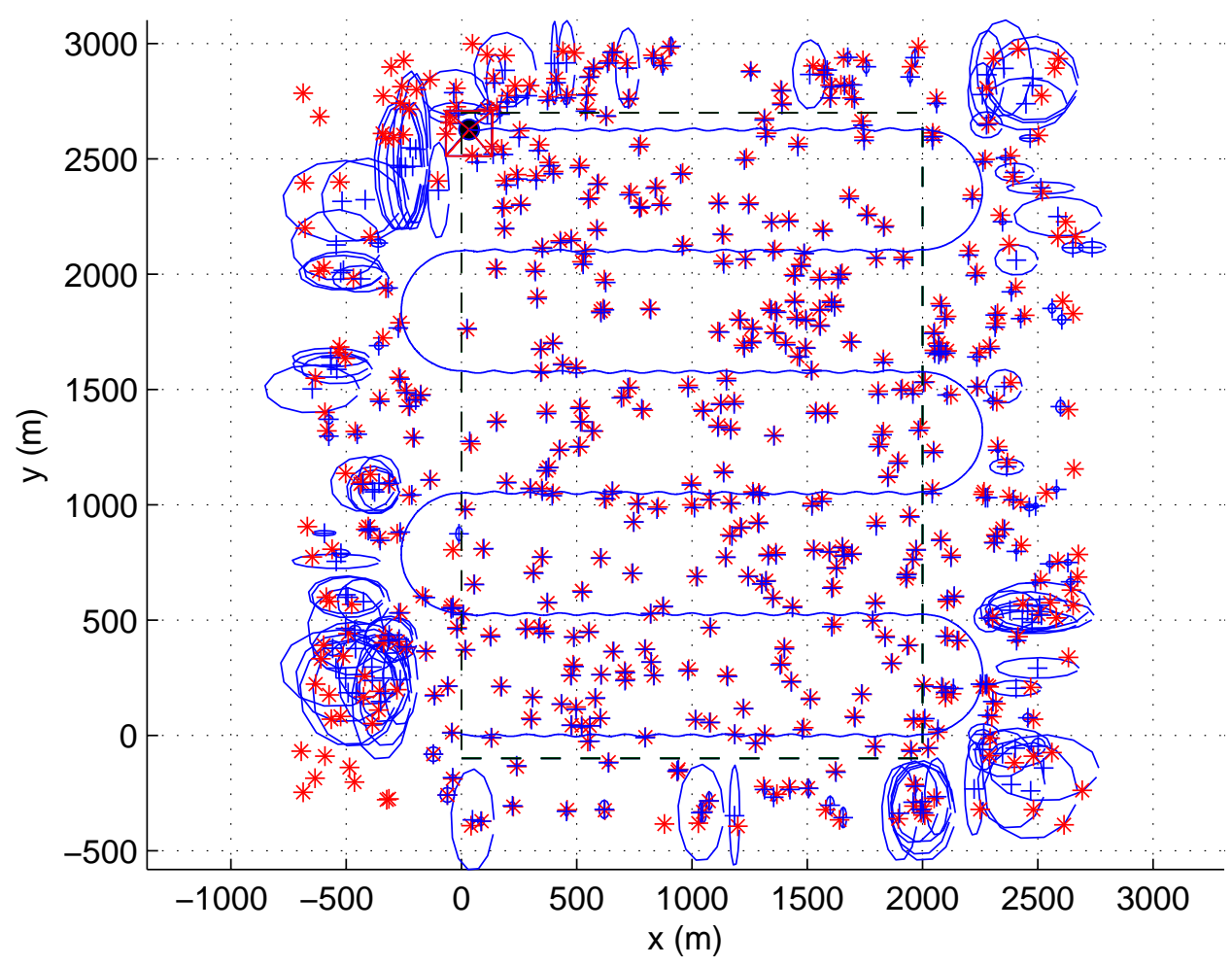

Figura 7.8: Região utilizada para análise de erro delimitada pelo retângulo preto.

Os resultados das simulações são mostrados da Tabela 7.5 à 7.34, sendo que da Tabela 7.5 à 7.14 são mostrados os valores de erro para posicionamento de features, da Tabela 7.15 à 7.24 o erro de posicionamento do VANT e da Tabela 7.25 à 7.34 o erro angular do VANT. Estas tabelas apresentam a média e desvio padrão de valores estimados pelo filtro comparados com os valores reais sem ruídos e também avaliando-se somente a matriz de covariância de estado, que seria a única referência para avaliação de erro em um voo real. Para simplificação, somente a diagonal principal da matriz de covariância de estado é utilizada para a avaliação de resultados dos voos.

De maneira global, observa-se que diminuindo a frequência do GPS para qualquer frequência de IMU, a precisão e acurácia de posicionamento das features, posição e atitude do VANT sempre diminuem e isto também é refletido na matriz de covariância de estado. Isto ocorre porque, como o GPS funciona como referência de posicionamento global, a diminuição da frequência implica em uma navegação inercial por um tempo maior. Este tipo de navegação gera drift e as imagens, além de possuírem uma frequência de amostragem bem menor do que a do GPS, não são suficientes para manter um posicionamento preciso e a estimação de posição das features funcionam como um referencial relativo e não absoluto 
como o GPS.

As primeiras simulações foram feitas com o VANT sobrevoando 2 faixas da região e os resultados são mostrados nas Tabelas 7.5, 7.6, 7.15, 7.16, 7.25 e 7.26 onde é feito um voo estável e nas Tabelas 7.7, 7.8, 7.17, 7.18, 7.27 e 7.28 com oscilação. Avaliando-se a mudança de frequência da IMU para uma frequência qualquer de GPS, observa-se uma mudança no padrão de comportamento de precisão das features e de posição e atitude do VANT. No voo sem oscilação, os piores resultados são observados com a IMU operando a $50 \mathrm{~Hz}$ e no voo com oscilação, os melhores resultados são nesta mesma frequência. Este comportamento do voo oscilatório se deve ao fato da variação de leitura de aceleração em cada passo ser maior do que o ruído do acelerômetro, ou seja, há um aproveitamento maior do sinal na frequência de $50 \mathrm{~Hz}$ do que nas outras. As Figuras 7.9, $7.10 \mathrm{e}$ 7.11 comparam a variação da aceleração real entre uma leitura e a próxima com a faixa de ruído dos acelerômetros. Quanto mais o sinal de variação de aceleração real sai da faixa de ruído do acelerômetro, melhor a acurácia de posicionamento, porém, se o sinal for muito maior do que o ruído torna-se necessário uma maior discretização do sinal para uma melhor representação do mesmo, ou seja, aumentar a frequência do sensor. A Figura 7.11 mostra que esta variação de aceleração a $100 \mathrm{~Hz}$ não tem uma amplitude muito maior do que a do ruído dos acelerômetros, justificando a piora nos resultados uma vez que essa diferença pequena acaba prejudicando a estimação de estado e até mesmo pode ser interpretada como bias. Na Figura 7.10, a diferença já é maior do que no caso anterior resultando em estimações mais precisas a $50 \mathrm{~Hz}$. Já no caso de $20 \mathrm{~Hz}$, a Figura 7.9 , mostra que a variação de aceleração é bem maior do que os outros casos, porém não há uma melhoria de precisão nos resultados, indicando que uma discretização maior do sinal de aceleração é necessário. Nos três casos, a variação da velocidade angular tem influência muito pequena na precisão dos resultados já que ela é bem menor do que a faixa de ruído dos giroscópios.

Na situação de IMU a $50 \mathrm{~Hz}$, a introdução de oscilação no voo propicia uma diminuição de erro de posicionamento das features de aproximadamente 2 vezes para o erro real e de 2,3 vezes para o erro estimado pela matriz de covariância de estado. O erro de posicionamento real do VANT nestes dois padrões de voo também é melhorado com a oscilação chegando a uma diminuição de 1,2 vezes, mas o ganho deste movimento não é tão alto como ocorre com o erro de posicionamento de features ficando praticamente imperceptivel ao ser avaliado pela covariância de estado. O erro de atitude real do VANT sofre reduções que variam de $0,1^{\circ}$ à $0,5^{\circ}$ com o movimento oscilatório (redução de 1,1 a 1,5 vezes no erro), 
mas também não são ganhos tão altos como das features.

Ao aumentar a quantidade de faixas (Tabelas 7.9, 7.10, 7.11, 7.12, 7.19, 7.20, $7.21,7.22,7.29,7.30,7.31,7.32$,), esta melhoria na frequência de $50 \mathrm{~Hz}$ da IMU em um movimento oscilatório é bem mais sutil, uma vez que o correlacionamento entre as features começa a ter uma importância maior na acurácia global. $O$ ganho de um voo oscilatório começa a ser mais significativo para frequências de GPS mais baixas $(1 \mathrm{~Hz})$, mas ainda assim os erros para frequências maiores de GPS são menores. Nesta situação (GPS a 1Hz), obtém-se menores valores de erros de posicionamento de features com o voo oscilatório e nota-se que isto também é claramente observado nos resultados obtidos pela matriz de covariância de estado. Já para erros de posicionamento e atitude do VANT, as diferenças não são tão significativas, da mesma forma que ocorre no caso de 2 faixas de voo, e na maioria das situações o erro tem um pequeno aumento.

Aumentando a quantidade de features visualizadas e sobrevoando de forma oscilatória a mesma quantidade de faixas da situação anterior (6 faixas), já não é observado um ganho na estimação de posição das mesmas. Isto ocorre porque, apesar de serem em uma quantidade maior, isto não implica na quantidade de vezes que cada uma delas é visualizada durante o voo, portanto a quantidade de informação ruidosa inserida no filtro é maior. Os maiores erros ocorrem para baixas frequência de GPS e IMU, aparecendo a mesma situação nas outras simulações, porém com amplitudes menores. 


\begin{tabular}{|c|c|c|c|c|c|c|}
\hline \multirow{2}{*}{\multicolumn{2}{|c|}{ Erro médio (m) }} & \multicolumn{5}{|c|}{ Frequência de GPS (Hz) } \\
\hline & & 50 & 25 & 20 & 10 & 1 \\
\hline \multirow{3}{*}{ Frequência de IMU $(\mathrm{Hz})$} & 100 & 4,30 & 4,27 & $\mathrm{X}$ & 4,27 & 5,42 \\
\hline & 50 & 8,32 & 9,08 & $\mathrm{X}$ & 10,38 & 10,24 \\
\hline & 20 & $\mathrm{X}$ & $\mathrm{X}$ & 6,44 & 5,91 & 7,84 \\
\hline \multirow{2}{*}{\multicolumn{2}{|c|}{ Desvio padrão(m) }} & \multicolumn{5}{|c|}{ Frequência de GPS (Hz) } \\
\hline & & 50 & 25 & 20 & 10 & 1 \\
\hline \multirow{3}{*}{ Frequência de IMU (Hz) } & 100 & 7,25 & 7,03 & $\mathrm{X}$ & 7,00 & 9,77 \\
\hline & 50 & 13,44 & 14,93 & $\mathrm{X}$ & 16,79 & 18,38 \\
\hline & 20 & $\mathrm{X}$ & $\mathrm{X}$ & 13,51 & 11,57 & 13,59 \\
\hline
\end{tabular}

Tabela 7.5: Resultados de simulações para avaliação de erro de posicionamento de features. Voo a $600 \mathrm{~m}$ de altitude, 2 faixas, sem oscilação e 400 features distribuídas no solo. Comparação feita entre features reais e estimadas pelo filtro.

\begin{tabular}{|c|c|c|c|c|c|c|}
\hline \multirow{2}{*}{\multicolumn{2}{|c|}{ Erro médio (m) }} & \multicolumn{5}{|c|}{ Frequência de GPS (Hz) } \\
\cline { 3 - 8 } & & 50 & 25 & 20 & 10 & 1 \\
\hline \multirow{3}{*}{ Frequência de IMU (Hz) } & 100 & 10,24 & 10,30 & $\mathrm{X}$ & 10,49 & 10,91 \\
\cline { 2 - 8 } & 50 & 10,62 & 10,74 & $\mathrm{X}$ & 11,08 & 11,80 \\
\cline { 2 - 8 } & 20 & $\mathrm{X}$ & $\mathrm{X}$ & 9,84 & 11,10 & 12,00 \\
\hline \hline \multirow{2}{*}{ Desvio padrão(m) } & & 50 & 25 & 20 & 10 & 1 \\
\cline { 3 - 8 } & 100 & 29,53 & 29,55 & $\mathrm{X}$ & 29,64 & 29,93 \\
\cline { 2 - 8 } Frequência de IMU (Hz) & 50 & 25,77 & 25,84 & $\mathrm{X}$ & 25,98 & 26,49 \\
\cline { 2 - 7 } & 20 & $\mathrm{X}$ & $\mathrm{X}$ & 26,88 & 30,58 & 30,96 \\
\hline
\end{tabular}

Tabela 7.6: Resultados de simulações para avaliação de erro de posicionamento de features. Voo a $600 \mathrm{~m}$ de altitude, 2 faixas, sem oscilação e 400 features distribuídas no solo. Dados calculados a partir da matriz de covariância de estado $P$. 


\begin{tabular}{|c|c|c|c|c|c|c|}
\hline \multirow{2}{*}{ Erro médio (m) } & \multicolumn{5}{|c|}{ Frequência de GPS (Hz) } \\
\cline { 3 - 8 } & 50 & 25 & 20 & 10 & 1 \\
\hline \multirow{3}{*}{ Frequência de IMU (Hz) } & 100 & 5,21 & 6,13 & $\mathrm{X}$ & 6,83 & 16,66 \\
\cline { 2 - 8 } & 50 & 4,48 & 4,64 & $\mathrm{X}$ & 4,96 & 5,95 \\
\cline { 2 - 8 } & 20 & $\mathrm{X}$ & $\mathrm{X}$ & 8,71 & 9,24 & 12,60 \\
\hline \multirow{2}{*}{ Desvio padrão (m) } & \multicolumn{6}{|c|}{ Frequência de GPS (Hz) } \\
\cline { 3 - 8 } & 50 & 25 & 20 & 10 & 1 \\
\hline \multirow{2}{*}{ Frequência de IMU (Hz) } & 100 & 8,64 & 10,03 & $\mathrm{X}$ & 11,39 & 33,87 \\
\cline { 2 - 8 } & 50 & 8,80 & 8,93 & $\mathrm{X}$ & 9,98 & 10,60 \\
\cline { 2 - 8 } & 20 & $\mathrm{X}$ & $\mathrm{X}$ & 17,80 & 19,50 & 21,50 \\
\hline
\end{tabular}

Tabela 7.7: Resultados de simulações para avaliação de erro de posicionamento de features. Voo a $600 \mathrm{~m}$ de altitude, 2 faixas, com oscilação e 400 features distribuídas no solo. Comparação feita entre features reais e estimadas pelo filtro.

\begin{tabular}{|c|c|c|c|c|c|c|}
\hline \multirow{2}{*}{\multicolumn{2}{|c|}{ Erro médio (m) }} & \multicolumn{5}{|c|}{ Frequência de GPS (Hz) } \\
\hline & & \multirow{2}{*}{$\frac{50}{7,05}$} & \multirow{2}{*}{$\frac{25}{7,45}$} & \multirow{2}{*}{$\frac{20}{X}$} & \multirow{2}{*}{\begin{tabular}{|c|}
10 \\
7,52 \\
\end{tabular}} & \multirow{2}{*}{$\frac{1}{8,12}$} \\
\hline \multirow{3}{*}{\multicolumn{2}{|c|}{ Frequência de IMU (Hz) }} & & & & & \\
\hline & & 4,50 & 4,59 & $\mathrm{X}$ & 4,74 & 5,41 \\
\hline & & $\mathrm{X}$ & $\mathrm{X}$ & 8,92 & 9,10 & 9,95 \\
\hline \multirow{2}{*}{\multicolumn{2}{|c|}{ Desvio padrão(m) }} & \multicolumn{5}{|c|}{ Frequência de GPS (Hz) } \\
\hline & & 50 & 25 & 20 & 10 & 1 \\
\hline \multirow{3}{*}{ Frequência de IMU (Hz) } & 100 & 17,08 & 17,50 & $\mathrm{X}$ & 17,85 & 19,00 \\
\hline & 50 & 7,20 & 7,40 & $\mathrm{X}$ & 7,73 & 9,38 \\
\hline & 20 & $\mathrm{X}$ & $\mathrm{X}$ & 22,37 & 22,50 & 23,25 \\
\hline
\end{tabular}

Tabela 7.8: Resultados de simulações para avaliação de erro de posicionamento de features. Voo a $600 \mathrm{~m}$ de altitude, 2 faixas, com oscilação e 400 features distribuídas no solo. Dados calculados a partir da matriz de covariância de estado $P$. 


\begin{tabular}{|c|c|c|c|c|c|c|}
\hline \multirow{2}{*}{ Erro médio $(\mathrm{m})$} & \multicolumn{5}{|c|}{ Frequência de GPS $(\mathrm{Hz})$} \\
\cline { 3 - 8 } & & 50 & 25 & 20 & 10 & 1 \\
\hline \multirow{3}{*}{ Frequência de IMU (Hz) } & 100 & 9,60 & 10,43 & $\mathrm{X}$ & 8,58 & 14,92 \\
\cline { 2 - 8 } & 50 & 6,04 & 6,83 & $\mathrm{X}$ & 7,73 & 20,87 \\
\cline { 2 - 8 } & 20 & $\mathrm{X}$ & $\mathrm{X}$ & 7,38 & 8,01 & 18,01 \\
\hline \multirow{2}{*}{ Desvio padrão (m) } & \multicolumn{5}{|c|}{ Frequência de GPS (Hz) } \\
\cline { 3 - 8 } & 50 & 25 & 20 & 10 & 1 \\
\hline \multirow{3}{*}{ Frequência de IMU (Hz) } & 100 & 12,94 & 14,24 & $\mathrm{X}$ & 12,66 & 18,37 \\
\cline { 2 - 8 } & 50 & 9,23 & 10,03 & $\mathrm{X}$ & 10,76 & 43,91 \\
\cline { 2 - 8 } & 20 & $\mathrm{X}$ & $\mathrm{X}$ & 11,83 & 12,11 & 27,78 \\
\hline
\end{tabular}

Tabela 7.9: Resultados de simulações para avaliação de erro de posicionamento de features. Voo a $600 \mathrm{~m}$ de altitude, 6 faixas, sem oscilação e 400 features distribuídas no solo. Comparação feita entre features reais e estimadas pelo filtro.

\begin{tabular}{|c|c|c|c|c|c|c|}
\hline \multirow{2}{*}{\multicolumn{2}{|c|}{ Erro médio (m) }} & \multicolumn{5}{|c|}{ Frequência de GPS (Hz) } \\
\hline & & \multirow{2}{*}{$\frac{50}{7,45}$} & \multirow{2}{*}{$\begin{array}{c}25 \\
7,68\end{array}$} & \multirow{2}{*}{$\frac{20}{X}$} & \multirow{2}{*}{\begin{tabular}{c|}
10 \\
7,73
\end{tabular}} & \multirow{2}{*}{$\frac{1}{8,31}$} \\
\hline \multirow{3}{*}{\multicolumn{2}{|c|}{ Frequência de IMU (Hz) }} & & & & & \\
\hline & & 6,09 & 6,20 & $\mathrm{X}$ & 6,36 & 9,47 \\
\hline & & $\mathrm{X}$ & $\mathrm{X}$ & 6,69 & 6,82 & 7,82 \\
\hline \multirow{2}{*}{\multicolumn{2}{|c|}{ Desvio padrão(m) }} & \multicolumn{5}{|c|}{ Frequência de GPS (Hz) } \\
\hline & & 50 & 25 & 20 & 10 & 1 \\
\hline \multirow{3}{*}{ Frequência de IMU (Hz) } & 100 & 14,63 & 14,87 & $\mathrm{X}$ & 14,91 & 15,64 \\
\hline & 50 & 11,50 & 11,65 & $\mathrm{X}$ & 11,88 & 24,54 \\
\hline & 20 & $\mathrm{X}$ & $\mathrm{X}$ & 13,78 & 13,86 & 16,61 \\
\hline
\end{tabular}

Tabela 7.10: Resultados de simulações para avaliação de erro de posicionamento de features. Voo a $600 \mathrm{~m}$ de altitude, 6 faixas, sem oscilação e 400 features distribuídas no solo. Dados calculados a partir da matriz de covariância de estado $P$. 


\begin{tabular}{|c|c|c|c|c|c|c|}
\hline \multirow{2}{*}{ Erro médio (m) } & \multicolumn{5}{|c|}{ Frequência de GPS (Hz) } \\
\cline { 3 - 8 } \multicolumn{2}{|c|}{} & 50 & 25 & 20 & 10 & 1 \\
\hline \multirow{3}{*}{ Frequência de IMU (Hz) } & 100 & 11,07 & 12,77 & $\mathrm{X}$ & 13,47 & 18,43 \\
\cline { 2 - 8 } & 50 & 5,86 & 6,08 & $\mathrm{X}$ & 6,63 & 9,77 \\
\cline { 2 - 8 } & 20 & $\mathrm{X}$ & $\mathrm{X}$ & 9,63 & 9,81 & 18,74 \\
\hline \multirow{2}{*}{ Desvio padrão (m) } & & \multicolumn{5}{|c|}{ Frequência de GPS (Hz) } \\
\cline { 3 - 8 } & 50 & 25 & 20 & 10 & 1 \\
\hline \multirow{3}{*}{ Frequência de IMU (Hz) } & 100 & 14,73 & 17,16 & $\mathrm{X}$ & 17,94 & 26,10 \\
\cline { 2 - 7 } & 50 & 9,03 & 9,07 & $\mathrm{X}$ & 10,64 & 17,30 \\
\cline { 2 - 7 } & 20 & $\mathrm{X}$ & $\mathrm{X}$ & 18,87 & 19,02 & 31,86 \\
\hline
\end{tabular}

Tabela 7.11: Resultados de simulações para avaliação de erro de posicionamento de features. Voo a $600 \mathrm{~m}$ de altitude, 6 faixas, com oscilação e 400 features distribuídas no solo. Comparação feita entre features reais e estimadas pelo filtro.

\begin{tabular}{|c|c|c|c|c|c|c|}
\hline \multirow{2}{*}{\multicolumn{2}{|c|}{ Erro médio $(\mathrm{m})$}} & \multicolumn{5}{|c|}{ Frequência de GPS (Hz) } \\
\hline & & \multirow{2}{*}{\begin{tabular}{|c|}
50 \\
4,35
\end{tabular}} & \multirow{2}{*}{$\frac{25}{4,80}$} & \multirow{2}{*}{$\frac{20}{X}$} & \multirow{2}{*}{\begin{tabular}{c|}
10 \\
4,53
\end{tabular}} & \multirow{2}{*}{$\frac{1}{5,45}$} \\
\hline \multirow{3}{*}{ Frequência de IMU $(\mathrm{Hz})$} & 10 & & & & & \\
\hline & 50 & 4,15 & 4,20 & $\mathrm{X}$ & 4,25 & 4,70 \\
\hline & 20 & $\mathrm{X}$ & $\mathrm{X}$ & 5,22 & 5,34 & 6,45 \\
\hline \multirow{2}{*}{\multicolumn{2}{|c|}{ Desvio padrão(m) }} & \multicolumn{5}{|c|}{ Frequência de GPS (Hz) } \\
\hline & & 50 & 25 & 20 & 10 & 1 \\
\hline \multirow{3}{*}{ Frequência de IMU (Hz) } & 100 & 5,80 & 10,43 & $\mathrm{X}$ & 6,15 & 11,31 \\
\hline & 50 & 9,70 & 9,74 & $\mathrm{X}$ & 9,81 & 10,39 \\
\hline & 20 & $\mathrm{X}$ & $\mathrm{X}$ & 15,84 & 15,95 & 20,92 \\
\hline
\end{tabular}

Tabela 7.12: Resultados de simulações para avaliação de erro de posicionamento de features. Voo a $600 \mathrm{~m}$ de altitude, 6 faixas, com oscilação e 400 features distribuídas no solo. Dados calculados a partir da matriz de covariância de estado $P$. 


\begin{tabular}{|c|c|c|c|c|c|c|}
\hline \multirow{2}{*}{\multicolumn{2}{|c|}{ Erro médio (m) }} & \multicolumn{5}{|c|}{ Frequência de GPS (Hz) } \\
\cline { 3 - 8 } & & 50 & 25 & 20 & 10 & 1 \\
\hline \multirow{3}{*}{ Frequência de IMU (Hz) } & 100 & 10,11 & 11,01 & $\mathrm{X}$ & 12,41 & 12,35 \\
\cline { 2 - 8 } & 50 & 6,87 & 7,35 & $\mathrm{X}$ & 8,80 & 23,55 \\
\cline { 2 - 8 } & 20 & $\mathrm{X}$ & $\mathrm{X}$ & 11,47 & 11,50 & 59,00 \\
\hline \hline \multirow{2}{*}{ Desvio padrão (m) } & \multicolumn{5}{|c|}{ Frequência de GPS (Hz) } \\
\cline { 3 - 8 } & 50 & 25 & 20 & 10 & 1 \\
\hline \multirow{3}{*}{ Frequência de IMU (Hz) } & 100 & 13,52 & 14,02 & $\mathrm{X}$ & 16,78 & 15,70 \\
\cline { 2 - 8 } & 50 & 9,46 & 9,96 & $\mathrm{X}$ & 12,27 & 42,90 \\
\cline { 2 - 8 } & 20 & $\mathrm{X}$ & $\mathrm{X}$ & 14,87 & 15,07 & 155,81 \\
\hline
\end{tabular}

Tabela 7.13: Resultados de simulações para avaliação de erro de posicionamento de features. Voo a $600 \mathrm{~m}$ de altitude, 6 faixas, com oscilação e 1200 features distribuídas no solo. Comparação feita entre features reais e estimadas pelo filtro.

\begin{tabular}{|c|c|c|c|c|c|c|}
\hline \multirow{2}{*}{\multicolumn{2}{|c|}{ Erro médio (m) }} & \multicolumn{5}{|c|}{ Frequência de GPS (Hz) } \\
\cline { 3 - 8 } & & 50 & 25 & 20 & 10 & 1 \\
\hline \multirow{3}{*}{ Frequência de IMU (Hz) } & 100 & 3,90 & 3,94 & $\mathrm{X}$ & 3,95 & 4,15 \\
\cline { 2 - 8 } & 50 & 4,19 & 4,21 & $\mathrm{X}$ & 4,24 & 4,64 \\
\cline { 2 - 8 } & 20 & $\mathrm{X}$ & $\mathrm{X}$ & 4,14 & 4,16 & 8,93 \\
\hline \hline \multirow{2}{*}{ Desvio padrão(m) } & \multicolumn{5}{|c|}{ Frequência de GPS (Hz) } \\
\cline { 3 - 8 } & 50 & 25 & 20 & 10 & 1 \\
\hline \multirow{3}{*}{ Frequência de IMU (Hz) } & 100 & 4,92 & 5,00 & $\mathrm{X}$ & 5,05 & 5,38 \\
\cline { 2 - 7 } & 50 & 9,10 & 9,13 & $\mathrm{X}$ & 9,17 & 9,77 \\
\cline { 2 - 7 } & 20 & $\mathrm{X}$ & $\mathrm{X}$ & 9,32 & 9,36 & 27,48 \\
\hline
\end{tabular}

Tabela 7.14: Resultados de simulações para avaliação de erro de posicionamento de features. Voo a $600 \mathrm{~m}$ de altitude, 6 faixas, com oscilação e 1200 features distribuídas no solo. Dados calculados a partir da matriz de covariância de estado $P$. 

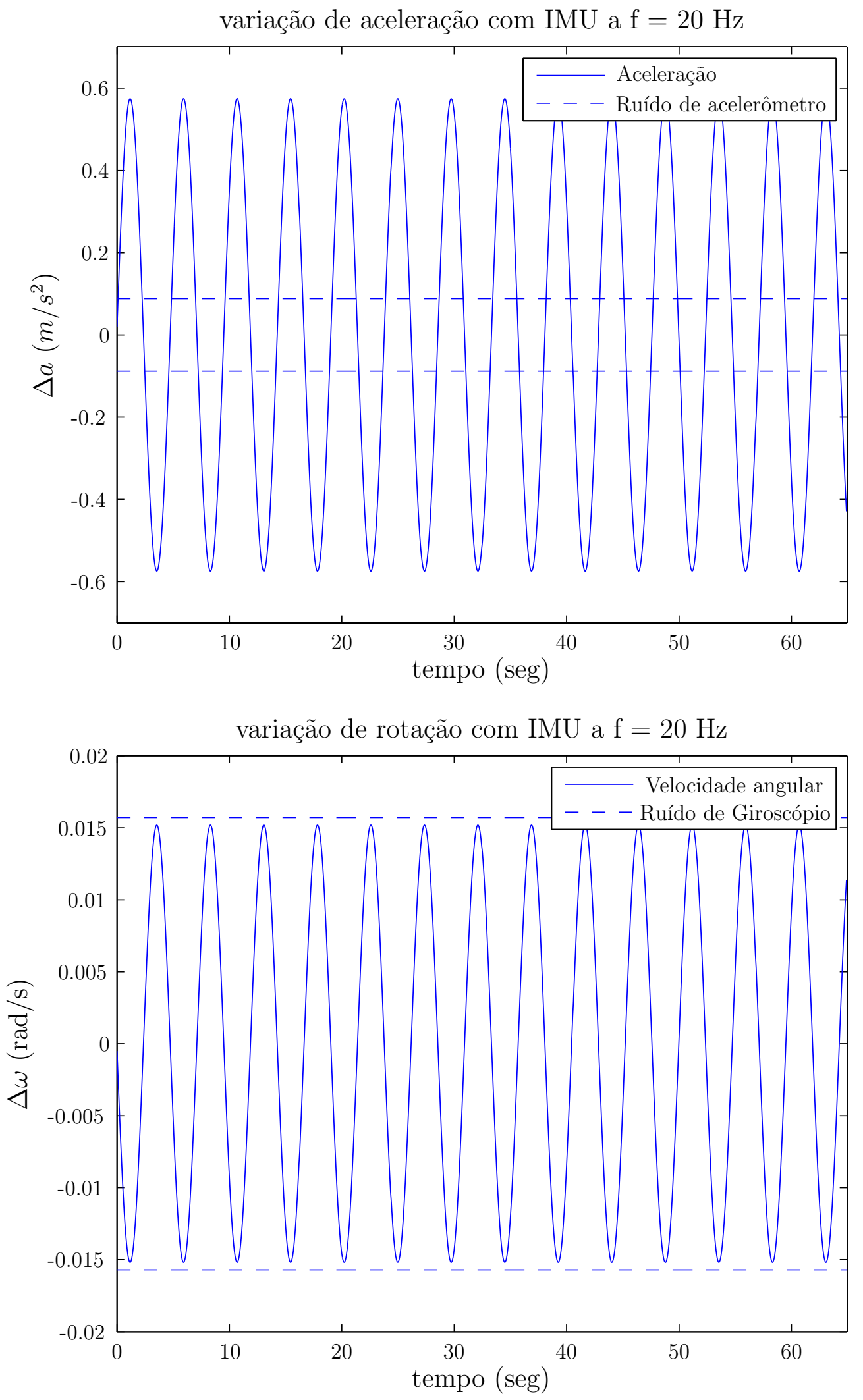

Figura 7.9: Variação da aceleração e velocidade angular no sistema de coordenadas da terra com IMU a $f=20 H z$. 

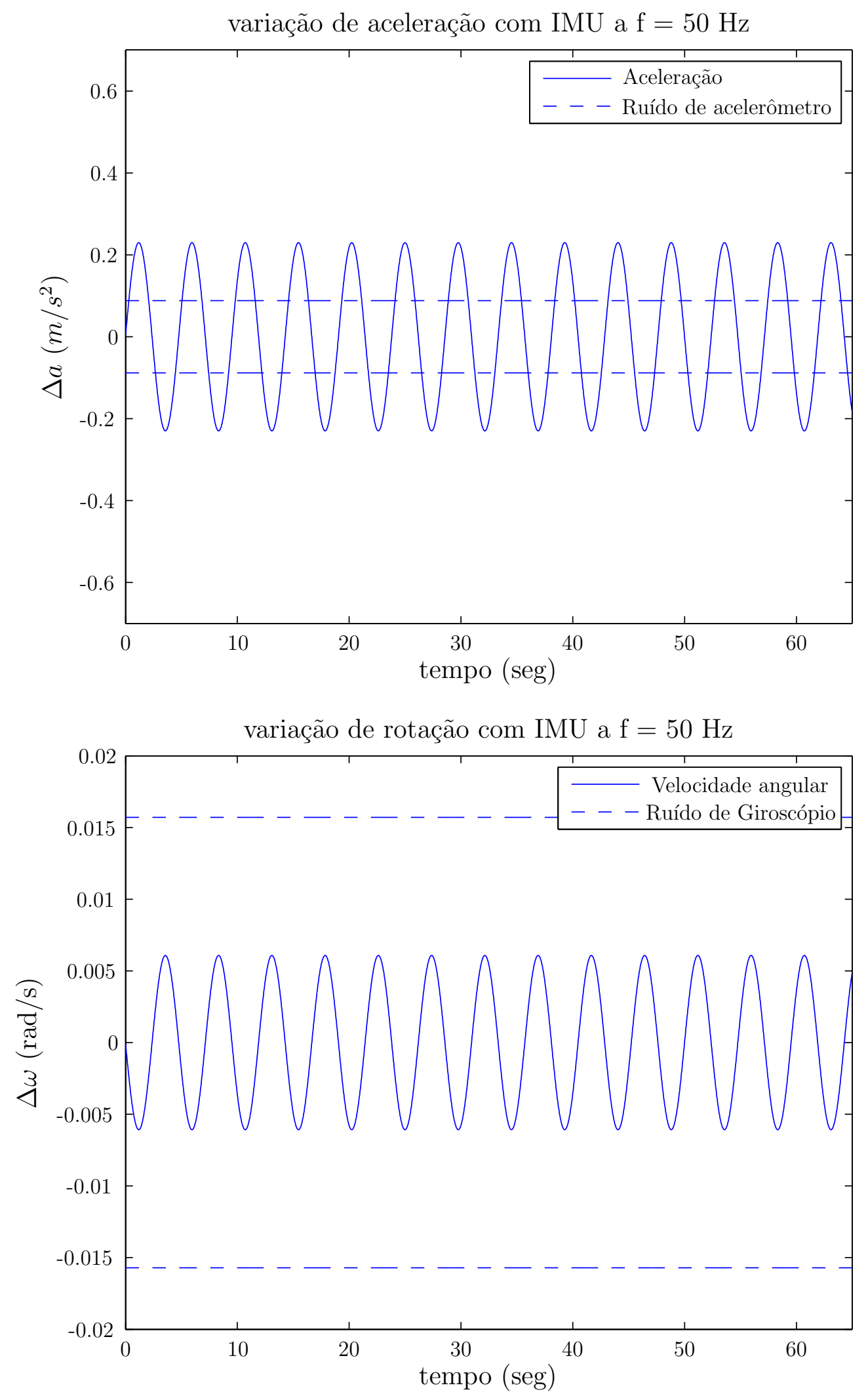

Figura 7.10: Variação da aceleração e velocidade angular no sistema de coordenadas da terra com IMU a $f=50 \mathrm{~Hz}$. 

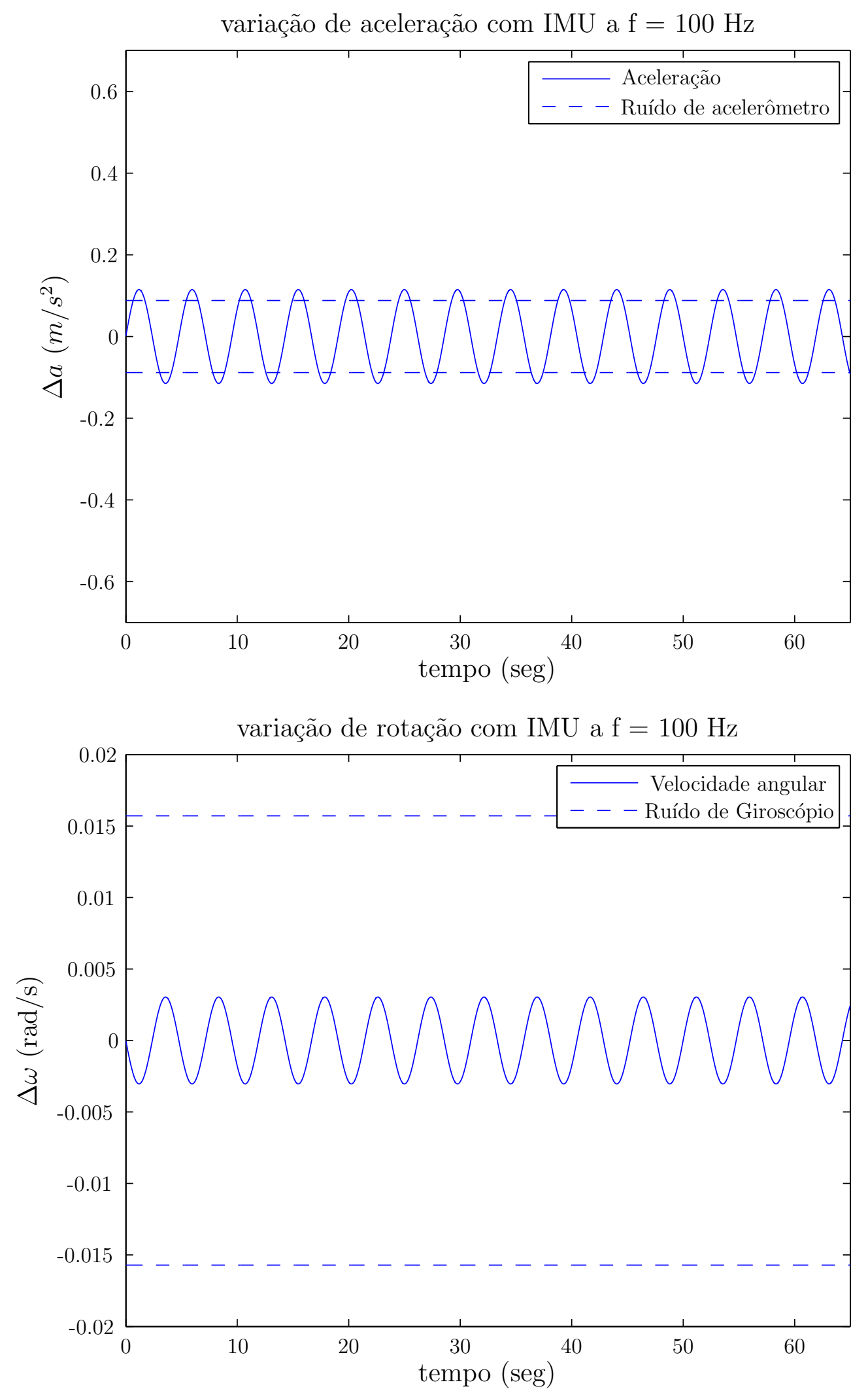

Figura 7.11: Variação da aceleração e velocidade angular no sistema de coordenadas da terra com IMU a $f=100 \mathrm{~Hz}$. 


\begin{tabular}{|c|c|c|c|c|c|c|}
\hline \multirow{2}{*}{\multicolumn{2}{|c|}{ Erro médio $(\mathrm{m})$}} & \multicolumn{5}{|c|}{ Frequência de GPS (Hz) } \\
\hline & & 50 & 25 & 20 & 10 & 1 \\
\hline \multirow{3}{*}{ Frequência de IMU (Hz) } & 100 & 0,88 & 1,19 & $\mathrm{X}$ & 1,64 & 4,52 \\
\hline & 50 & 0,98 & 1,35 & $\mathrm{X}$ & 2,48 & 5,93 \\
\hline & 20 & $\mathrm{X}$ & $\mathrm{X}$ & 1,33 & 1,64 & 5,09 \\
\hline \multirow{2}{*}{\multicolumn{2}{|c|}{ Desvio padrão $(\mathrm{m})$}} & \multicolumn{5}{|c|}{ Frequência de GPS (Hz) } \\
\hline & & 50 & 25 & 20 & 10 & 1 \\
\hline \multirow{3}{*}{ Frequência de IMU $(\mathrm{Hz})$} & 100 & 0,41 & 0,56 & $\mathrm{X}$ & 0,81 & 2,39 \\
\hline & 50 & 0,44 & 0,63 & $\mathrm{X}$ & 1,28 & 3,40 \\
\hline & 20 & $\mathrm{X}$ & $\mathrm{X}$ & 0,67 & 0,85 & 3,01 \\
\hline
\end{tabular}

Tabela 7.15: Resultados de simulações para avaliação de erro de posicionamento do VANT. Voo a $600 \mathrm{~m}$ de altitude, 2 faixas, sem oscilação e 400 features distribuídas no solo. Comparação feita entre posicionamento real e estimado pelo filtro.

\begin{tabular}{|c|c|c|c|c|c|c|}
\hline \multirow{2}{*}{ Erro médio (m) } & \multicolumn{5}{|c|}{ Frequência de GPS (Hz) } \\
\cline { 3 - 8 } & & 50 & 25 & 20 & 10 & 1 \\
\hline \multirow{3}{*}{ Frequência de IMU (Hz) } & 100 & 0,93 & 1,23 & $\mathrm{X}$ & 1,78 & 4,51 \\
\cline { 2 - 7 } & 50 & 0,89 & 1,18 & $\mathrm{X}$ & 1,71 & 4,38 \\
\cline { 2 - 7 } & 20 & $\mathrm{X}$ & $\mathrm{X}$ & 1,26 & 1,67 & 4,31 \\
\hline \hline \multirow{2}{*}{ Desvio padrão (m) } & & 50 & 25 & 20 & 10 & 1 \\
\cline { 3 - 8 } & 100 & 0,14 & 0,20 & $\mathrm{X}$ & 0,30 & 0,75 \\
\cline { 2 - 7 } & 50 & 0,11 & 0,18 & $\mathrm{X}$ & 0,29 & 0,73 \\
\cline { 2 - 7 } & 20 & $\mathrm{X}$ & $\mathrm{X}$ & 0,14 & 0,24 & 0,70 \\
\hline
\end{tabular}

Tabela 7.16: Resultados de simulações para avaliação de erro de posicionamento do VANT. Voo a 600m de altitude, 2 faixas, sem oscilação e 400 features distribuídas no solo. Dados calculados a partir da matriz de covariância de estado $P$. 


\begin{tabular}{|c|c|c|c|c|c|c|}
\hline \multirow{2}{*}{\multicolumn{2}{|c|}{ Erro médio (m) }} & \multicolumn{5}{|c|}{ Frequência de GPS (Hz) } \\
\cline { 3 - 8 } & 50 & 25 & 20 & 10 & 1 \\
\hline \multirow{3}{*}{ Frequência de IMU (Hz) } & 100 & 0,84 & 1,23 & $\mathrm{X}$ & 2,09 & 10,48 \\
\cline { 2 - 8 } & 50 & 0,84 & 1,10 & $\mathrm{X}$ & 1,61 & 4,82 \\
\cline { 2 - 8 } & 20 & $\mathrm{X}$ & $\mathrm{X}$ & 1,34 & 1,83 & 5,06 \\
\hline \hline \multirow{2}{*}{ Desvio padrão (m) } & & \multicolumn{5}{|c|}{ Frequência de GPS (Hz) } \\
\cline { 3 - 8 } & 50 & 25 & 20 & 10 & 1 \\
\hline \multirow{3}{*}{ Frequência de IMU (Hz) } & 100 & 0,44 & 0,55 & $\mathrm{X}$ & 1,03 & 7,69 \\
\cline { 2 - 7 } & 50 & 0,42 & 0,53 & $\mathrm{X}$ & 0,74 & 2,19 \\
\cline { 2 - 7 } & 20 & $\mathrm{X}$ & $\mathrm{X}$ & 0,59 & 0,87 & 2,48 \\
\hline
\end{tabular}

Tabela 7.17: Resultados de simulações para avaliação de erro de posicionamento do VANT. Voo a $600 \mathrm{~m}$ de altitude, 2 faixas, com oscilação e 400 features distribuídas no solo. Comparação feita entre posicionamento real e estimado pelo filtro.

\begin{tabular}{|c|c|c|c|c|c|c|}
\hline \multirow{2}{*}{\multicolumn{2}{|c|}{ Erro médio (m) }} & \multicolumn{5}{|c|}{ Frequência de GPS (Hz) } \\
\hline & & 50 & 25 & 20 & 10 & 1 \\
\hline \multirow{3}{*}{ Frequência de IMU (Hz) } & 100 & 0,95 & 1,26 & $\mathrm{X}$ & 1,82 & 4,62 \\
\hline & 50 & 0,90 & 1,20 & $\mathrm{X}$ & 1,73 & 4,41 \\
\hline & 20 & $\mathrm{X}$ & $\mathrm{X}$ & 1,29 & 1,71 & 4,46 \\
\hline \multirow{2}{*}{\multicolumn{2}{|c|}{ Desvio padrão (m) }} & \multicolumn{5}{|c|}{ Frequência de GPS (Hz) } \\
\hline & & 50 & 25 & 20 & 10 & 1 \\
\hline \multirow{3}{*}{ Frequência de IMU $(\mathrm{Hz})$} & 100 & 0,14 & 0,20 & $\mathrm{X}$ & 0,30 & 0,76 \\
\hline & 50 & 0,11 & 0,18 & $\mathrm{X}$ & 0,29 & 0,72 \\
\hline & 20 & $\mathrm{X}$ & $\mathrm{X}$ & 0,14 & 0,25 & 0,74 \\
\hline
\end{tabular}

Tabela 7.18: Resultados de simulações para avaliação de erro de posicionamento do VANT. Voo a 600m de altitude, 2 faixas, com oscilação e 400 features distribuídas no solo. Dados calculados a partir da matriz de covariância de estado $P$. 


\begin{tabular}{|c|c|c|c|c|c|c|}
\hline \multirow{2}{*}{\multicolumn{2}{|c|}{ Erro médio (m) }} & \multicolumn{5}{|c|}{ Frequência de GPS (Hz) } \\
\hline & & 50 & 25 & 20 & 10 & 1 \\
\hline \multirow{3}{*}{ Frequência de IMU (Hz) } & 100 & 0,95 & 1,42 & $\mathrm{X}$ & 1,82 & 8,62 \\
\hline & 50 & 0,85 & 1,17 & $\mathrm{X}$ & 1,82 & 9,55 \\
\hline & 20 & $\mathrm{X}$ & $\mathrm{X}$ & 1,38 & 1,86 & 8,09 \\
\hline \multirow{2}{*}{\multicolumn{2}{|c|}{ Desvio padrão $(\mathrm{m})$}} & \multicolumn{5}{|c|}{ Frequência de GPS (Hz) } \\
\hline & & 50 & 25 & 20 & 10 & 1 \\
\hline \multirow{3}{*}{ Frequência de IMU (Hz) } & 100 & 0,49 & 0,70 & $\mathrm{X}$ & 1,01 & 4,52 \\
\hline & 50 & 0,42 & 0,65 & $\mathrm{X}$ & 0,96 & 6,97 \\
\hline & 20 & $\mathrm{X}$ & $\mathrm{X}$ & 0,81 & 1,02 & 4,35 \\
\hline
\end{tabular}

Tabela 7.19: Resultados de simulações para avaliação de erro de posicionamento do VANT. Voo a $600 \mathrm{~m}$ de altitude, 6 faixas, sem oscilação e 400 features distribuídas no solo. Comparação feita entre posicionamento real e estimado pelo filtro.

\begin{tabular}{|c|c|c|c|c|c|c|}
\hline \multirow{2}{*}{ Erro médio (m) } & \multicolumn{5}{|c|}{ Frequência de GPS (Hz) } \\
\cline { 3 - 8 } & & 50 & 25 & 20 & 10 & 1 \\
\hline \multirow{3}{*}{ Frequência de IMU (Hz) } & 100 & 0,91 & 1,21 & $\mathrm{X}$ & 1,75 & 4,37 \\
\cline { 2 - 7 } & 50 & 0,87 & 1,16 & $\mathrm{X}$ & 1,67 & 4,22 \\
\cline { 2 - 7 } & 20 & $\mathrm{X}$ & $\mathrm{X}$ & 1,20 & 1,59 & 4,06 \\
\hline \hline \multirow{2}{*}{ Desvio padrão (m) } & & 50 & 25 & 20 & 10 & 1 \\
\cline { 3 - 8 } & 100 & 0,11 & 0,16 & $\mathrm{X}$ & 0,23 & 0,63 \\
\cline { 2 - 7 } & 50 & 0,10 & 0,14 & $\mathrm{X}$ & 0,21 & 0,56 \\
\cline { 2 - 7 } & 20 & $\mathrm{X}$ & $\mathrm{X}$ & 0,12 & 0,18 & 0,53 \\
\hline
\end{tabular}

Tabela 7.20: Resultados de simulações para avaliação de erro de posicionamento do VANT. Voo a 600m de altitude, 6 faixas, sem oscilação e 400 features distribuídas no solo. Dados calculados a partir da matriz de covariância de estado $P$. 


\begin{tabular}{|c|c|c|c|c|c|c|}
\hline \multirow{2}{*}{\multicolumn{2}{|c|}{ Erro médio (m) }} & \multicolumn{5}{|c|}{ Frequência de GPS (Hz) } \\
\cline { 3 - 8 } & 50 & 25 & 20 & 10 & 1 \\
\hline \multirow{3}{*}{ Frequência de IMU (Hz) } & 100 & 1,06 & 1,49 & $\mathrm{X}$ & 2,31 & 8,59 \\
\cline { 2 - 8 } & 50 & 0,95 & 1,29 & $\mathrm{X}$ & 1,92 & 6,04 \\
\cline { 2 - 8 } & 20 & $\mathrm{X}$ & $\mathrm{X}$ & 1,94 & 2,69 & 10,72 \\
\hline \hline \multirow{2}{*}{ Desvio padrão (m) } & & \multicolumn{5}{|c|}{ Frequência de $\mathrm{GPS}(\mathrm{Hz})$} \\
\cline { 3 - 8 } & 50 & 25 & 20 & 10 & 1 \\
\hline \multirow{3}{*}{ Frequência de IMU (Hz) } & 100 & 0,58 & 0,84 & $\mathrm{X}$ & 1,33 & 5,64 \\
\cline { 2 - 7 } & 50 & 0,54 & 0,71 & $\mathrm{X}$ & 1,03 & 2,96 \\
\cline { 2 - 7 } & 20 & $\mathrm{X}$ & $\mathrm{X}$ & 1,20 & 1,64 & 6,45 \\
\hline
\end{tabular}

Tabela 7.21: Resultados de simulações para avaliação de erro de posicionamento do VANT. Voo a $600 \mathrm{~m}$ de altitude, 6 faixas, com oscilação e 400 features distribuídas no solo. Comparação feita entre posicionamento real e estimado pelo filtro.

\begin{tabular}{|c|c|c|c|c|c|c|}
\hline \multirow{2}{*}{ Erro médio (m) } & \multicolumn{5}{|c|}{ Frequência de GPS (Hz) } \\
\cline { 3 - 8 } & & 50 & 25 & 20 & 10 & 1 \\
\hline \multirow{3}{*}{ Frequência de IMU (Hz) } & 100 & 0,92 & 1,22 & $\mathrm{X}$ & 1,76 & 4,39 \\
\cline { 2 - 7 } & 50 & 0,88 & 1,16 & $\mathrm{X}$ & 1,68 & 4,24 \\
\cline { 2 - 7 } & 20 & $\mathrm{X}$ & $\mathrm{X}$ & 1,22 & 1,61 & 4,13 \\
\hline \hline \multirow{2}{*}{ Desvio padrão (m) } & & 50 & 25 & 20 & 10 & 1 \\
\cline { 3 - 8 } & 100 & 0,11 & 0,16 & $\mathrm{X}$ & 0,23 & 0,61 \\
\cline { 2 - 7 } & 50 & 0,10 & 0,14 & $\mathrm{X}$ & 0,21 & 0,58 \\
\cline { 2 - 7 } & 20 & $\mathrm{X}$ & $\mathrm{X}$ & 0,12 & 0,19 & 0,57 \\
\hline
\end{tabular}

Tabela 7.22: Resultados de simulações para avaliação de erro de posicionamento do VANT. Voo a $600 \mathrm{~m}$ de altitude, 6 faixas, com oscilação e 400 features distribuídas no solo. Dados calculados a partir da matriz de covariância de estado $P$. 


\begin{tabular}{|c|c|c|c|c|c|c|}
\hline \multirow{2}{*}{\multicolumn{2}{|c|}{ Erro médio $(\mathrm{m})$}} & \multicolumn{5}{|c|}{ Frequência de GPS (Hz) } \\
\hline & & 50 & 25 & 20 & 10 & 1 \\
\hline \multirow{3}{*}{ Frequência de IMU (Hz) } & 100 & 1,07 & 1,49 & $\mathrm{X}$ & 2,26 & 6,82 \\
\hline & 50 & 1,02 & 1,43 & $\mathrm{X}$ & 2,52 & 16,20 \\
\hline & 20 & $\mathrm{X}$ & $\mathrm{X}$ & 2,19 & 3,07 & 28,53 \\
\hline \multirow{2}{*}{\multicolumn{2}{|c|}{ Desvio padrão $(\mathrm{m})$}} & \multicolumn{5}{|c|}{ Frequência de GPS (Hz) } \\
\hline & & 50 & 25 & 20 & 10 & 1 \\
\hline \multirow{3}{*}{ Frequência de IMU (Hz) } & 100 & 0,60 & 0,87 & $\mathrm{X}$ & 1,41 & 4,44 \\
\hline & 50 & 0,56 & 0,74 & $\mathrm{X}$ & 1,27 & 11,88 \\
\hline & 20 & $\mathrm{X}$ & $\mathrm{X}$ & 1,31 & 1,79 & 38,41 \\
\hline
\end{tabular}

Tabela 7.23: Resultados de simulações para avaliação de erro de posicionamento do VANT. Voo a $600 \mathrm{~m}$ de altitude, 6 faixas, com oscilação e 1200 features distribuídas no solo. Comparação feita entre posicionamento real e estimado pelo filtro.

\begin{tabular}{|c|c|c|c|c|c|c|}
\hline \multirow{2}{*}{ Erro médio (m) } & \multicolumn{5}{|c|}{ Frequência de GPS (Hz) } \\
\cline { 3 - 8 } & & 50 & 25 & 20 & 10 & 1 \\
\hline \multirow{3}{*}{ Frequência de IMU (Hz) } & 100 & 0,90 & 1,18 & $\mathrm{X}$ & 1,69 & 4,11 \\
\cline { 2 - 7 } & 50 & 0,85 & 1,12 & $\mathrm{X}$ & 1,60 & 3,95 \\
\cline { 2 - 7 } & 20 & $\mathrm{X}$ & $\mathrm{X}$ & 1,16 & 1,53 & 3,81 \\
\hline \hline \multirow{2}{*}{ Desvio padrão (m) } & & 50 & 25 & 20 & 10 & 1 \\
\cline { 3 - 8 } & 100 & 0,12 & 0,16 & $\mathrm{X}$ & 0,23 & 0,53 \\
\cline { 2 - 7 } & 50 & 0,10 & 0,14 & $\mathrm{X}$ & 0,21 & 0,51 \\
\cline { 2 - 7 } & 20 & $\mathrm{X}$ & $\mathrm{X}$ & 0,12 & 0,17 & 0,48 \\
\hline
\end{tabular}

Tabela 7.24: Resultados de simulações para avaliação de erro de posicionamento do VANT. Voo a $600 \mathrm{~m}$ de altitude, 6 faixas, com oscilação e 1200 features distribuídas no solo. Dados calculados a partir da matriz de covariância de estado $P$. 


\begin{tabular}{|c|c|c|c|c|c|c|}
\hline \multirow{2}{*}{\multicolumn{2}{|c|}{ Erro médio $\left(^{\circ}\right)$}} & \multicolumn{5}{|c|}{ Frequência de GPS (Hz) } \\
\hline & & 50 & 25 & 20 & 10 & 1 \\
\hline \multirow{3}{*}{ Frequência de IMU (Hz) } & 100 & 1,04 & 1,07 & $\mathrm{X}$ & 1,21 & 1,73 \\
\hline & 50 & 1,26 & 1,43 & $\mathrm{X}$ & 1,88 & 2,06 \\
\hline & 20 & $\mathrm{X}$ & $\mathrm{X}$ & 1,18 & 1,25 & 1,74 \\
\hline \multirow{2}{*}{\multicolumn{2}{|c|}{ Desvio padrão $\left(^{\circ}\right)$}} & \multicolumn{5}{|c|}{ Frequência de GPS (Hz) } \\
\hline & & 50 & 25 & 20 & 10 & 1 \\
\hline \multirow{3}{*}{ Frequência de IMU (Hz) } & 100 & 1,05 & 1,07 & $\mathrm{X}$ & 1,24 & 2,61 \\
\hline & 50 & 1,18 & 1,40 & $\mathrm{X}$ & 1,82 & 2,69 \\
\hline & 20 & $\mathrm{X}$ & $\mathrm{X}$ & 1,46 & 1,62 & 2,09 \\
\hline
\end{tabular}

Tabela 7.25: Resultados de simulações para avaliação de erro angular do

VANT. Voo a $600 \mathrm{~m}$ de altitude, 2 faixas, sem oscilação e 400 features distribuídas no solo. Comparação feita entre posicionamento real e estimado pelo filtro.

\begin{tabular}{|c|c|c|c|c|c|c|}
\hline \multirow{2}{*}{\multicolumn{2}{|c|}{ Erro médio $\left({ }^{\circ}\right)$}} & \multicolumn{5}{|c|}{ Frequência de GPS (Hz) } \\
\hline & & 50 & 25 & 20 & 10 & 1 \\
\hline \multirow{3}{*}{ Frequência de IMU (Hz) } & 100 & 1,47 & 1,57 & $\mathrm{X}$ & 1,70 & 1,99 \\
\hline & 50 & 1,24 & 1,32 & $\mathrm{X}$ & 1,42 & 1,64 \\
\hline & 20 & $\mathrm{X}$ & $\mathrm{X}$ & 1,13 & 1,19 & 1,39 \\
\hline \multirow{2}{*}{\multicolumn{2}{|c|}{ Desvio padrão $\left(^{\circ}\right)$}} & \multicolumn{5}{|c|}{ Frequência de GPS (Hz) } \\
\hline & & 50 & 25 & 20 & 10 & 1 \\
\hline \multirow{3}{*}{ Frequência de IMU $(\mathrm{Hz})$} & 100 & 0,92 & 0,97 & $\mathrm{X}$ & 1,04 & 1,21 \\
\hline & 50 & 0,76 & 0,80 & $\mathrm{X}$ & 0,85 & 0,97 \\
\hline & 20 & $\mathrm{X}$ & $\mathrm{X}$ & 0,69 & 0,73 & 0,83 \\
\hline
\end{tabular}

Tabela 7.26: Resultados de simulações para avaliação de erro angular do VANT. Voo a $600 \mathrm{~m}$ de altitude, 2 faixas, sem oscilação e 400 features distribuídas no solo. Dados calculados a partir da matriz de covariância de estado $P$. 


\begin{tabular}{|c|c|c|c|c|c|c|}
\hline \multirow{2}{*}{\multicolumn{2}{|c|}{ Erro médio $\left(^{\circ}\right)$}} & \multicolumn{5}{|c|}{ Frequência de GPS (Hz) } \\
\hline & & 50 & 25 & 20 & 10 & 1 \\
\hline \multirow{3}{*}{ Frequência de IMU (Hz) } & 100 & 1,28 & 1,43 & $\mathrm{X}$ & 2,01 & 5,30 \\
\hline & 50 & 1,13 & 1,13 & $\mathrm{X}$ & 1,24 & 1,50 \\
\hline & 20 & $\mathrm{X}$ & $\mathrm{X}$ & 1,22 & 1,33 & 1,84 \\
\hline \multirow{2}{*}{\multicolumn{2}{|c|}{ Desvio padrão $\left(^{\circ}\right)$}} & \multicolumn{5}{|c|}{ Frequência de GPS (Hz) } \\
\hline & & 50 & 25 & 20 & 10 & 1 \\
\hline \multirow{3}{*}{ Frequência de IMU (Hz) } & 100 & 1,46 & 1,29 & $\mathrm{X}$ & 2,44 & 9,14 \\
\hline & 50 & 1,17 & 1,18 & $\mathrm{X}$ & 1,36 & 1,59 \\
\hline & 20 & $\mathrm{X}$ & $\mathrm{X}$ & 1,32 & 1,53 & 1,99 \\
\hline
\end{tabular}

Tabela 7.27: Resultados de simulações para avaliação de erro angular do VANT. Voo a $600 \mathrm{~m}$ de altitude, 2 faixas, com oscilação e 400 features distribuídas no solo. Comparação feita entre posicionamento real e estimado pelo filtro.

\begin{tabular}{|c|c|c|c|c|c|c|}
\hline \multirow{2}{*}{\multicolumn{2}{|c|}{ Erro médio $\left(^{\circ}\right)$}} & \multicolumn{5}{|c|}{ Frequência de GPS (Hz) } \\
\hline & & 50 & 25 & 20 & 10 & 1 \\
\hline \multirow{3}{*}{ Frequência de IMU (Hz) } & 100 & 1,54 & 1,66 & $\mathrm{X}$ & 1,82 & 2,17 \\
\hline & 50 & 1,26 & 1,36 & $\mathrm{X}$ & 1,48 & 1,74 \\
\hline & 20 & $\mathrm{X}$ & $\mathrm{X}$ & 1,26 & 1,35 & 1,64 \\
\hline \multirow{2}{*}{\multicolumn{2}{|c|}{ Desvio padrão $\left(^{\circ}\right)$}} & \multicolumn{5}{|c|}{ Frequência de GPS (Hz) } \\
\hline & & 50 & 25 & 20 & 10 & 1 \\
\hline \multirow{3}{*}{ Frequência de IMU $(\mathrm{Hz})$} & 100 & 0,93 & 1,01 & $\mathrm{X}$ & 1,12 & 1,34 \\
\hline & 50 & 0,79 & 0,85 & $\mathrm{X}$ & 0,93 & 1,11 \\
\hline & 20 & $\mathrm{X}$ & $\mathrm{X}$ & 0,84 & 0,91 & 1,11 \\
\hline
\end{tabular}

Tabela 7.28: Resultados de simulações para avaliação de erro angular do VANT. Voo a $600 \mathrm{~m}$ de altitude, 2 faixas, com oscilação e 400 features distribuídas no solo. Dados calculados a partir da matriz de covariância de estado $P$. 


\begin{tabular}{|c|c|c|c|c|c|c|}
\hline \multirow{2}{*}{\multicolumn{2}{|c|}{ Erro médio $\left(^{\circ}\right)$}} & \multicolumn{5}{|c|}{ Frequência de GPS (Hz) } \\
\hline & & 50 & 25 & 20 & 10 & 1 \\
\hline \multirow{3}{*}{ Frequência de IMU (Hz) } & 100 & 1,61 & 1,74 & $\mathrm{X}$ & 1,65 & 2,93 \\
\hline & 50 & 1,19 & 1,39 & $\mathrm{X}$ & 1,54 & 3,60 \\
\hline & 20 & $\mathrm{X}$ & $\mathrm{X}$ & 1,40 & 1,49 & 2,59 \\
\hline \multirow{2}{*}{\multicolumn{2}{|c|}{ Desvio padrão $\left(^{\circ}\right)$}} & \multicolumn{5}{|c|}{ Frequência de GPS (Hz) } \\
\hline & & 50 & 25 & 20 & 10 & 1 \\
\hline \multirow{3}{*}{ Frequência de IMU (Hz) } & 100 & 1,78 & 1,93 & $\mathrm{X}$ & 1,86 & 3,15 \\
\hline & 50 & 1,45 & 1,75 & $\mathrm{X}$ & 1,86 & 4,72 \\
\hline & 20 & $\mathrm{X}$ & $\mathrm{X}$ & 1,80 & 1,97 & 2,64 \\
\hline
\end{tabular}

Tabela 7.29: Resultados de simulações para avaliação de erro angular do

VANT. Voo a $600 \mathrm{~m}$ de altitude, 6 faixas, sem oscilação e 400 features distribuídas no solo. Comparação feita entre posicionamento real e estimado pelo filtro.

\begin{tabular}{|c|c|c|c|c|c|c|}
\hline \multirow{2}{*}{\multicolumn{2}{|c|}{ Erro médio $\left(^{\circ}\right)$}} & \multicolumn{5}{|c|}{ Frequência de GPS (Hz) } \\
\hline & & 50 & 25 & 20 & 10 & 1 \\
\hline \multirow{3}{*}{ Frequência de IMU (Hz) } & 100 & 1,45 & 1,55 & $\mathrm{X}$ & 1,68 & 1,97 \\
\hline & 50 & 1,17 & 1,25 & $\mathrm{X}$ & 1,35 & 1,54 \\
\hline & 20 & $\mathrm{X}$ & $\mathrm{X}$ & 1,00 & 1,05 & 1,20 \\
\hline \multirow{2}{*}{\multicolumn{2}{|c|}{ Desvio padrão $\left(^{\circ}\right)$}} & \multicolumn{5}{|c|}{ Frequência de GPS (Hz) } \\
\hline & & 50 & 25 & 20 & 10 & 1 \\
\hline \multirow{3}{*}{ Frequência de IMU $(\mathrm{Hz})$} & 100 & 0,95 & 1,00 & $\mathrm{X}$ & 1,09 & 1,29 \\
\hline & 50 & 0,71 & 0,75 & $\mathrm{X}$ & 0,81 & 0,95 \\
\hline & 20 & $\mathrm{X}$ & $\mathrm{X}$ & 0,58 & 0,61 & 0,72 \\
\hline
\end{tabular}

Tabela 7.30: Resultados de simulações para avaliação de erro angular do VANT. Voo a $600 \mathrm{~m}$ de altitude, 6 faixas, sem oscilação e 400 features distribuídas no solo. Dados calculados a partir da matriz de covariância de estado $P$. 


\begin{tabular}{|c|c|c|c|c|c|c|}
\hline \multirow{2}{*}{\multicolumn{2}{|c|}{ Erro médio $\left(^{\circ}\right)$}} & \multicolumn{5}{|c|}{ Frequência de GPS (Hz) } \\
\hline & & 50 & 25 & 20 & 10 & 1 \\
\hline \multirow{3}{*}{ Frequência de IMU (Hz) } & 100 & 1,74 & 1,90 & $\mathrm{X}$ & 2,20 & 3,21 \\
\hline & 50 & 1,28 & 1,42 & $\mathrm{X}$ & 1,57 & 2,12 \\
\hline & 20 & $\mathrm{X}$ & $\mathrm{X}$ & 2,00 & 2,20 & 3,63 \\
\hline \multirow{2}{*}{\multicolumn{2}{|c|}{ Desvio padrão $\left(^{\circ}\right)$}} & \multicolumn{5}{|c|}{ Frequência de GPS (Hz) } \\
\hline & & 50 & 25 & 20 & 10 & 1 \\
\hline \multirow{3}{*}{ Frequência de IMU (Hz) } & 100 & 1,82 & 1,93 & $\mathrm{X}$ & 2,40 & 3,25 \\
\hline & 50 & 1,36 & 1,53 & $\mathrm{X}$ & 1,63 & 2,26 \\
\hline & 20 & $\mathrm{X}$ & $\mathrm{X}$ & 2,76 & 3,06 & 4,64 \\
\hline
\end{tabular}

Tabela 7.31: Resultados de simulações para avaliação de erro angular do VANT. Voo a 600m de altitude, 6 faixas, com oscilação e 400 features distribuídas no solo. Comparação feita entre posicionamento real e estimado pelo filtro.

\begin{tabular}{|c|c|c|c|c|c|c|}
\hline \multirow{2}{*}{\multicolumn{2}{|c|}{ Erro médio $\left({ }^{\circ}\right)$}} & \multicolumn{5}{|c|}{ Frequência de GPS (Hz) } \\
\hline & & 50 & 25 & 20 & 10 & 1 \\
\hline \multirow{3}{*}{ Frequência de IMU (Hz) } & 100 & 1,43 & 1,54 & $\mathrm{X}$ & 1,69 & 2,00 \\
\hline & 50 & 1,17 & 1,25 & $\mathrm{X}$ & 1,36 & 1,58 \\
\hline & 20 & $\mathrm{X}$ & $\mathrm{X}$ & 1,05 & 1,11 & 1,29 \\
\hline \multirow{2}{*}{\multicolumn{2}{|c|}{ Desvio padrão $\left(^{\circ}\right)$}} & \multicolumn{5}{|c|}{ Frequência de GPS (Hz) } \\
\hline & & 50 & 25 & 20 & 10 & 1 \\
\hline \multirow{3}{*}{ Frequência de IMU (Hz) } & 100 & 0,86 & 0,94 & $\mathrm{X}$ & 1,04 & 1,30 \\
\hline & 50 & 0,71 & 0,76 & $\mathrm{X}$ & 0,84 & 1,01 \\
\hline & 20 & $\mathrm{X}$ & $\mathrm{X}$ & 0,65 & 0,69 & 0,82 \\
\hline
\end{tabular}

Tabela 7.32: Resultados de simulações para avaliação de erro angular do VANT. Voo a $600 \mathrm{~m}$ de altitude, 6 faixas, com oscilação e 400 features distribuídas no solo. Dados calculados a partir da matriz de covariância de estado $P$. 


\begin{tabular}{|c|c|c|c|c|c|c|}
\hline \multirow{2}{*}{\multicolumn{2}{|c|}{ Erro médio $\left(^{\circ}\right)$}} & \multicolumn{5}{|c|}{ Frequência de GPS (Hz) } \\
\hline & & 50 & 25 & 20 & 10 & 1 \\
\hline \multirow{3}{*}{ Frequência de IMU (Hz) } & 100 & 1,58 & 1,67 & $\mathrm{X}$ & 1,88 & 2,01 \\
\hline & 50 & 1,34 & 1,53 & $\mathrm{X}$ & 1,87 & 4,18 \\
\hline & 20 & $\mathrm{X}$ & $\mathrm{X}$ & 1,80 & 1,90 & 6,24 \\
\hline \multirow{2}{*}{\multicolumn{2}{|c|}{ Desvio padrão $\left(^{\circ}\right)$}} & \multicolumn{5}{|c|}{ Frequência de GPS (Hz) } \\
\hline & & 50 & 25 & 20 & 10 & 1 \\
\hline \multirow{3}{*}{ Frequência de IMU $(\mathrm{Hz})$} & 100 & 1,48 & 1,68 & $\mathrm{X}$ & 1,84 & 2,02 \\
\hline & 50 & 1,44 & 1,59 & $\mathrm{X}$ & 2,08 & 4,48 \\
\hline & 20 & $\mathrm{X}$ & $\mathrm{X}$ & 1,85 & 1,98 & 9,62 \\
\hline
\end{tabular}

Tabela 7.33: Resultados de simulações para avaliação de erro angular do

VANT. Voo a 600m de altitude, 6 faixas, com oscilação e 1200 features distribuídas no solo. Comparação feita entre posicionamento real e estimado pelo filtro.

\begin{tabular}{|c|c|c|c|c|c|c|}
\hline \multirow{2}{*}{\multicolumn{2}{|c|}{ Erro médio $\left(^{\circ}\right)$}} & \multicolumn{5}{|c|}{ Frequência de GPS (Hz) } \\
\hline & & 50 & 25 & 20 & 10 & 1 \\
\hline \multirow{3}{*}{ Frequência de IMU (Hz) } & 100 & 1,28 & 1,37 & $\mathrm{X}$ & 1,48 & 1,69 \\
\hline & 50 & 1,04 & 1,10 & $\mathrm{X}$ & 1,18 & 1,31 \\
\hline & 20 & $\mathrm{X}$ & $\mathrm{X}$ & 0,89 & 0,92 & 1,02 \\
\hline \multirow{2}{*}{\multicolumn{2}{|c|}{ Desvio padrão $\left(^{\circ}\right)$}} & \multicolumn{5}{|c|}{ Frequência de GPS (Hz) } \\
\hline & & 50 & 25 & 20 & 10 & 1 \\
\hline \multirow{3}{*}{ Frequência de IMU $(\mathrm{Hz})$} & 100 & 0,80 & 0,86 & $\mathrm{X}$ & 0,95 & 1,14 \\
\hline & 50 & 0,62 & 0,67 & $\mathrm{X}$ & 0,73 & 0,82 \\
\hline & 20 & $\mathrm{X}$ & $\mathrm{X}$ & 0,53 & 0,55 & 0,61 \\
\hline
\end{tabular}

Tabela 7.34: Resultados de simulações para avaliação de erro angular do VANT. Voo a $600 \mathrm{~m}$ de altitude, 6 faixas, com oscilação e 1200 features distribuídas no solo. Dados calculados a partir da matriz de covariância de estado $P$. 


\section{Parte III}

\section{Conclusões}




\section{Conclusões e Trabalhos Futuros}

Desenvolveu-se neste trabalho um método de geração offline de mapas geográficos a partir de modelos estocásticos utilizando Filtro de Kalman Estendido e realizando a fusão sensorial de dados inerciais, de GPS e dados gerados a partir de Visão Computacional. A técnica Simultaneous Localization And Mapping (SLAM) serviu como base para a geração tanto do mapa como da trajetória efetuada pelo conjunto IMU, GPS e câmera.

Estudou-se o comportamento de diversas frequências de sensores em diversos padrões de voo seguindo faixas para varredura de uma área de $3400 \mathrm{~m}$ x 3400m, sendo: 2 faixas em voo estável e oscilatório, 6 faixas em voo estável e oscilatório e 6 faixas em voo oscilatório com aumento de 3 vezes na quantidade de features identificadas em solo. Extrai-se como resultado destas simulações que:

- Em voos com poucas faixas, a oscilação da aeronave aumenta a acurácia tanto das features como da posição e atitude da aeronave. Um exemplo para uso deste resultado é a captura de imagens em regiões estreitas, como estradas e margens de rios, por exemplo;

- Em voos com uma quantidade de faixas maiores a oscilação já não tem grande contribuição no aumento de acurácia, sendo o fator mais importante para diminuição de erro o correlacionamento entre as features das diversas faixas;

- O aumento de features não gera necessariamente um aumento de acurácia, uma vez que estas não são visualizadas muitas vezes entre uma imagem e outra devido a baixa sobreposição quando comparada a um video;

Além disso, na escolha da frequência de sensores deve se levar em consideração o ruído dos sensores e a dinâmica do veículo onde este será embarcado. Quanto maior o ruído de uma IMU, maior deverá ser as acelerações e rotações para que 
suas variações saiam da faixa de ruído dos sensores e estes tenham um aproveitamento maior pelo filtro. Porém, um aumento excessivo nestas acelerações e rotações implicam em uma discretização maior do sinal, ou seja, é necessário aumentar sua frequência de amostragem para que o sinal seja reconstruído com maior fidelidade.

A importância das manobras efetuadas durante o voo aumenta a importância da utilização de um VANT, pois, utilizando uma aeronave tripulada, estas manobras ficam extremamente limitadas a tolerância física do piloto, além do aumento significativo do risco deste tipo de voo. Outro fator a ser levado em conta é a diminuição de custos variáveis neste tipo de operação, ou seja, diminuição de custos com combustível (uma aeronave tripulada gasta em torno de 60 litros/hora e um VANT 1 litro/hora) e local de armazenamento (o VANT pode ser guardado em uma caixa e o avião necessita de um hangar).

Segue abaixo algumas propostas para trabalhos futuros:

- Implementação em Tempo-Real - poderá ser utilizado como módulo de navegação de uma aeronave e possíveis falhas no mapeamento podem ser observadas e corrigidas durante o vôo, além de ser possível visualizar o terreno e evitar uma possível colisão com o mesmo;

- Realidade aumentada - como a estimação de posição baseia-se em imagens, pode-se inserir objetos virtuais nas filmagens em tempo-real ou póstratamento do vídeo;

- Utilização de diversas aeronaves para mapeamento colaborativo com SLAM;

- Utilização da matriz de covariância de estado para re-planejamento de trajetória objetivando a diminuição de erro de estado (Active SLAM). 


\section{Referências}

BAY, H.; TUYTELAARS, T.; GOOL, L. V. Surf: Speeded up robust features. In: In ECCV. [S.l.: s.n.], 2006. p. 404-417.

BOUGUET, J.-Y. Camera Calibration Toolbox for Matlab. [S.l.], 2003. Disponível em: <http://www.vision.caltech.edu/bouguetj/calib_doc/>.

BRYSON, M. T.; JOHNSON-ROBERSON, M.; SUKKARIEH, S. Airborne smoothing and mapping using vision and inertial sensors. Proceedings of the 2009 IEEE International Conference on Robotics 86 Automation (ICRA 2009), Maio 2009.

BRYSON, M. T.; SUKKARIEH, S. Observability analysis and active control for airborne SLAM. IEEE Transactions on Aerospace and Electronic Systems, v. 44, p. 261-280, 2008.

BRYSON, M. T.; SUKKARIEH, S. Architectures for cooperative airborne simultaneous localisation and mapping. Journal of Intelligent and Robotic Systems, Special Issue on Airborne SLAM, Springer, v. 55, Junho 2009.

Campos Filho, R. F. d.; MARUYAMA, N. Aerophotogrammetry using uavs: a stochastic sensor fusion approach. In: COBEM - INTERNATIONAL CONGRESS OF MECHANICAL ENGINEERING. Natal - RN, 2011.

Campos Filho, R. F. d. et al. Robot position estimation and tracking using sequential monte carlo algorithms. In: COBEM - INTERNATIONAL CONGRESS OF MECHANICAL ENGINEERING. Gramado - RS, 2009.

ÇELIK, K. et al. Monocular vision SLAM for indoor aerial vehicles. In: Proceedings of the 2009 IEEE/RSJ International Conference on Intelligent Robots and Systems. Piscataway, NJ, USA: IEEE Press, 2009. (IROS'09), p. 1566-1573. ISBN 978-1-4244-3803-7. Disponível em: <http://dl.acm.org/citation.cfm?id=1733343.1733624>.

CORKE, P.; LOBO, J.; DIAS, J. An introduction to inertial and visual sensing. The International Journal of Robotics Research, v. 26, 2007.

CRIMINISI, A.; REID, I.; ZISSERMAN, A. A plane measuring device. Proc. BMVC, 1997.

DAVISON, A. J. Real-time simultaneous localisation and mapping with a single camera. Proceedings of the Ninth IEEE International Conference on Computer Vision, 2003.

DAVISON, A. J. et al. MonoSLAM: Real-time single camera SLAM. Pattern Analysis and Machine Intelligence, IEEE Transactions on, v. 29, n. 6, p. 1052-1067, 2007. 
DECEA. AIC N 21/10. setembro 2010.

DUDA, R. O.; HART, P. E. Use of the Hough transformation to detect lines and curves in pictures. Graphics and Image Processing, 1972.

DURRANT-WHYTE, H.; BAILEY, T. Simultaneous localisation and mapping (SLAM): Part I the essential algorithms. IEEE ROBOTICS AND AUTOMATION MAGAZINE, v. 13, n. 2, 2006.

DURRANT-WHYTE, H.; BAILEY, T. Simultaneous localisation and mapping (SLAM): Part II state of the art. IEEE ROBOTICS AND AUTOMATION MAGAZINE, v. 13, n. 3, 2006.

GOSHTASBY, A. Image registration by local approximation methods. Image Vision Comput., v. 6, n. 4, p. 255-261, 1988. Disponível em: $<$ http://dblp.uni-trier.de/db/journals/ivc/ivc6.html\#Goshtasby88>.

GOSHTASBY, A. A. Piecewise linear mapping functions for image registration. Pattern Recognition, v. 19, n. 6, p. 459-466, 1986. Disponível em: $<$ http://dblp.uni-trier.de/db/journals/pr/pr19.html\#Goshtasby86>.

HAMILTON, W. R. On Quaternions, or on a New System of Imaginaries in Algebra. Philosophical Magazine, v. 25, n. 3, p. 489-495, 1844.

HARRIS, C.; STEPHENS, M. A combined corner and edge detector. Proceedings of The Fourth Alvey Vision Conference, p. 147-151, 1988.

HARTLEY, R.; ZISSERMAN, A. Multiple View Geometry in Computer Vision. [S.l.]: Cambridge University Press, 2000.

HOL, J. D. Pose Estimation and Calibration Algorithms for Vision and Inertial Sensors. Dissertação (Mestrado) — Linköping University, 2008.

HOL, J. D. et al. Robust real-time tracking by fusing measurements from inertial and vision sensors. Journal of Real-Time Image Processing, v. 2, p. 149-160, 2007.

HOUGH, P. Method and Means for Recognizing Complex Patterns. [S.l.]: United States Patent Office, dez. 1962. U.S. Patent 3.069.654.

IDOETA, I. V. Metodologia de Elaboração Automatizada de Modelo Digital de Elevação e Ortofoto em Média e Pequena Escala. Tese (Doutorado) - Escola Politécnica da Universidade de São Paulo, 2007.

KALMAN, R. E. A new approach to linear filtering and prediction problems. Transactions of the ASME-Journal of Basic Engineering, v. 82, n. Series D, p. 35-45, 1960.

KANNALA, J.; BRANDT, S. S. A generic camera model and calibration method for conventional, wide-angle, and fish-eye lenses. IEEE Trans. Pattern Analysis and Machine Intelligence, v. 28, p. 1335-1340, 2006.

KARLSTROEM, A. Estimação de Posição e Quantificação de Erro Utilizando Geometria Epipolar entre Imagens. Dissertação (Mestrado) - Escola Politécnica da Universidade de São Paulo (in Portuguese), 2007. 
KLINKEN, R. D. van et al. Mapping mesquite (prosopis) distribution and density using visual aerial surveys. Rangeland Ecology Management, v. 60, p. 408-416, 2007.

KUIPERS, J. B. Quaternions and Rotation Sequences: A Primer with Applications to Orbits, Aerospace and Virtual Reality. [S.l.]: Princeton University Press, 1999.

LINDSTEN, F. et al. Geo-referencing for UAV navigation using environmental classification. Proceedings of the International Conference on Robotics and Automation (ICRA), May 2010.

LOWE, D. Object recognition from local scale-invariant features. In: Proceedings of the International Conference on Computer Vision. [S.l.: s.n.], 1999. p. $1150-1157$.

MEDLIN, C. R. et al. Using remote sensing to detect weed infestations in glycine max. Weed Science, v. 48, n. 3, p. 393-398, 2000.

RIBAS, D.; RIDAO, P.; NEIRA, J. Underwater SLAM for Structured Environments Using an Imaging Sonar. Springer, 2010. 1-119 p. (Springer Tracts in Advanced Robotics, v. 65). ISBN 978-3-642-14039-6. Disponível em: $<$ http://dblp.uni-trier.de/db/series/star/index.html\#RibasRN10>.

RIBAS, D. et al. SLAM using an imaging sonar for partially structured underwater environments. In: PROC. OF IEEE/RSJ INTERNATIONAL CONFERENCE ON INTELLIGENT ROBOTS AND SYSTEMS. [S.l.: s.n.], 2006.

ROSTEN, E.; DRUMMOND, T. Fusing points and lines for high performance tracking. Proceedings of the IEEE International Conference on Computer Vision, v. 2, p. 1508-1511, 2005.

RUY, R. da S. Desenvolvimento e Validação Geométrica de um Sistema para Mapeamento com Câmaras Digitais de Médio Formato. Tese (Doutorado) Universidade Estadual Paulista, 2008.

SÁEZ, J. M. et al. Underwater 3d SLAM through entropy minimization. In: IEEE Conference on Robotics and Automation. [S.l.: s.n.], 2006. p. 3562-3567.

SANTOS, R. B. dos. Metodologia para geração e atualização de mosaicos de fotos aéreas no Projeto ARARA. Dissertação (Mestrado) - Universidade de São Paulo, 2004.

SHI, J.; TOMASI, C. Good features to track. In: Proc. IEEE Conf. Computer Vision and Pattern Recognition. [S.l.: s.n.], 1994. p. 593-600.

TÖRNQVIST, D. et al. Particle filter SLAM with high dimensional vehicle model. Journal of Intelligent and Robotic Systems, August 2009.

TRIGGS, B. et al. Bundle adjustment - a modern synthesis. In: Vision Algorithms: Theory and Practice, LNCS. [S.l.]: Springer Verlag, 2000. p. 298-375.

WELCH, G.; BISHOP, G. An Introduction to the Kalman Filter. 2001. SIGGRAPH. 
ZHANG, Z. A flexible new technique for camera calibration. IEEE Transactions on Pattern Analysis and Machine Intelligence, v. 22, p. 1330-1334, 1998. 


\section{Apêndice A - Quaternions}

Este apêndice lista brevemente algumas operações, propriedades e conversões de quaternions. Mais detalhes sobre quaternions veja Hamilton (1844), Kuipers (1999).

\section{A.1 Operações e propriedades}

Um quaternion $q \in \Re^{4}$ é uma 4-tupla de números reais escrito na forma $q=$ $\left(q_{0}, q_{1}, q_{2}, q_{3}\right)$. Alternativamente, pode ser escrito como $q=\left(q_{0}, \mathbf{q}\right)$, onde $q_{0}$ é a parte escalar e $\mathbf{q}$ a parte vetorial do quaternion. Grupos especiais de quaternions são $Q_{s}=\left\{q \in \Re^{4} \mid \mathbf{q}=\mathbf{0}\right\}, Q_{v}=\left\{q \in \Re^{4} \mid q_{0}=0\right\}$ e $Q_{1}=\left\{q \in \Re^{4} \mid\|q\|=1\right\}$

As seguintes operações são definidas para quaternions:

$$
\begin{aligned}
& \text { adição } p+q \triangleq\left(p_{0}+q_{0}, \mathbf{p}+\mathbf{q}\right) \\
& \text { multiplicação } \quad p \odot q \triangleq\left(p_{0} q_{0}-\mathbf{p} \cdot \mathbf{q}, p_{0} \mathbf{q}+q_{0} \mathbf{p}+\mathbf{p} \times \mathbf{q}\right) \\
& \text { conjugado } \quad q^{c} \triangleq\left(q_{0},-\mathbf{q}\right) \\
& \text { norma } \quad\|q\| \triangleq\left(q_{0}^{2}+\mathbf{q} \cdot \mathbf{q}\right)^{\frac{1}{2}} \\
& \text { inversa } \quad q^{-1} \triangleq\|q\|^{-2} q^{c} \\
& \text { produto interno ou escalar } \quad p \cdot q \triangleq p_{0} q_{0}+\mathbf{p} \cdot \mathbf{q} \\
& \text { produto externo ou vetorial } p \otimes q \triangleq \frac{1}{2}(p \odot q-q \odot p) \text {. }
\end{aligned}
$$

As propriedades associativas e distributivas permanecem, mas só as adições são comutativas.

$$
\begin{aligned}
p+(q+r) & =(p+q)+r \\
p+q & =q+p \\
p \odot(q \odot r) & =(p \odot q \odot) r \\
p \odot(q+r) & =p \odot q+p \odot r \\
p \odot q & \neq q \odot p .
\end{aligned}
$$


Uma excessão é a multiplicação por escalar:

$$
\lambda q=(\lambda, 0) \odot\left(q_{0}, \mathbf{q}\right)=\left(\lambda q_{0}, \lambda \mathbf{q}\right)=q \lambda
$$

Além disto, as seguintes propriedades são úteis:

$$
\begin{aligned}
(p \odot q)^{c} & =q^{c} \odot p^{c} \\
(p \odot q)^{-1} & =q^{-1} \odot p^{-1} \\
\|p \odot q\| & =\|p\|\|q\| .
\end{aligned}
$$

\section{A.2 Exponencial}

A exponencial de quaternion é definida pela série:

$$
\exp (q) \triangleq \sum_{n=0}^{\infty} \frac{q^{n}}{n !}
$$

A exponencial do vetor $v \in Q_{v}$ é um caso especial, desde que $v=(0, \mathbf{v})$ e $v^{2}=v \odot v=(0 \cdot 0-\mathbf{v} \cdot \mathbf{v}, 0 \mathbf{v}+0 \mathbf{v}+\mathbf{v} \times \mathbf{v})=\left(-\|\mathbf{v}\|^{2}, 0\right)$, portanto:

$$
\begin{aligned}
\exp (v) & =\sum_{n=0}^{\infty} \frac{v^{n}}{n !}=\sum_{n=0}^{\infty} \frac{v^{2 n}}{(2 n) !}+\sum_{n=0}^{\infty} \frac{v^{2 n+1}}{(2 n+1) !} \\
& =\left(\sum_{n=0}^{\infty}(-1)^{n} \frac{\|\mathbf{v}\|^{2 n}}{(2 n) !}, \frac{\mathbf{v}}{\|\mathbf{v}\|} \sum_{n=0}^{\infty}(-1)^{n} \frac{\|\mathbf{v}\|^{2 n+1}}{(2 n+1) !}\right) \\
& =\left(\cos \|\mathbf{v}\|, \frac{\mathbf{v}}{\|\mathbf{v}\|} \sin \|\mathbf{v}\|\right)
\end{aligned}
$$

A operação inversa $\log q$ para o quaternion $q=\left(q_{0}, \mathbf{q}\right)$ é dado por:

$$
\log (q)=\frac{q}{\|q\|} \arccos \left(q_{0}\right)
$$




\section{A.3 Notação matricial e vetorial}

A multiplicação de quaternions também pode ser escrita utilizando notação matricial e vetorial:

$$
\begin{aligned}
p \odot q= & \left(p_{0} q_{0}-\mathbf{p} \cdot \mathbf{q}, p_{0} \mathbf{q}+q_{0} \mathbf{p}+\mathbf{p} \times \mathbf{q}\right) \\
& =\underbrace{\left[\begin{array}{cccc}
p_{0} & -p_{1} & -p_{2} & -p_{3} \\
p_{1} & p_{0} & -p_{3} & p_{2} \\
p_{2} & p_{3} & p_{0} & -p_{1} \\
p_{3} & -p_{2} & p_{1} & p_{0}
\end{array}\right]}_{p_{L}}\left[\begin{array}{l}
q_{0} \\
q_{1} \\
q_{2} \\
q_{3}
\end{array}\right] \\
& =\underbrace{\left[\begin{array}{cccc}
q_{0} & -q_{1} & -q_{2} & -q_{3} \\
q_{1} & q_{0} & q_{3} & -q_{2} \\
q_{2} & -q_{3} & q_{0} & q_{1} \\
q_{3} & q_{2} & -q_{1} & q_{0}
\end{array}\right]}_{q_{R}}\left[\begin{array}{l}
p_{0} \\
p_{1} \\
p_{2} \\
p_{3}
\end{array}\right],
\end{aligned}
$$

onde os operadores $\cdot_{L} \mathrm{e} \cdot{ }_{R}$ estão definidos na equação acima. Note que

$$
\begin{aligned}
& \left(q^{c}\right)_{L}=q_{L}^{T} \\
& \left(q^{c}\right)_{R}=q_{R}^{T} .
\end{aligned}
$$

Esta notação é útil para derivar expressões como:

$$
\begin{aligned}
& \frac{\mathrm{d}}{\mathrm{d} p}(p \odot q)=\frac{\mathrm{d}}{\mathrm{d} p}\left(q_{R} p\right)=q_{R} \\
& \frac{\mathrm{d}}{\mathrm{d} q}(p \odot q)=\frac{\mathrm{d}}{\mathrm{d} q}\left(p_{L} q\right)=p_{L}
\end{aligned}
$$

\section{A.4 Matriz de rotação}

A rotação $x^{a}=q^{a b} x^{b} q^{b a}$ pode ser escrita na forma $x^{a}=R^{a b} x^{b}$ com:

$$
R=\left[\begin{array}{ccc}
2 q_{0}^{2}+2 q_{1}^{2}-1 & 2 q_{1} q_{2}-2 q_{0} q_{3} & 2 q_{1} q_{3}+2 q_{0} q_{2} \\
2 q_{1} q_{2}+2 q_{0} q_{3} & 2 q_{0}^{2}+2 q_{2}^{2}-1 & 2 q_{2} q_{3}-2 q_{0} q_{1} \\
2 q_{1} q_{3}-2 q_{0} q_{2} & 2 q_{2} q_{3}+2 q_{0} q_{1} & 2 q_{0}^{2}+2 q_{3}^{2}-1
\end{array}\right]
$$




\section{A.5 Vetor rotação}

Uma rotação em torno de um eixo $n$ por um ângulo $\alpha$ é definido pelo vetor $e \triangleq \alpha n$ e a sua conversão para quaternion é dada por:

$$
\begin{aligned}
& q^{a b}=\exp \left(\frac{1}{2} e^{a b}\right) \\
& e^{a b}=2 \log \left(q^{a b}\right) .
\end{aligned}
$$

